\title{
HEAT TRANSFER FROM MULTIPLE ROW ARRAYS OF LOW ASPECT RATIO PIN FINS
}

\author{
Seth A. Lawson \\ Thesis submitted to the Faculty \\ of the Virginia Polytechnic Institute and State University \\ in partial fulfillment of the requirements for the degree of \\ Master of Science \\ in \\ Mechanical Engineering \\ Dr. K.A. Thole, Chair \\ Dr. W. F. O’Brien \\ Dr. B. Vick \\ February 8, 2007 \\ Blacksburg, VA
}

Keywords: pin fins, heat transfer, gas turbines, internal cooling, heat transfer augmentation 


\section{Heat Transfer from Multiple Row Arrays of Low Aspect Ratio Pin Fins}

\section{Seth A. Lawson \\ Preface}

This thesis is organized in manuscript format containing two papers. The first paper consists of the analysis of heat transfer characteristics from multiple row arrays of low aspect ratio pin fins. A broad range of array geometries were tested to analyze the independent effects of Reynolds number, pin spacing, and pin aspect ratio on pin and endwall Nusselt numbers. The second paper consists of a similar study to analyze the heat transfer characteristics in multiple row arrays of pin fins with different coolant flow incidence angles. Again, a broad range of geometries were tested to determine the independent heat transfer effects of Reynolds number, pin spacing, and pin aspect ratio on arrays with different flow incidence angles. Following the second paper is a conclusions and summary section. There are three appendices included in this thesis to provide a detailed analysis of certain issues that could not be explained in detail in either paper. These appendices provide a detailed analysis of the experimental uncertainty associated with the results, describe the calculations performed to account for heat loss during the experiments, and show Nusselt number augmentation contour plots for every geometry tested in both papers. The two papers in this study will eventually be submitted for possible journal entry. 


\title{
Heat Transfer from Multiple Row Arrays of Low Aspect Ratio Pin Fins
}

\section{Seth A. Lawson}

\begin{abstract}
The heat transfer characteristics through arrays of pin fins were studied for the further development of internal cooling methods for turbine airfoils. Low aspect ratio pin fin arrays were tested through a range of Reynolds numbers between 5000 and 30,000 to determine the effects of pin spacing as well as aspect ratio on pin and endwall heat transfer. Experiments were also conducted to determine the independent effects of pin spacing and aspect ratio on arrays with different flow incidence angles. The pin Nusselt numbers showed almost no dependence on pin spacing or flow incidence angle. Using an infrared thermogaphy technique, spatiallyresolved Nusselt numbers were measured along the endwalls of each array. The endwall results showed that streamwise spacing had a larger effect than spanwise spacing on array-averaged Nusselt numbers. Endwall heat transfer patterns showed that arrays with flow incidence angles experienced less wake interaction between pins than arrays with perpendicular flow, which caused a slight decrease in heat transfer in arrays with flow incidence angles. The effect of flow incidence angle on array-average Nusselt number was greater at tighter pin spacings. Even though the pin Nusselt number was independent of pin spacing, the ratio of pin-to-endwall Nusselt number was dependent on flow conditions as well as pin spacing. The pin aspect ratio had little effect on the array-average Nusselt number for arrays with perpendicular flow; however, the effect of flow incidence angle on array-average Nusselt number increased as aspect ratio decreased.
\end{abstract}




\section{Acknowledgements}

My experience as a member of the VTExCCL group at Virginia Tech has been a great one. The knowledge that I have gained in the lab could not have been taught in any class and I will never forget it. Work in a lab setting to solve problems and meet long term goals teaches valuable lessons in engineering as well as life.

This experience would not have been as enjoyable without the unique people who have made up VTExCCL during my time with the group (Nick Cardwell, Eric Lyall, Will Colban Scott Brumbaugh, Alan Thrift, Mike Lawson, Cam Land, Joe Scrittore, Sundar Narayan, Steve Lynch, Mike Barringer, and Jason Ostanek). Although they worked for different advisors, I would also like to thank Jeff Carullo and Andrew Duggleby for their close work with the group and their friendship.

I would like to specifically thank a few individuals who I worked closely with throughout the past year and a half. Eric Lyall played a major role in my acclimation into the lab. I would like to thank him for being there to act as a mentor and to share his knowledge with me from the very beginning of my research. Alan Thrift was my brother in the lab who worked on a parallel project. He is a good friend who was always there to provide psychological and technical advice through even the most frustrating times. I would also like to thank Mike Barringer who provided an immense amount of assistance through the end of the experimental stage and throughout the thesis writing process. He was always available to answer my questions to make my life easier and I appreciate his friendship very much.

This project would not have existed without Pratt and Whitney and my mentors Atul Kohli and George Suljak. Atul and George always kept a good attitude and provided great advice through the experimental process even when things weren't going so well. I also want to thank my advisor Karen Thole to whom I owe my greatest appreciation. She urged me to work hard and helped to show me the way from the very beginning by providing excellent advice, a positive problem solving attitude, and, on top of all that, friendship.

Last, but definitely not least, I would like to thank my friends and family who have put up with my absence throughout the past couple of months during the thesis writing process. You have provided an amazing amount of support and I love you all for it. 


\section{Contents}

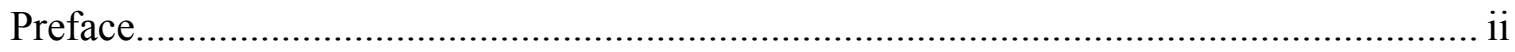

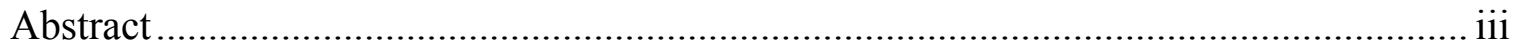

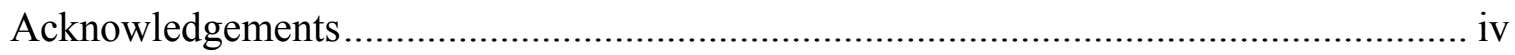

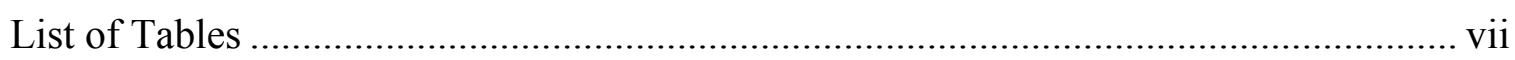

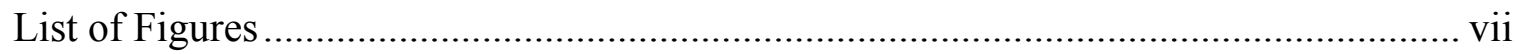

Paper 1: Heat Transfer from Multiple Row Arrays of Low Aspect Ratio Pin Fins .......1

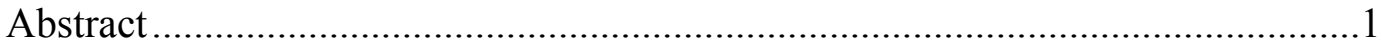

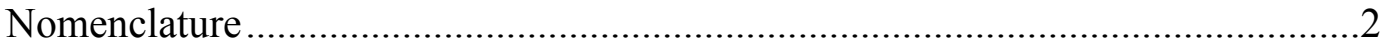

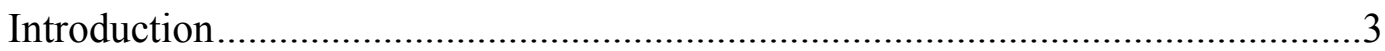

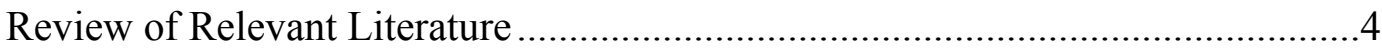

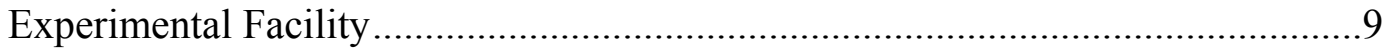

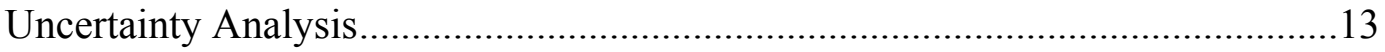

Effect of Reynolds Number on Endwall and Pin Heat Transfer..........................13

Effect of Pin Spacing on Endwall Heat Transfer.................................................19

Effect of Pin Aspect Ratio on Endwall Heat Transfer .......................................22

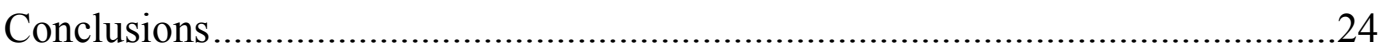

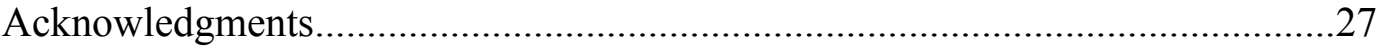

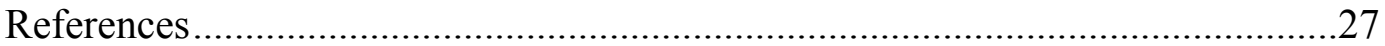

Paper 2: Heat Transfer from Multiple Row Arrays of Low Aspect Ratio Pin Fins with

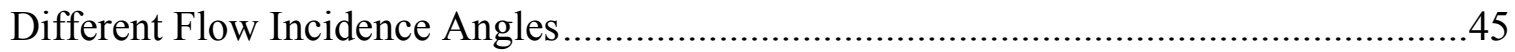

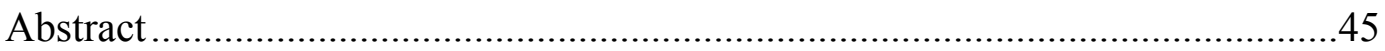

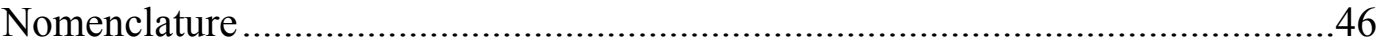

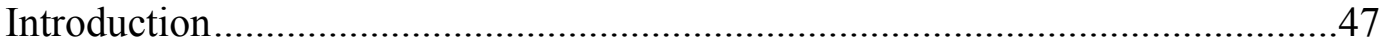

Review of Relevant Literature ..................................................................48

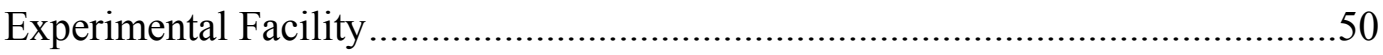

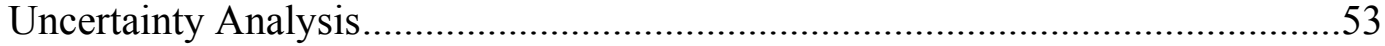

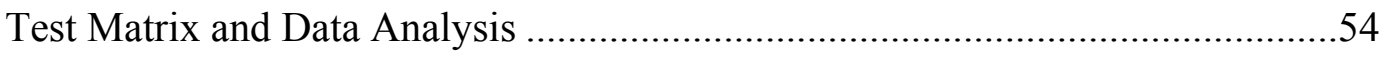

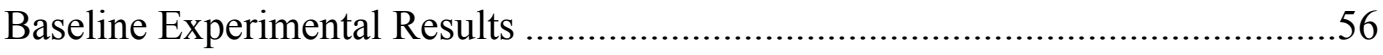


Effects of Flow Incidence Angle on Array Heat Transfer.

Effects of Aspect Ratio on Array Heat Transfer for Arrays with Flow Incidence

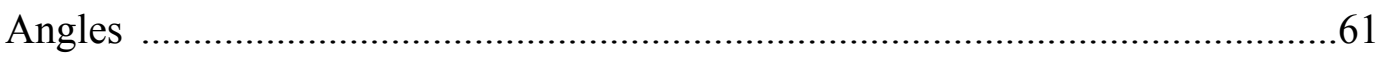

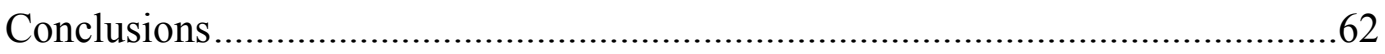

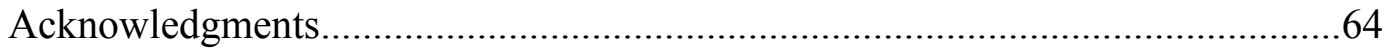

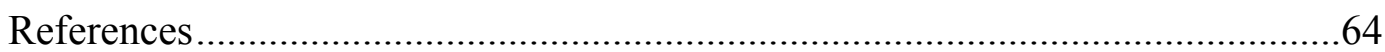

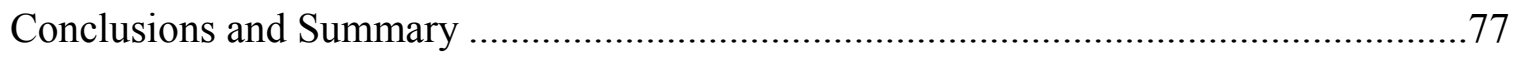

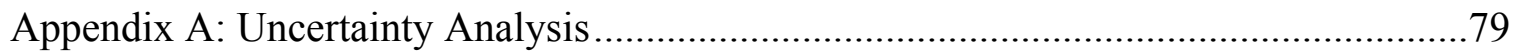

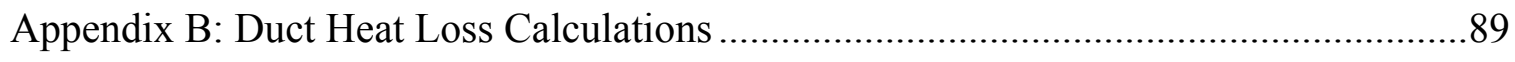

Appendix C: Endwall Augmentation Contour Plots.................................................92 


\section{List of Tables}

Table 1.1 Array Nusselt Number Dependence on Reynolds Number from Literature....29

Table 1.2 First Row Nusselt Number Correlations ....................................................30

Table 1.3 Multiple Row Geometries Tested for this Study.......................................30

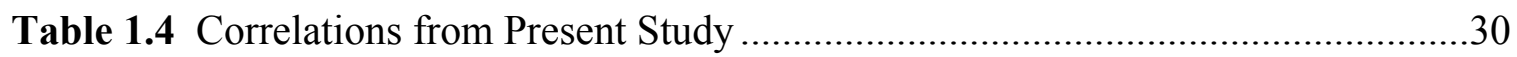

Table 2.1 Multiple Row Geometries Tested for Flow Incidence Angle Study...............66

Table 2.2 Correlations from Present Study ...............................................................66

\section{List of Figures}

Figure 1.1 Schematic showing the spacing definitions used in the tested pin fin arrays

Figure 1.2 Schematic of the closed loop test facility used for pin fin array testing.........31

Figure 1.3 Schematic of the test section used for pin fin array testing ..........................32

Figure 1.4 Schematic of the $\mathrm{S} 1 / \mathrm{d}=4, \mathrm{~S} 2 / \mathrm{d}=3.46, \mathrm{H} / \mathrm{d}=1$ seven row array as placed in the test section 32

Figure 1.5 Schematic of the instrumented pin fin used for pin heat transfer tests. .33

Figure 1.6 Endwall contour plots of Nusselt number augmentation for the $\mathrm{S} 1 / \mathrm{d}=2, \mathrm{~S} 2 / \mathrm{d}=1.73$, $\mathrm{H} / \mathrm{d}=1$ geometry 33

Figure 1.7 Endwall contour plots of Nusselt number augmentation for the $\mathrm{S} 1 / \mathrm{d}=4, \mathrm{~S} 2 / \mathrm{d}=3.46$, $\mathrm{H} / \mathrm{d}=1$ geometry

Figure 1.8 Row resolved endwall augmentation values for the $\mathrm{S} 1 / \mathrm{d}=2, \mathrm{~S} 2 / \mathrm{d}=1.73, \mathrm{H} / \mathrm{d}=1$ seven row pin fin array. 34

Figure 1.9 Midline pin Nusselt numbers found in the literature for a pin placed in the first row of a multiple row array 35

Figure 1.10 Average pin Nusselt numbers for the $\mathrm{S} 1 / \mathrm{d}=2, \mathrm{~S} 2 / \mathrm{d}=1.73, \mathrm{H} / \mathrm{d}=1$ and $\mathrm{S} 1 / \mathrm{d}=4$, $\mathrm{S} 2 / \mathrm{d}=3.46, \mathrm{H} / \mathrm{d}=1$ geometries compared with results from the literature 
Figure 1.11 First row combined pin and endwall Nusselt number results plotted with results from the literature

Figure 1.12 Pin, endwall, and array-average Nusselt number versus pin Reynolds number for an $\mathrm{S} 1 / \mathrm{d}=2, \mathrm{~S} 2 / \mathrm{d}=1.73, \mathrm{H} / \mathrm{d}=1$ array compared with Metzger et al. [1982a] 36

Figure 1.13 Pin-to-endwall Nusselt number as a function of pin Reynolds number .......37

Figure 1.14 Array-average Nusselt number augmentation versus Reynolds number for the $\mathrm{S} 1 / \mathrm{d}=2, \mathrm{~S} 2 / \mathrm{d}=1.73, \mathrm{H} / \mathrm{d}=1$ and $\mathrm{S} 1 / \mathrm{d}=4, \mathrm{~S} 2 / \mathrm{d}=3.46, \mathrm{H} / \mathrm{d}=1$ geometries 37

Figure 1.15 Average endwall Nusselt numbers for $\mathrm{S} 1 / \mathrm{d}=2, \mathrm{~S} 2 / \mathrm{d}=3.46, \mathrm{H} / \mathrm{d}=1$ and $\mathrm{S} 1 / \mathrm{d}=4$, $\mathrm{S} 2 / \mathrm{d}=3.46, \mathrm{H} / \mathrm{d}=1$ geometries 38

Figure 1.16 Average endwall Nusselt numbers for $\mathrm{S} 1 / \mathrm{d}=2, \mathrm{~S} 2 / \mathrm{d}=1.73, \mathrm{H} / \mathrm{d}=1$ and $\mathrm{S} 1 / \mathrm{d}=4$, $\mathrm{S} 2 / \mathrm{d}=1.73, \mathrm{H} / \mathrm{d}=1$ geometries 38

Figure 1.17 Endwall row average Nusselt numbers for the $\mathrm{S} 1 / \mathrm{d}=2, \mathrm{~S} 2 / \mathrm{d}=1.73, \mathrm{H} / \mathrm{d}=1$ and $\mathrm{S} 1 / \mathrm{d}=4, \mathrm{~S} 2 / \mathrm{d}=1.73, \mathrm{H} / \mathrm{d}=1$ geometries. 39

Figure 1.18 Average endwall Nusselt numbers for $\mathrm{S} 1 / \mathrm{d}=2, \mathrm{~S} 2 / \mathrm{d}=1.73, \mathrm{H} / \mathrm{d}=1$ and $\mathrm{S} 1 / \mathrm{d}=2$, $\mathrm{S} 2 / \mathrm{d}=3.46, \mathrm{H} / \mathrm{d}=1$ geometries 39

Figure 1.19 Row resolved endwall Nusselt numbers for the $\mathrm{S} 1 / \mathrm{d}=2, \mathrm{~S} 2 / \mathrm{d}=1.73, \mathrm{H} / \mathrm{d}=1$ and $\mathrm{S} 1 / \mathrm{d}=2, \mathrm{~S} 2 / \mathrm{d}=3.46, \mathrm{H} / \mathrm{d}=1$ geometries. 40

Figure 1.20 Average endwall Nusselt numbers for $\mathrm{S} 1 / \mathrm{d}=4, \mathrm{~S} 2 / \mathrm{d}=1.73, \mathrm{H} / \mathrm{d}=1$ and $\mathrm{S} 1 / \mathrm{d}=4$, $\mathrm{S} 2 / \mathrm{d}=3.46, \mathrm{H} / \mathrm{d}=1$ geometries .40

Figure 1.21 Row resolved endwall Nusselt numbers for the $\mathrm{S} 1 / \mathrm{d}=4, \mathrm{~S} 2 / \mathrm{d}=1.73, \mathrm{H} / \mathrm{d}=1$ and $\mathrm{S} 1 / \mathrm{d}=4, \mathrm{~S} 2 / \mathrm{d}=3.46, \mathrm{H} / \mathrm{d}=1$ geometries.

Figure 1.22 Array-average Nusselt numbers for all geometries with $\mathrm{H} / \mathrm{d}=1$

Figure 1.23 Array-average Nusselt numbers predicted by Equation 1.3 plotted with respect to $\mathrm{S} 1 / \mathrm{d}$ or $\mathrm{S} 2 / \mathrm{d}$.. ..42

Figure 1.24 Array-average Nusselt number correlation (Equation 1.3) plotted with relevant correlations from the literature all having $\mathrm{H} / \mathrm{d}=1$ 42

Figure 1.25 Contour plots comparing endwall Nusselt number augmentation for the $\mathrm{S} 1 / \mathrm{d}=2$, $\mathrm{S} 2 / \mathrm{d}=1.73, \mathrm{H} / \mathrm{d}=0.5$ and $\mathrm{S} 1 / \mathrm{d}=2, \mathrm{~S} 2 / \mathrm{d}=1.73, \mathrm{H} / \mathrm{d}=1$ geometries

Figure 1.26 Average endwall Nusselt numbers for $\mathrm{S} 1 / \mathrm{d}=2, \mathrm{~S} 2 / \mathrm{d}=1.73, \mathrm{H} / \mathrm{d}=1$ and $\mathrm{S} 1 / \mathrm{d}=2$, $\mathrm{S} 2 / \mathrm{d}=1.73, \mathrm{H} / \mathrm{d}=0.5$ geometries 
Figure 1.27 Row resolved endwall Nusselt number for $\mathrm{S} 1 / \mathrm{d}=2, \mathrm{~S} 2 / \mathrm{d}=1.73, \mathrm{H} / \mathrm{d}=1$ and $\mathrm{S} 1 / \mathrm{d}=2$, $\mathrm{S} 2 / \mathrm{d}=1.73, \mathrm{H} / \mathrm{d}=0.5$ geometries

Figure 1.28 Array-average Nusselt numbers for the $\mathrm{S} 1 / \mathrm{d}=2, \mathrm{~S} 2 / \mathrm{d}=1.73, \mathrm{H} / \mathrm{d}=0.5$ and $\mathrm{S} 1 / \mathrm{d}=2$, $\mathrm{S} 2 / \mathrm{d}=1.73, \mathrm{H} / \mathrm{d}=1$ geometries

Figure 2.1 Schematic illustrating the spacing definitions of a pin fin array with flow incidence angle, $\alpha$. .67

Figure 2.2 Schematic of the closed loop test facility used for pin fin array testing........67

Figure 2.3 Schematic of the test section used for pin fin array testing 68

Figure 2.4 Schematics showing an $\mathrm{S} 1 / \mathrm{d}=4$ array at angles of a) $\alpha=0^{\circ}$ and $b$ ) $\alpha=30^{\circ} \ldots \ldots .68$

Figure 2.5 Schematic of the instrumented pin fin used for pin heat transfer tests. 69

Figure 2.6 Row-by-row average areas shown on the augmentation contour plots for $\mathrm{S} 1 / \mathrm{d}=4$ arrays at (a) $\alpha=0^{\circ}$ (b) $\alpha=30^{\circ}$

Figure 2.7 Nusselt number augmentation contour plots for $\mathrm{S} 1 / \mathrm{d}=2, \mathrm{~S} 2 / \mathrm{d}=1.73$ and $\mathrm{S} 1 / \mathrm{d}=4$, $\mathrm{S} 2 / \mathrm{d}=3.46$ arrays having $\mathrm{H} / \mathrm{d}=1$ 70

Figure 2.8 Average endwall Nusselt numbers for the $\mathrm{S} 1 / \mathrm{d}=2, \mathrm{~S} 2 / \mathrm{d}=1.73$ arrays with $\mathrm{H} / \mathrm{d}=0.5$ and $\mathrm{H} / \mathrm{d}=1$ along with the $\mathrm{S} 1 / \mathrm{d}=4, \mathrm{~S} 2 / \mathrm{d}=3.46$ array with $\mathrm{H} / \mathrm{d}=1$ 70

Figure 2.9 Average pin Nusselt numbers for the $\mathrm{S} 1 / \mathrm{d}=2, \mathrm{~S} 2 / \mathrm{d}=1.73, \mathrm{H} / \mathrm{d}=1, \alpha=0$, the $\mathrm{S} 1 / \mathrm{d}=4$, $\mathrm{S} 2 / \mathrm{d}=3.46, \mathrm{H} / \mathrm{d}=1, \alpha=0$, and the $\mathrm{S} 1 / \mathrm{d}=4, \mathrm{~S} 2 / \mathrm{d}=3.46, \mathrm{H} / \mathrm{d}=1, \alpha=30$ geometries

Figure 2.10 Pin-to-endwall Nusselt number ratio for the $\mathrm{S} 1 / \mathrm{d}=2, \mathrm{~S} 2 / \mathrm{d}=1.73, \alpha=0^{\circ}$, the $\mathrm{S} 1 / \mathrm{d}=4$, $\mathrm{S} 2 / \mathrm{d}=3.46, \alpha=0^{\circ}$, and the $\mathrm{S} 1 / \mathrm{d}=4, \mathrm{~S} 2 / \mathrm{d}=3.46, \alpha=30^{\circ}$ geometries all having $\mathrm{H} / \mathrm{d}=1$

Figure 2.11 Augmentation contour plots for the $S 1 / d=4$ arrays at (a) $\alpha=0^{\circ}, \operatorname{Re}=5318$ (b) $\alpha=30^{\circ}$, $\operatorname{Re}=4985$ (c) $\alpha=0^{\circ}, \operatorname{Re}=31,936$ (d) $\alpha=30^{\circ}, \operatorname{Re}=29,940$ .72

Figure 2.12 Augmentation contour plots for $\mathrm{S} 1 / \mathrm{d}=4$ arrays at (a) $\alpha=0^{\circ}, \mathrm{Re}=13,876$ (b) $\alpha=15^{\circ}$, $\operatorname{Re}=13,009$, (c) $\alpha=30^{\circ}, \operatorname{Re}=13,019$.... 72

Figure 2.13 Array-average incidence angle effectiveness ratios for the $\mathrm{S} 1 / \mathrm{d}=2, \mathrm{~S} 2 / \mathrm{d}=1.73$, $\alpha=30^{\circ}$ array as well as the $\mathrm{S} 1 / \mathrm{d}=4, \mathrm{~S} 2 / \mathrm{d}=3.46, \alpha=15^{\circ}$, and $\alpha=30^{\circ}$ arrays 73

Figure 2.14 Row-resolved endwall Nusselt numbers for $\mathrm{S} 1 / \mathrm{d}=4, \mathrm{~S} 2 / \mathrm{d}=3.46, \mathrm{H} / \mathrm{d}=1$ arrays at $\alpha=0^{\circ}, 15^{\circ}$, and $30^{\circ}$. .73 
Figure 2.15 Array-average Nusselt numbers for $\mathrm{S} 1 / \mathrm{d}=2, \mathrm{~S} 2 / \mathrm{d}=1.73, \mathrm{H} / \mathrm{d}=1, \alpha=0^{\circ}$ and $30^{\circ}$ arrays along with $\mathrm{S} 1 / \mathrm{d}=4, \mathrm{~S} 2 / \mathrm{d}=3.46, \mathrm{H} / \mathrm{d}=1, \alpha=0^{\circ}, 15^{\circ}$ and $30^{\circ}$ arrays .................................74

Figure 2.16 Endwall Nusselt number augmentation contour plots for the $\mathrm{S} 2 / \mathrm{d}=2, \mathrm{~S} 2 / \mathrm{d}=1.73$, $\mathrm{H} / \mathrm{d}=0.5$ and $\mathrm{H} / \mathrm{d}=1$ arrays at a flow incidence angle of $\alpha=30^{\circ}$

Figure 2.17 Array-average incidence angle effectiveness ratios for all studied cases with flow incidence angles

Figure 2.18 Row-resolved Endwall Nusselt numbers through the $\mathrm{S} 1 / \mathrm{d}=2, \mathrm{~S} 2 / \mathrm{d}=1.73, \mathrm{H} / \mathrm{d}=0.5$ array at flow incidence angles of $\alpha=0^{\circ}$ and $30^{\circ}$ .75

Figure 2.19 Array-average Nusselt number with respect to Reynolds number for the $\mathrm{S} 1 / \mathrm{d}=2$, $\mathrm{S} 2 / \mathrm{d}=1.73, \alpha=0^{\circ}$ and $30^{\circ}$ arrays at aspect ratios of $\mathrm{H} / \mathrm{d}=0.5$ and $\mathrm{H} / \mathrm{d}=1$ .76 


\title{
Paper 1
}

\section{Heat Transfer from Multiple Row Arrays of Low Aspect Ratio Pin Fins}

\author{
Abstract \\ The heat transfer characteristics through arrays of pin fins were studied for the further \\ development of internal cooling methods for turbine blades and vanes. Pin fin arrays with low \\ aspect ratios were tested with multiple streamwise and spanwise spacings as well as aspect \\ ratios. Experiments were conducted through a range of Reynolds numbers between 5000 and \\ 30,000. Using an infrared thermogaphy technique, spatially-resolved Nusselt numbers were \\ measured along the endwalls of each array. Pin Nusselt numbers were calculated using discrete \\ thermocouple measurements. The pin Nusselt numbers showed little difference between \\ different array spacings. The endwall results showed that streamwise spacing had a larger effect \\ than spanwise spacing on array-average Nusselt numbers as well as the heat transfer \\ development through the array. The ratio of pin-to-endwall Nusselt number varied from 1.85 to \\ 1.4 and was dependent on flow conditions as well as pin spacing. Endwall Nusselt number \\ augmentation decreased with a decrease in pin aspect ratio while array-average Nusselt number \\ showed little dependence on pin aspect ratio.
}




\section{Nomenclature}

\section{Subscripts:}

variable

variable

0

$\mathrm{amb}$

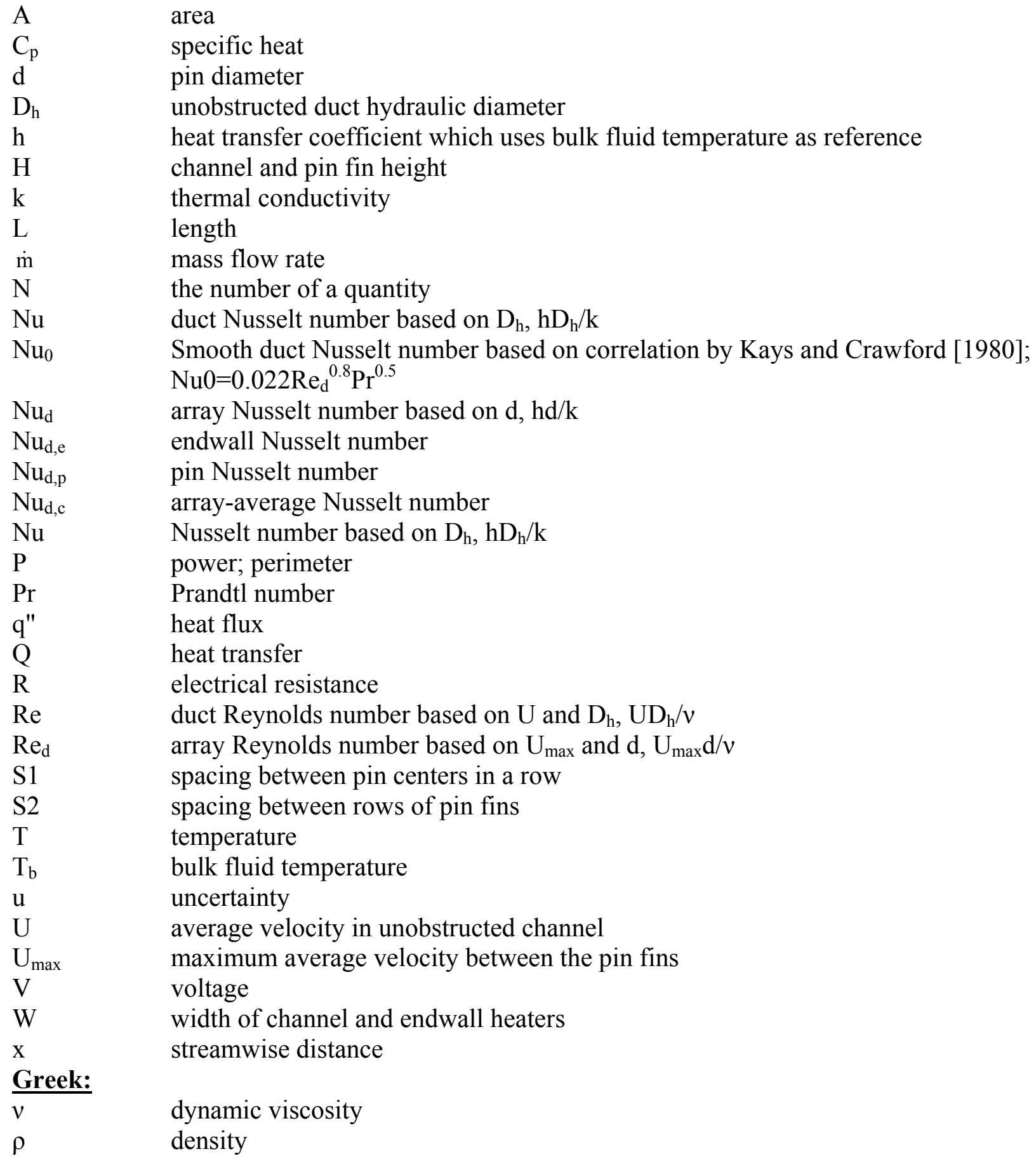

area

specific heat

pin diameter

unobstructed duct hydraulic diameter

heat transfer coefficient which uses bulk fluid temperature as reference channel and pin fin height

thermal conductivity

length

mass flow rate

the number of a quantity

duct Nusselt number based on $\mathrm{D}_{\mathrm{h}}, \mathrm{hD}_{\mathrm{h}} / \mathrm{k}$

Smooth duct Nusselt number based on correlation by Kays and Crawford [1980]; $\mathrm{Nu} 0=0.022 \mathrm{Re}_{\mathrm{d}}{ }^{0.8} \mathrm{Pr}^{0.5}$

array Nusselt number based on $\mathrm{d}, \mathrm{hd} / \mathrm{k}$

endwall Nusselt number

pin Nusselt number

array-average Nusselt number

Nusselt number based on $\mathrm{D}_{\mathrm{h}}, \mathrm{hD}_{\mathrm{h}} / \mathrm{k}$

power; perimeter

Prandtl number

heat flux

heat transfer

electrical resistance

duct Reynolds number based on $\mathrm{U}$ and $\mathrm{D}_{\mathrm{h}}, \mathrm{UD}_{\mathrm{h}} / v$

array Reynolds number based on $\mathrm{U}_{\max }$ and $\mathrm{d}, \mathrm{U}_{\max } \mathrm{d} / \mathrm{v}$

spacing between pin centers in a row

spacing between rows of pin fins

temperature

bulk fluid temperature

uncertainty

average velocity in unobstructed channel

maximum average velocity between the pin fins

voltage

width of channel and endwall heaters

streamwise distance

dynamic viscosity

density

spanwise averaged value

area averaged value

unobstructed duct baseline condition

ambient conditions 


\section{Introduction}

A major consideration in the operation of a gas turbine engine is the temperature at which the gas exiting the combustor enters the first stage of the turbine. To maximize the performance of an engine, the turbine inlet temperature should be as high as possible. Today's turbine inlet temperatures are higher than the melting point of the material used to construct the turbine blades and vanes, so improved methods, such as the insertion of pin fin arrays to internal cooling channels, are necessary. In most turbine designs, coolant air is extracted from the compressor and routed through internal cooling channels in each turbine blade.

Cooling the trailing edge of a turbine blade is a particularly difficult engineering challenge because of its thin cross-section. It is a challenge because the external heat transfer coefficients associated with the mainstream core flow through the turbine are very high and the thin trailing edge section does not allow cooling technologies, such as film-cooling, because of the needed structural integrity. The cooling technology most commonly used for the trailing edge section of the blade are cylindrical pin fins with relatively low aspect ratios (pin height-todiameter). These pin fins, which can be used in staggered or in-line configurations, are placed in the internal cooling channels of the airfoils to increase the wetted heat transfer area and to increase the turbulence levels of the channel flow thereby increasing the convection. The most common cooling designs for the trailing edge employ pin fins with aspect ratios between 0.5 and 4.0 [Lau et al., 1985]. Because of the large range of pin aspect ratios that lead to differing flow effects, such as the pin fin wake interaction with the endwalls, interpolation between aspect ratios do not provide accurate results [Armstrong and Winstanley, 1988]. As the aspect ratio is decreased, the pins no longer provide the advantage of increasing the wetted heat transfer area; therefore, it is of interest to find the most effective aspect ratio to satisfy both heat transfer and structural requirements. The heat transfer characteristics of low aspect ratio pin fin arrays has not been as widely studied as the heat transfer in high aspect ratio pin fin arrays commonly used in heat exchanger applications.

This paper presents experimental studies that were performed to develop new and improved correlations to predict Nusselt number for a duct flow having a low aspect ratio with an array of pin fins. The duct and pin fin geometries are applicable to the cooling channel technology within gas turbine engines. In these studies, the heat transfer from the surface of the pins as well as the heat transfer from the duct walls, also known as endwalls, is measured. Heat 
transfer coefficients are measured for multiple row arrays of pin fins to determine the effects of changing the aspect ratio as well as the spanwise and streamwise spacings of the pin fins.

\section{Review of Relevant Literature}

Since the 1950's much progress has been made on the methods used for turbine blade cooling. The development of new cooling methods such as the addition of intricate geometries to the cooling channels can be largely attributed to the research conducted throughout the past 50 years. Numerous researchers have tested many different arrangements of pin fin arrays. The following section will discuss the results available in the current literature concerning the effects of Reynolds number, pin spacing, and pin aspect ratio on heat transfer. This section will also discuss the research that has been conducted concerning the relationship between pin and endwall heat transfer. The different parameters used by various researchers to characterize heat transfer are explained.

Pin fin arrays with aspect ratios between 0.5 and 4 have been studied by various researchers to obtain correlations for predicting heat transfer characteristics. Much of this work has been conducted on arrays with an aspect ratio of one because it is low enough that the cooling channels are small and high enough that the wetted heat transfer area is significantly increased by adding the pins. Table 1.1 shows a summary of the correlations from the literature for low aspect ratio arrays of cylindrical pin fins. The correlations shown predict average pin, average endwall, and array-average Nusselt number based on Reynolds number.

Metzger et al. [1982a] determined Nusselt number correlations for staggered arrays with an aspect ratio of one. They studied arrays with two different streamwise spacings. The array having the larger streamwise spacing had the greater Reynolds number dependence.

Yeh and Chyu [1998] obtained Nusselt numbers for arrays with aspect ratios of one and 2.8. The array with the larger aspect ratio also had the higher Reynolds number dependence.

Lyall et al. [2006] studied pin and endwall heat transfer in single rows of pin fins with a height-to-diameter ratio of one at spanwise spacings of two, four, and eight. They used an infrared thermography technique in which they spatially resolved the heat transfer coefficients on the endwall, similar to Uzol and Camci [2005] who used liquid crystal thermography. Lyall et al. [2006] found that the pin heat transfer for the geometries with spanwise spacings of four and eight had a stronger Reynolds number dependency than the geometry with the spanwise spacing 
of two. The combined endwall and pin heat transfer, also known as array-average heat transfer, had comparable Reynolds number dependence for all three geometries tested.

Multiple studies have been conducted to determine the effects of pin spacing on array heat transfer. Metzger et al. [1982c], Simoneau and VanFossen [1984], and Lyall et al. [2006] all determined that tighter pin spacings increased heat transfer in an array of pin fins.

Metzger et al. [1982c] studied the effects of streamwise spacing by holding the spanwise spacing constant and varying the streamwise spacing. For streamwise spacings between 1.05 and 5.0 they found that array-average Nusselt number decreased with increased streamwise spacing. They concluded that closer spaced pins yielded higher Nusselt numbers.

Simoneau and VanFossen [1984] obtained average Nusselt numbers on a single heated pin in cross flow. They found that the Nusselt number on a single pin was between $7 \%-15 \%$ lower than the Nusselt number on the same pin when placed in an array with a spanwise and streamwise spacing of 2.67 and an aspect ratio of three.

Lyall et al. [2006] found that pin heat transfer increased with increased spanwise spacing while endwall heat transfer decreased with increased spanwise spacing. They attributed this to the decreased interaction between pins as the spacing was increased. The array-average Nusselt number also decreased with increased spanwise spacing because the endwall surface area was much greater than the pin surface area at an aspect ratio of one. The decreased heat transfer with increased pin spacing is consistent with the results obtained by Simoneau and VanFossen [1984].

Some studies have been conducted to determine the effects of pin aspect ratio on array heat transfer. Brigham and VanFossen [1984] and Yeh and Chyu [1998] both observed decreased array heat transfer with decreased pin aspect ratio.

Brigham and VanFossen [1984] used a Nusselt number based on duct hydraulic diameter as the characteristic length. By compiling results from different researchers, they found that Nusselt number augmentation over a smooth duct Nusselt number decreased with decreased pin aspect ratio for ratios greater than two. The Nusselt number augmentation in arrays with aspect ratios less than two was independent of aspect ratio. This conclusion was based on research by VanFossen [1982] in which he studied arrays with aspect ratios of 2 and 0.5. He found no difference in the Nusselt number results obtained for either aspect ratio. Armstrong and Winstanley [1988] attributed the effect of decreased heat transfer with decreased aspect ratios to the lesser wetted area devoted to the pin surface at low pin aspect ratios. As the aspect ratio 
decreases, the endwall dominates the array-average Nusselt number. As the aspect ratio increases, the pin Nusselt number, which is typically higher than endwall Nusselt number, contributes more to the array-average Nusselt number.

Yeh and Chyu [1998] measured pin and endwall Nusselt numbers for two arrays having aspect ratios of 1 and 2.8. They observed a similar development trend through each array and similar endwall heat transfer for both arrays. They found that the array with an aspect ratio of one had higher array-average heat transfer than the array with an aspect ratio of 2.8 at low Reynolds numbers. For the majority of the Reynolds number range, however, the array with an aspect ratio of 2.8 had higher array-average Nusselt number than the array with an aspect ratio of one. This is consistent with the findings of Brigham and VanFossen [1984].

Many researchers have focused on the relationship between the pin Nusselt numbers relative to the endwall Nusselt numbers. The relationship between pin and endwall Nusselt number has received great attention because of the inconsistent results obtained by multiple researchers. Studies agree that Nusselt number is greater on the pin than the endwall, but the relative amount is the true question.

VanFossen [1982] was among the first to study pin heat transfer coefficients and compare them to the heat transfer coefficients obtained on the endwall. The heat transfer coefficients on four rows of pins in a staggered array were measured. He tested the same geometry once with conductive copper pins and a second time with non-conductive wood pins. He was able to deduce the relative heat transfer coefficient from the endwall and pin to find that the pins had a $35 \%$ higher heat transfer coefficient than the endwalls. Metzger et al. [1984] studied pin and endwall Nusselt number using the same method as VanFossen [1982] with thermally conductive and non-conductive pins. They found that pin Nusselt numbers were 1.8 to 2 times that of the endwall. Chyu et al. [1998] studied the pin versus endwall Nusselt number. Rather than using the heated conductive and non-conductive pin technique, they used a naphthalene sublimation technique. They found that the pin Nusselt numbers were at most $20 \%$ higher than the endwall Nusselt numbers. This result is lower than what was reported by both Metzger et al. [1984] and VanFossen [1982].

Yeh and Chyu [1998] studied the relationship between pin and endwall heat transfer at aspect ratios of 1 and 2.8. The pin Nusselt number for the array with an aspect ratio of one was as much as $10 \%$ higher than the endwalls while the array with an aspect ratio of 2.8 showed an 
increase as high as $20 \%$ in the pin Nusselt number over the endwalls. This is similar to the findings of Chyu et al. [1998].

Lyall et al. [2006] also studied relative pin and endwall Nusselt numbers for single rows of pin fins. They found that the pin-to-endwall Nusselt number ratio depended highly on Reynolds number and spanwise spacing. The highest ratio of pin-to-endwall Nusselt number occurred at the lowest Reynolds number and the widest spanwise spacing. For a spanwise spacing of eight pin diameters, the pin-to-endwall Nusselt number ratio went from 3.4 at the lowest Reynolds number to 2.3 at the highest Reynolds number. For a spanwise spacing of two pin diameters, the pin-to-endwall Nusselt number ratio went from 2.0 at the lowest Reynolds number to 1.5 at the highest Reynolds number.

Some studies focused on the row-by-row variation of Nusselt number in a pin fin array. Metzger et al. [1982a], Chyu [1990], Yeh and Chyu [1998], and Ames et al. [2005] all observed an initial increase in Nusselt number through the entrance of the array before a slight decrease through the remainder of the array.

Metzger and Haley [1982b] explained the development trend observed by Metzger et al. [1982a] by measuring hot-wire turbulence intensities which showed a similar trend with an initial increase followed by a gradual decrease through the remainder of the array.

Chyu [1990] measured spanwise average Nusselt number through seven rows of in-line and staggered pin fins. He concluded that the maximum Nusselt number in an array is the result of wake impingement from upstream pins and flow acceleration in the spacing between two spanwise neighboring pins. Chyu [1990] determined that for a given array, the maximum Nusselt number occurred at the row that experienced the first direct wake shedding from the upstream rows. This maximum occurred at row two for the in-line array and row three for the staggered array which is consistent with the findings of Metzger et al. [1982a]. Hwang et al. [2001] measured the local effects of endwall Nusselt numbers in an in-line array located in a rectangular duct with uniform channel height. They observed that the maximum Nusselt number occurred at the second row, which is consistent with the findings of Chyu [1990].

Yeh and Chyu [1998] studied the Nusselt number through ten rows of staggered pin fins at aspect ratios of 1.0 and 2.8. They observed the same trend for both arrays with the Nusselt number development through the first three rows with a decrease through the rest of the array. The average difference between the maximum Nusselt number row and the last row was 
approximately 16\% less. Metzger et al. [1982a] found a similar result with a decrease of about $12 \%$ between the maximum Nusselt number row and the last row.

Ames et al. [2005] obtained row-resolved Nusselt numbers as well as circumferential Nusselt numbers around a pin fin in each row of an eight row staggered array. Their circumferential measurements showed high Nusselt numbers in row one at the leading edge, which decreased to the point of separation. The Nusselt number increased toward the back side of the pin as a result of wake shedding. The Nusselt number gradually increased through row two before a large increase in row three. This increase between rows two and three was attributed to direct wake shedding from row one which impacted the leading edge of the row three pin. Downstream of row three, the turbulence levels reached a plateau while the local velocity slightly decreased through the array causing the Nusselt number through the array to also gradually decrease. This is very similar to the trend observed by Metzger et al. [1982a] and Yeh and Chyu [1998]. These results were further investigated by Ames et al. [2006] to clarify the physics of Nusselt number enhancement through the array. They found that the wake shedding from row two was stronger than the wake shedding from row one, which explained the occurrence of the peak Nusselt number in row three. They also verified that the intensity of shedding correlated well with the heat transfer rates off the back sides of pins.

Lyall et al. [2006] measured pin and endwall Nusselt numbers for a single row of pin fins at various spacings and found good agreement with correlations for the first row in a multiple row array developed by Metzger et al. [1982a] and Chyu [1990]. Hwang et al. [2001] developed a correlation to predict Nusselt numbers in the first row of an in-line array located in a wedged duct. They compared their correlation with the correlations developed by Metzger et al. [1982a] and Chyu [1990] and found good agreement. Table 1.2 shows the correlations developed by Metzger et al. [1982], Chyu [1990], and Hwang et al. [2001] for Nusselt numbers in the first row of a multiple row array.

Overall, the research available in the literature discussed the effects of Reynolds number, pin spacing, and aspect ratio on array heat transfer. Previous studies showed that array-average Nusselt number increased with decreased pin spacing and had a larger dependence on streamwise spacing than spanwise spacing. The literature also showed that array-average heat transfer decreased with decreased pin aspect ratio to a certain extent. At pin aspect ratios less than two, the Nusselt number augmentation remained constant with a decrease in pin aspect 
ratio. Many experiments were conducted to study the effects of pin-to-endwall heat transfer and every study concluded that pin heat transfer was greater than endwall heat transfer; however, no two studies agreed on the relative amount that pin heat transfer was greater than endwall heat transfer. Nusselt number development through multiple row arrays of pin fins was studied by many researchers. They all observed the same trend of an initial increase in Nusselt number through the entrance of an array to reach a fully developed value before, in some cases, a slight decrease through the remainder of the array. The location of peak Nusselt number in an array usually occurred between rows two and four and depended on the direct wake impingement from upstream rows of pins and flow acceleration between spanwise pins.

Up to now most of the experimental research conducted on low aspect ratio pin fin arrays covered a limited range of spanwise and streamwise spacings. The present work investigates a wider range of streamwise and spanwise spacings to gain a better understanding of the effects, which have been seen in the past on low aspect ratio arrays. There have also been limited studies conducted to investigate the effects of pin aspect ratio on array heat transfer. There has been some discrepancy among previous studies concerning the relationship between the pin and endwall Nusselt number. Using a new technique, the pin-to-endwall Nusselt number ratio was also investigated.

The objectives of the present work are to further investigate the effects of Reynolds number, pin spacing, and pin aspect ratio using an advanced infrared thermography technique. This method allows for the visualization of Nusselt number patterns on the endwall surface of pin fin arrays with multiple rows. The Nusselt number patterns on the endwall have not been widely observed before. A connection is made between the observed Nusselt number patterns and the quantitative data.

\section{Experimental Facility}

To measure the convective heat transfer in pin fin arrays, different geometries were placed in an experimental facility that provided the correct flow conditions for large-scale, array models. Experiments were conducted to determine endwall Nusselt numbers across seven rows of copper pin fins placed having different spanwise (S1/d) and streamwise (S2/d) spacings. Experiments were also conducted using non-conductive instrumented pins to measure pin heat 
transfer. Definitions for these parameters are shown in Figure 1.1 while Table 1.3 shows the specific details for each array that was studied.

A schematic of the closed loop facility, similar to the one used by Lyall et al. [2006], is shown in Figure 1.2. In Figure 1.2, the flow moves in the clockwise direction. As flow entered the plenum, it first encountered a splash plate, which prevented the inlet air from propagating through to the test section without mixing. The air then passed through a finned tube heat exchanger that was used to ensure a constant air temperature to the test section. As the flow exited the plenum, it was directed through a rounded test section inlet to ensure uniform flow entering the duct. The rounded inlet was constructed from sections of piping. Strips of 60 grit sandpaper were added to uniformly trip the boundary layer across the entire span of the channel. Flow developed for 40 hydraulic diameters before the heated section and 44 hydraulic diameters before the pin fin array.

Downstream of the test section, the flow entered an extension that transitioned the flow from a rectangular duct to a round pipe. A venturi flowmeter was placed 15 pipe diameters downstream of the extension. The venturi was followed by a pipe length of eight diameters that was needed to ensure accurate flow measurements. The calculation of volumetric flowrate required the measure of absolute pressure and temperature of the air at the flowmeter as well as the pressure differential across characterized geometry of the venturi. The calculation of volumetric flowrate is explained in more detail in Appendix A.

The flowrate for the experiments was manually regulated by the blower shown in Figure 1.2 to set the desired Reynolds number. Pressure regulating valves, also shown in Figure 1.2, were installed on both the suction and the discharge sides of the blower. These regulating valves were used to equilibrate the pressure inside the test section with that on the outside of the test section. Pressure equilibration was necessary because a thin heater was used as the endwall surface of the pin fin array. A pressure differential between the test section and external surroundings caused the endwall to either bow outward or contract inward. If the pressure in the channel is higher than the ambient pressure, the endwall heater bows outward creating a gap between the pin fins and the endwall. If the pressure in the channel is much lower than the ambient pressure, the endwall heater contracts inward creating a non-uniform duct height through the array. It is important to note that the flowrate was quantified directly downstream of 
the test section such that it was an accurate measure and was independent of the settings on the regulator valves.

The test section of the facility, as was indicated in Figure 1.2, was constructed as a parallel plate duct as shown in Figure 1.3. The test section channel had a width of $61 \mathrm{~cm}$ and a height of $0.95 \mathrm{~cm}$ giving a width to height ratio of $64: 1$. The test section contained an unheated entrance length followed by a heated entrance length after which was placed the array of copper pin fins. Figure 1.4 shows an example of one of the pin fin array configurations in which the large red rectangle represents the heated endwall area and the small blue rectangle represents the region viewed by the infrared camera.

Within the test section, shown in Figure 1.3, heaters placed along the walls of the duct were used to create a constant heat flux boundary condition on the endwalls of the pin fin array. A constant heat flux boundary condition was used to simplify the experimental setup and predict accurate heat transfer coefficients. Using a constant heat flux boundary condition versus an isothermal boundary condition would impact the final heat transfer results if the flow conditions being modeled were laminar; however, in this case with highly turbulent internal flows, the constant heat flux boundary condition is adequate for measuring heat transfer. The difference between using a constant heat flux versus isothermal boundary condition is not significant for turbulent flows because the heat transfer is driven by the eddy behavior of the flow in turbulent conditions. The heaters were powered by individual power supplies and placed in series with a precision resistor. The resistor was used to make accurate current measurements through the heater. The power supplies were adjusted to provide the same power to the top and bottom endwall heaters. The net heat flux convected to the flow was calculated knowing the power supplied to the heaters using Equation 1.1,

$$
\mathrm{q}_{\text {net }} "=\frac{\mathrm{P}-\mathrm{q}_{\text {loss }} "(2 \mathrm{~L} \cdot \mathrm{W})}{2 \mathrm{~L} \cdot \mathrm{W}+0.5 \mathrm{~N} \pi \cdot \mathrm{d}^{2}}
$$

where $\mathrm{P}$ is the total power to the heaters, qloss" is the calculated heat flux loss due to conduction, $\mathrm{L}$ is the length of each heater, $\mathrm{W}$ is the width of each heater, $\mathrm{N}$ is the number of pins, and $\mathrm{d}$ is the pin diameter. The term in the denominator is the wetted area which incorporates the pin surface area into the overall heat flux area. 
The heat flux loss due to conduction was estimated using thermocouple measurements made on the outside of the test section walls to measure loss temperature (see Figure 1.3). The heat flux loss was calculated using the difference between the measured wall temperature and the loss temperature along with the associated thermal resistance. In general, the heat losses were less than $5 \%$ of the total supplied by the heater at the lowest Reynolds number and decreased with increasing Reynolds number. A detailed analysis of the heat loss flux is shown in Appendix B. Knowing the net heat flux to the flow, the heat transfer coefficients were calculated using the calculated bulk air temperature as the fluid reference temperature. The bulk air temperature was calculated using an energy balance.

The spatially-resolved endwall measurements for the pin fin arrays were made through a $17 \mathrm{~cm}$ by $33 \mathrm{~cm}$ rectangular slot (shown in Figure 1.4 by the blue rectangle) in which the external side of the endwall heater was optically exposed through a zinc selenide window. Zinc selenide was chosen because of its insulating characteristics and its transparency to infrared. Directly on the external side of the heater was a thin air gap. This air gap helped to reduce conductive losses from the heater. While the test surface was coming to steady-state conditions, a $5 \mathrm{~cm}$ thick piece of insulation was placed on the external side of the window. After steady-state was achieved and before the infrared camera measurements were made, the insulation was removed to allow optical access to the heater surface. Measurements were acquired over a time period of less than two minutes with minimal heat loss to the environment.

Spatially-resolved endwall temperature measurements were taken with an infrared camera. As was stated, after-steady-state conditions were reached, the insulation over the zinc selenide window was removed and a series of pictures of the external side of the endwall heater was taken. On the external side of the heater a thin layer of copper was vacuum deposited to ensure an even heat flux distribution on the surface. This copper surface was painted black to provide a highly emissive surface for viewing with the infrared camera. Three thermocouples were attached to the back side of the heater with thermally conductive epoxy and were used to calibrate the infrared images. During image calibration an emissivity of 0.96 was assumed for the endwall surface. Each heater was composed of inconel strips arranged in a serpentine fashion and encapsulated in Kapton. Although each heater was composed of many layers of material, the total thickness was only $254 \mu \mathrm{m}$. 
In addition to the endwall studies, experiments were performed to acquire pin heat transfer data. Two pins were constructed from balsa wood and the surface of each was covered with inconel heating foil. A schematic of a balsa pin is shown in Figure 1.5. Balsa wood was used because of its insulating properties to minimize conduction losses through the pin. Three thermocouples were embedded around the surface of each balsa pin on the inside of the inconel heater strip. Each thermocouple was placed at a different circumferential location to determine a heat transfer coefficient at the leading edge, the trailing edge, and $90^{\circ}$ from the leading edge on the side of the pin. Comparisons with the literature showed that these three measurement locations gave a good average of pin heat transfer coefficients. During pin tests, the array was placed on a non-conductive surface to prevent conduction losses to the endwall. Both pins were placed in the row of interest and the results from both pins were averaged to decrease the uncertainty of the results for each row. Tests were performed through the full range of Reynolds numbers for each row individually.

\section{Uncertainty Analysis}

An uncertainty analysis was conducted using the methods described by Moffat [1988]. The uncertainty was calculated at low and high Reynolds numbers for the highest and lowest values of pin and endwall Nusselt numbers. The calculated Reynolds number uncertainty was $4.0 \%$ and $2.5 \%$ at Reynolds numbers of 5000 and 30,000 respectively. The maximum pin Nusselt number $\left(\mathrm{Nu}_{\mathrm{d}, \mathrm{p}}\right)$ uncertainty was $5.5 \%$. The uncertainty for the duct Nusselt number $(\mathrm{Nu})$ was less than $13 \%$ for all cases tested. Most of the uncertainty in the calculation of the duct Nusselt number was due to the calibration of the infrared camera. The combined pin and endwall also referred to as array-average Nusselt number uncertainty was less than $8 \%$ for all cases tested. A more detailed discussion of the uncertainty analysis can be found in Appendix A.

\section{Effect of Reynolds Number on Endwall and Pin Heat Transfer}

Convective heat transfer in pin fin arrays depends not only on pin spacing but Reynolds number as well. This section discusses the effects of Reynolds number on endwall and pin heat transfer. The relationship between pin and endwall Nusselt number will also be explored. Two definitions of Reynolds number are used throughout this section. The duct Reynolds number $(\mathrm{Re})$ is based on the bulk velocity through the channel and uses the channel hydraulic diameter as 
the characteristic length. The array Reynolds number $\left(\operatorname{Re}_{\mathrm{d}}\right)$ is based on the maximum velocity through the array and uses the pin diameter as the characteristic length. Two definitions of Nusselt numbers are also used. The duct Nusselt number $(\mathrm{Nu})$ uses the channel hydraulic diameter as the characteristic length while the array Nusselt number $\left(\mathrm{Nu}_{\mathrm{d}}\right)$ uses the pin diameter as the characteristic length. The array Nusselt number is commonly used throughout the paper to draw comparisons between different array geometries based on endwall Nusselt number $\left(\mathrm{Nu}_{\mathrm{d}, \mathrm{e}}\right)$ and pin Nusselt number $\left(\mathrm{Nu}_{\mathrm{d}, \mathrm{p}}\right)$.

Figures 1.6 and 1.7 show contour plots that illustrate the endwall Nusselt number augmentation $\left(\mathrm{Nu} / \mathrm{Nu}_{0}\right)$ through a range of Reynolds numbers for the $\mathrm{S} 1 / \mathrm{d}=2, \mathrm{~S} 2 / \mathrm{d}=1.73, \mathrm{H} / \mathrm{d}=1$ and $\mathrm{S} 1 / \mathrm{d}=4, \mathrm{~S} 2 / \mathrm{d}=3.46, \mathrm{H} / \mathrm{d}=1$ arrays respectively. The Nusselt number augmentation is the ratio of duct Nusselt number $(\mathrm{Nu})$ to the correlated smooth duct Nusselt number $\left(\mathrm{Nu}_{0}\right)$ at the same duct Reynolds number [Kays and Crawford, 1980]. In Figures 1.6 and 1.7, the flow is moving from the bottom to the top of each contour. The vertical axis is the non-dimensional streamwise distance $(\mathrm{x} / \mathrm{d})$ measured from the first row of the array where $\mathrm{x}$ is the streamwise distance and $\mathrm{d}$ is the pin diameter. The horizontal axis is the non-dimensional spanwise distance (y/d) where $y$ is the spanwise distance measured from the center of the image. Duct Reynolds number and duct Nusselt number are typically used to characterize heat transfer and flow when discussing augmentation. To keep with convention, the array Nusselt number and array Reynolds number are used when comparing to results from the literature. Each contour plot represents the same physical area independent of pin spacing differences which is why fewer pins are shown in Figure 1.7 relative to Figure 1.6. These contour plots show that augmentation decreases with increasing Reynolds number for both pin spacings. This decrease is observed because at low Reynolds numbers adding pin fins greatly increases the turbulence relative to an empty duct while at high Reynolds numbers the turbulence is only slightly increased by adding pin fins.

Augmentation upstream of the array is expected to be equal to one for all pin fin array spacings because the upstream Nusselt numbers should be equivalent to smooth duct Nusselt numbers. The upstream augmentation data is limited because the infrared viewing area is not large enough to see far upstream. The contours in Figures 1.6 and 1.7 indicate that augmentation does approach one farther upstream of the array. At the highest Reynolds number for both array spacings, the visible area just upstream of the array has lower augmentation than at the lowest 
Reynolds number, which shows that the upstream Nusselt number augmentation is affected by Reynolds number. Figure 1.6 shows the downstream as well as the upstream augmentation for the $\mathrm{S} 1 / \mathrm{d}=2, \mathrm{~S} 2 / \mathrm{d}=1.73, \mathrm{H} / \mathrm{d}=1$ geometry. Downstream of the array in Figure 1.6, the flow eventually remixes and the augmentation approaches one. At low Reynolds numbers effects are seen farther downstream than at high Reynolds numbers, which is consistent with the trend seen upstream of the array.

Figure 1.8 shows the spanwise average augmentation with respect to row number for the $\mathrm{S} 1 / \mathrm{d}=2, \mathrm{~S} 2 / \mathrm{d}=1.73, \mathrm{H} / \mathrm{d}=1$ geometry. Experiments were conducted at four Reynolds numbers between 5000 and 30,000. The Nusselt number for each row was calculated by taking a spanwise average of the Nusselt numbers from half of a row spacing $(0.5 \mathrm{X})$ upstream to half of a row spacing downstream of the location of interest. It is important to note that the data under each pin was not included in this average and are represented by the blue circles in the contour plots. Figure 1.8 confirms the effect seen in Figures 1.6 and 1.7 by showing that the augmentation is significantly lower at high Reynolds numbers at every location in the array. The row-by-row augmentation development through the array is independent of Reynolds number showing the same trend in every case. Closer analysis of the Nusselt number development on the endwall is discussed in later sections of this paper.

The Reynolds number effect on pin heat transfer was also measured. Comparisons with the literature regarding local heat transfer around the circumference of the pin fins are in the current study. The pin Nusselt number behavior can best be described by observing the first row measurements made by multiple researchers at low and high Reynolds numbers.

Figure 1.9 shows the general trend of pin Nusselt number around the circumference of the pin fin for low and high Reynolds numbers when placed in the first row of the array. Measurements made in the literature closely illustrate the detail of the circumferential Nusselt number behavior. The general trend of the data shows a maximum Nusselt number at the leading edge of the pin fin where stagnation occurs. The Nusselt number then declines and reaches a minimum value at the point of laminar boundary layer separation. Separation occurs at the point on the surface of the pin where the adverse pressure gradient is high enough to cause the velocity gradient on the surface of the pin to become zero. For a single pin in cross flow, separation generally occurs closer to the pin leading edge at lower Reynolds numbers, but the location of separation can depend on other factors such as the spacing of the pins placed 
downstream. Rows of pin fins placed downstream of the pin of interest can increase the adverse pressure gradient causing separation to occur closer to the leading edge of the pin especially at higher Reynolds numbers. This is a different effect than that seen by a single pin in cross flow.

The minimum Nusselt number at the separation point is sometimes followed by a sharp increase in Nusselt number caused by the transition to turbulent flow. The Metzger et al. [1982b] and Ames et al. [2005] results in Figure 1.9 both show this sharp increase in Nusselt number following separation. Downstream of the sharp increase, there is another decrease in Nusselt number which is caused by the further development of the turbulent boundary layer. The decrease can be seen in the Metzger et al. [1982b] data. The increase in Nusselt number sometimes seen at the trailing edge of the pin fin is caused by mixing in the wake region.

Even with the limited number of circumferential measurements, the Nusselt numbers on the pin in this study show a similar trend to the description above. The maximum heat transfer occurs at the leading edge. The Nusselt number then appears to decrease gradually around the pin all the way to the trailing edge. This trend can be explained by noting that the separation point could be located upstream or downstream of the $90^{\circ}$ measurement. If the separation point is located upstream of $90^{\circ}$, then the measurement at $90^{\circ}$ would be affected by the local maximum which occurs downstream of the separation point. If the separation point is located downstream of $90^{\circ}$ then the measurement at $90^{\circ}$ could be higher than at $180^{\circ}$ because the value on the trailing edge is not affected by mixing in the wake region. The latter case is similar to what Ames et al. [2005] observed in row one at their low Reynolds number.

Figure 1.10 shows the average pin Nusselt numbers $\left(\overline{\overline{\mathrm{Nu}}}_{\mathrm{d}, \mathrm{p}}\right)$ for the $\mathrm{S} 1 / \mathrm{d}=2, \mathrm{~S} 2 / \mathrm{d}=1.73$ and $\mathrm{S} 1 / \mathrm{d}=4, \mathrm{~S} 2 / \mathrm{d}=3.46$ geometries (both at $\mathrm{H} / \mathrm{d}=1$ ) compared to results from the literature. Results for pin heat transfer are given in terms of $\mathrm{Nu}_{\mathrm{d}}$ and $\mathrm{Re}_{\mathrm{d}}$ to be consistent with the literature. The pin Nusselt numbers for the two cases presented here are almost identical falling within experimental uncertainty of one another. These results differ from the single row findings of Lyall et al. [2006]. They found that the pin Nusselt number for the $\mathrm{S} 1 / \mathrm{d}=2$ row yielded lower results than the $\mathrm{S} 1 / \mathrm{d}=4$ row. They concluded that the data did not scale with the pin Reynolds number because the pin results did not scale with velocity alone. The multiple row geometries tested here do scale with pin Reynolds number indicating that, for multiple row arrays, the maximum velocity through the pin fin array is the main driving mechanism for convection. A 
correlation was developed to predict pin Nusselt number for arrays within the range of the designated geometries. The correlation shown by Equation 1.2

$$
\begin{gathered}
\overline{\overline{N u}}_{\mathrm{d}}=0.43 \mathrm{Re}_{\mathrm{d}}{ }^{0.564} \\
2 \leq \mathrm{S} 1 / \mathrm{d} \leq 4 ; 1.73 \leq \mathrm{S} 2 / \mathrm{d} \leq 3.46 ; \mathrm{H} / \mathrm{d}=1, \\
5000 \leq \mathrm{Re}_{\mathrm{d}} \leq 25,000
\end{gathered}
$$

is used to predict the average pin Nusselt numbers for the geometries for which pin measurements were not taken and is shown in Figure 1.10.

The Zukauskas [1972] inner row correlation predicts Nusselt number for large aspect ratio pin fin arrays with $\mathrm{S} 1 / \mathrm{d}$ ranging from 1.3 to 2.6 and $\mathrm{S} 2 / \mathrm{d}$ ranging from 0.6 to 3.9. The Zukauskas [1972] correlation agrees well with the results of the two geometries presented here but has a slightly higher Reynolds number dependence. The Chyu et al. [1998] and the Yeh and Chyu [1998] correlations have similar Reynolds number dependence as the geometries tested here but differ in magnitude.

Figure 1.11 shows the combined pin and endwall Nusselt number results from the first row of the $\mathrm{S} 1 / \mathrm{d}=2, \mathrm{~S} 2 / \mathrm{d}=1.73$ and $\mathrm{S} 1 / \mathrm{d}=4, \mathrm{~S} 2 / \mathrm{d}=3.46$ arrays both having $\mathrm{H} / \mathrm{d}=1$. The results in Figure 1.11 are plotted along with the single row combined pin and endwall Nusselt number results from Lyall et al. [2006] and first row correlations by Metzger et al. [1982a], Chyu [1990], and Hwang et al. [2001] shown in Table 1.2. It is important to note that the first row correlation by Hwang et al. [2001] predicts the endwall Nusselt numbers only. Every other correlation in Figure 1.11 shows the combined pin and endwall Nusselt numbers. The results from the present study are in good agreement with the results from Lyall et al. [2006] through the whole range of Reynolds numbers. The $\mathrm{S} 1 / \mathrm{d}=2, \mathrm{~S} 2 / \mathrm{d}=1.73, \mathrm{H} / \mathrm{d}=1$ results are also in good agreement with the Metzger et al. [1982a] first row correlation especially at low Reynolds numbers. At $\operatorname{Re}_{d}>10,000$ the Metzger et al. [1982a] correlation has a higher Reynolds number dependence. The Chyu [1990] and Hwang et al. [2001] correlations predict higher Nusselt numbers but show the same Reynolds number dependence as the results from the present study.

Figure 1.12 shows the relationship between the endwall, pin, and array-average heat transfer of the $\mathrm{S} 1 / \mathrm{d}=2, \mathrm{~S} 2 / \mathrm{d}=1.73, \mathrm{H} / \mathrm{d}=1$ geometry. As found in the literature, the pin Nusselt number for this geometry is higher than the endwall Nusselt number. For this particular geometry the pin heat transfer is at least $40 \%$ higher than that of the endwall through the entire Reynolds number range. The array-average Nusselt number is taken as an area average of pin 
and endwall Nusselt numbers and is therefore more dependent on endwall heat transfer because the area devoted to the endwall is higher than the area devoted to the pin. The array-average results for the $\mathrm{S} 1 / \mathrm{d}=2, \mathrm{~S} 2 / \mathrm{d}=1.73, \mathrm{H} / \mathrm{d}=1$ geometry fall within $15 \%$ of the array-average correlation for a ten row staggered array by Metzger et al. [1982a]. There is better agreement between the present study and the Metzger et al. [1982a] correlation at lower Reynolds numbers. The differences in results can be attributed to the pin spacing differences between experiments.

Figure 1.13 shows that the pin-to-endwall Nusselt number ratio depends greatly on Reynolds number and pin spacing. The highest ratio occurs at the lowest Reynolds number and the widest pin spacing. As the Reynolds number is increased, the ratio decreases until the highest Reynolds number. This is very similar to the findings of Lyall et al. [2006]. The relationship between pin to endwall Nusselt number ratio and pin spacing can be attributed to pin-wake interaction on the endwall. With wider pin spacings, wake interaction is not as prevalent. With less wake interaction, the average heat transfer on the endwall is lower, which increases the pin-to-endwall Nusselt number ratio. Note that Metzger et al. [1984] also found a pin-to-endwall Nusselt number dependence on pin spacing. They determined that the pin to endwall heat transfer ratio was 1.8 at $\mathrm{S} 1 / \mathrm{d}=2.5, \mathrm{~S} 2 / \mathrm{d}=2.5, \mathrm{H} / \mathrm{d}=1$ and 2.0 at $\mathrm{S} 1 / \mathrm{d}=2.5, \mathrm{~S} 2 / \mathrm{d}=1.5$, $\mathrm{H} / \mathrm{d}=1$. VanFossen [1982] reported a ratio of 1.35 and Chyu et al. [1998] determined a maximum pin-to-endwall Nusselt number ratio of 1.2. The results reported here show ratios ranging from 1.85 at the lowest Reynolds number and widest array spacing to approximately 1.4 at the highest Reynolds number and tightest array spacing. The results here seem to be more consistent with the findings of Metzger et al. [1984] and VanFossen [1982].

Figure 1.14 shows the array-average Nusselt number augmentation over open duct flow Nusselt number for the $\mathrm{S} 1 / \mathrm{d}=2, \mathrm{~S} 2 / \mathrm{d}=1.73$ and the $\mathrm{S} 1 / \mathrm{d}=4, \mathrm{~S} 2 / \mathrm{d}=3.46$ geometries both having $\mathrm{H} / \mathrm{d}=1$. The augmentation is greatest at the lowest Reynolds number for both spacings and gradually decreases through the rest of the Reynolds number range. This indicates that the Reynolds number dependence is greatest at lowest Reynolds numbers. At higher Reynolds numbers the flow is extremely turbulent even without pin fins. Adding pin fins does not augment heat transfer as much at high Reynolds numbers as it does at low Reynolds numbers. At low Reynolds numbers the flow is not very disturbed, so adding pin fins increases the velocity and turbulence levels through the array which greatly augments the Nusselt number. Augmentation for both pin spacings shows the same dependency on Reynolds number. 


\section{Effect of Pin Spacing on Endwall Heat Transfer}

The endwall Nusselt number measurements have a dominant effect on the array-average Nusselt numbers in arrays with low pin aspect ratios. Much can be learned about the overall array heat transfer by exploring the effects seen on the endwall. Specifically, this section focuses on the effects of spanwise and streamwise pin spacing on endwall Nusselt number. The results are presented in terms of array Nusselt number $\left(\mathrm{Nu}_{\mathrm{d}}\right)$ and array Reynolds number $\left(\mathrm{Re}_{\mathrm{d}}\right)$ to be consistent with the literature.

Figure 1.15 shows the average endwall Nusselt numbers $\left(\overline{\overline{\mathrm{Nu}}}_{\mathrm{d}, \mathrm{e}}\right)$ for the $\mathrm{S} 1 / \mathrm{d}=2$, $\mathrm{S} 2 / \mathrm{d}=3.46$ and $\mathrm{S} 1 / \mathrm{d}=4, \mathrm{~S} 2 / \mathrm{d}=3.46$ geometries both having $\mathrm{H} / \mathrm{d}=1$. Because both arrays represented in Figure 1.15 were set at the same streamwise spacing, the effects of spanwise spacing can be explored. Both data sets agree with one another indicating that there is a small spanwise effect on endwall Nusselt number. They also show similar Reynolds number dependence especially at higher Reynolds numbers. Figure 1.16 shows the average endwall Nusselt number for the $\mathrm{S} 1 / \mathrm{d}=2, \mathrm{~S} 2 / \mathrm{d}=1.73$ and $\mathrm{S} 1 / \mathrm{d}=4, \mathrm{~S} 2 / \mathrm{d}=1.73$ geometries (both at $\mathrm{H} / \mathrm{d}=1$ ). Once again, the two curves fall within experimental uncertainty of one another as shown by the error bars.

The Nusselt number development through the array for the $\mathrm{S} 1 / \mathrm{d}=2, \mathrm{~S} 2 / \mathrm{d}=1.73$ and $\mathrm{S} 1 / \mathrm{d}=4, \mathrm{~S} 2 / \mathrm{d}=1.73$ arrays, both having $\mathrm{H} / \mathrm{d}=1$, is shown in Figure 1.17 . Note that the duct Reynolds number (Re) is used to characterize the flow for each case in Figure 1.17. The ratio of duct Reynolds number $(\mathrm{Re})$ to array Reynolds number $\left(\mathrm{Re}_{\mathrm{d}}\right)$ is higher for wider pin spacings, because there are fewer pins to block the flow in the channel. Figure 1.17 shows that the Nusselt number development between these two geometries is very similar. Both arrays reach a fully developed Nusselt number between rows three and four. Both geometries have a more gradual Nusselt number development at lower Reynolds numbers than at high Reynolds numbers. The development trends are similar for both pin spacings because they are both staggered arrays in which upstream effects such as wake shedding are not experienced until rows three or four. The trend seen in Figure 1.17 is consistent with the conclusion by Chyu [1990] that the maximum Nusselt number occurs in the row that experiences the first direct wake impingement from upstream rows of pins.

To illustrate the effect of streamwise spacing, the comparison between average endwall Nusselt number for the $\mathrm{S} 1 / \mathrm{d}=2, \mathrm{~S} 2 / \mathrm{d}=1.73$ and $\mathrm{S} 1 / \mathrm{d}=2, \mathrm{~S} 2 / \mathrm{d}=3.46$ geometries (both at $\mathrm{H} / \mathrm{d}=1$ ) is 
shown in Figure 1.18. The two cases agree well at low Reynolds numbers but diverge at higher Reynolds numbers. The $\mathrm{S} 2 / \mathrm{d}=1.73$ case has a higher magnitude and Reynolds number dependence than the $\mathrm{S} 2 / \mathrm{d}=3.46$ case at high Reynolds numbers, because the $\mathrm{S} 2 / \mathrm{d}=1.73$ array is more tightly spaced and induces more wake interaction between pin rows than the array with the wider streamwise spacing.

Figure 1.19 shows the Nusselt number development through the $\mathrm{S} 1 / \mathrm{d}=2, \mathrm{~S} 2 / \mathrm{d}=1.73$ and $\mathrm{S} 1 / \mathrm{d}=2, \mathrm{~S} 2 / \mathrm{d}=3.46$ arrays both having $\mathrm{H} / \mathrm{d}=1$. The development trends for these two geometries are very different. The Nusselt number in the $\mathrm{S} 2 / \mathrm{d}=3.46$ array starts low, reaches a peak value at row two, then stays constant through the rest of the array. The first and second row Nusselt number values are very similar for both arrays. The $\mathrm{S} 2 / \mathrm{d}=1.73$ array continues to develop downstream of row two through row four. The longer development results in a higher fully developed Nusselt number for the $\mathrm{S} 2 / \mathrm{d}=1.73$ array than the $\mathrm{S} 2 / \mathrm{d}=3.46$ array. Recall that Chyu [1990] determined for a given array the maximum Nusselt number occurs at the row having the first direct wake shedding from the upstream rows. The $\mathrm{S} 1 / \mathrm{d}=2, \mathrm{~S} 2 / \mathrm{d}=3.46$ array is widely spaced in the streamwise direction relative to the spanwise direction. Because the streamwise spacing is wider than the spanwise spacing, row two experiences direct wake shedding from row one which constitutes the maximum Nusselt number occurrence in row two. Likewise, the first direct wake shedding from upstream rows in the $\mathrm{S} 2 / \mathrm{d}=1.73$ array is not experienced until rows three and four which is where the Nusselt number reaches its fully developed value. The largest difference between fully developed values of the $\mathrm{S} 2 / \mathrm{d}=1.73$ and $\mathrm{S} 2 / \mathrm{d}=3.46$ arrays occurs at the highest two Reynolds numbers which is where the two curves diverge in Figure 1.19. The difference in development trends between the two streamwise spacings is more obvious at high Reynolds numbers because the tighter streamwise spacing increases the wake interaction and hence the fully developed Nusselt number value. The augmentation development through each array can be observed in the contour plots in Appendix C.

The average endwall Nusselt numbers for the $\mathrm{S} 1 / \mathrm{d}=4, \mathrm{~S} 2 / \mathrm{d}=1.73$ and $\mathrm{S} 1 / \mathrm{d}=4, \mathrm{~S} 2 / \mathrm{d}=3.46$ arrays, both having $\mathrm{H} / \mathrm{d}=1$, are shown in Figure 1.20. The $\mathrm{S} 2 / \mathrm{d}=1.73$ heat transfer is higher than the $\mathrm{S} 2 / \mathrm{d}=3.46$ heat transfer across the entire range of Reynolds numbers. Similar to the results seen in Figure 1.18, the $\mathrm{S} 2 / \mathrm{d}=1.73$ array has a slightly higher Reynolds number dependence. The higher Reynolds number dependence again occurs because the wake interaction increases more with Reynolds number in the array with the tighter streamwise spacing. These results are 
consistent with the findings of Metzger et al. [1982c] which are also plotted in Figure 1.20. They show a similar trend between the Nusselt numbers for two arrays with a similar difference in streamwise spacings.

Figure 1.21 shows the Nusselt number development through the $\mathrm{S} 1 / \mathrm{d}=4, \mathrm{~S} 2 / \mathrm{d}=1.73$ and $\mathrm{S} 1 / \mathrm{d}=4, \mathrm{~S} 2 / \mathrm{d}=3.46$ arrays, both having $\mathrm{H} / \mathrm{d}=1$. The Nusselt number for the $\mathrm{S} 2 / \mathrm{d}=3.46$ array develops through the first three rows, reaches a maximum at row four and gradually declines and levels off through the remainder of the array. Recall that Metzger et al. [1982a] and Yeh and Chyu [1998] observed the same decline through the array downstream of the location where maximum Nusselt number was measured. This trend is consistent at all Reynolds numbers. The Nusselt number for the $\mathrm{S} 2 / \mathrm{d}=1.73$ array also develops through the first three rows and reaches a fully developed value at row four but does not decline in the same way as the $\mathrm{S} 2 / \mathrm{d}=3.46$ array. The first direct wake impingement occurs at rows three and four in both arrays which is where the Nusselt number reaches its fully developed value. The two geometries are in most disagreement at higher Reynolds numbers which supports the trend seen in Figure 1.20 that the $\mathrm{S} 2 / \mathrm{d}=1.73$ array has a higher Reynolds number dependence. The trends observed in Figures 1.21 and 1.19 indicate that Nusselt number development is dependent on the ratio of streamwise to spanwise spacing (S2/S1). Of the cases tested in this study, the only one that developed before rows three and four was the case when $\mathrm{S} 2 / \mathrm{S} 1$ was greater than 1.

The array-average Nusselt numbers for every $\mathrm{H} / \mathrm{d}=1$ array studied are shown in Figure 1.22. The array-average Nusselt numbers for the $\mathrm{S} 1 / \mathrm{d}=2, \mathrm{~S} 2 / \mathrm{d}=1.73$ and $\mathrm{S} 1 / \mathrm{d}=4, \mathrm{~S} 2 / \mathrm{d}=3.46$ geometries were calculated using the area-average of the pin and endwall Nusselt number obtained for those geometries. Pin results were not obtained for the other geometries, so the average pin Nusselt number correlation shown by Equation 1.2 was used to calculate the arrayaverage Nusselt numbers for the $\mathrm{S} 1 / \mathrm{d}=2, \mathrm{~S} 2 / \mathrm{d}=3.46$ and $\mathrm{S} 1 / \mathrm{d}=4, \mathrm{~S} 2 / \mathrm{d}=1.73$ geometries. Figure 1.22 shows that the two arrays with $\mathrm{S} 2 / \mathrm{d}=1.73$ are in extremely good agreement having higher Nusselt numbers than the two arrays with the $\mathrm{S} 2 / \mathrm{d}=3.46$. The array with the widest spanwise and streamwise spacings expectedly promotes the lowest heat transfer across the entire range of Reynolds numbers. The agreement between the two arrays with $\mathrm{S} 2 / \mathrm{d}=1.73$ shows that when the streamwise spacing is small, a decrease in spanwise spacing no longer significantly improves the heat transfer which suggests that the streamwise spacing plays a larger role in driving the convective heat transfer through pin fin arrays. 
Using the results presented in Figure 1.22, a correlation was developed to predict the array-average Nusselt numbers across the range of Reynolds numbers between 5,000 and 25,000. The correlation predicts the Nusselt numbers within the designated range of spanwise and streamwise spacings for arrays with an $\mathrm{H} / \mathrm{d}=1$. The correlation shown by Equation 1.3

$$
\begin{gathered}
\overline{\mathrm{Nu}}_{\mathrm{d}, \mathrm{c}}=\left[0.128(\mathrm{~S} 1 / \mathrm{d})^{0.165}(\mathrm{~S} 2 / \mathrm{d})^{(-0.310(\mathrm{~S} 1 / \mathrm{d})+1.182)}\right] . . \\
\ldots * \mathrm{Re}_{\mathrm{d}}\left[0.680(\mathrm{~S} 1 / \mathrm{d})^{-0.023}(\mathrm{~S} 2 / \mathrm{d})^{(0.048(\mathrm{~S} 1 / \mathrm{d})-0.224)}\right], \\
2 \leq \mathrm{S} 1 / \mathrm{d} \leq 4 ; 1.73 \leq \mathrm{S} 2 / \mathrm{d} \leq 3.46 ; \mathrm{H} / \mathrm{d}=1
\end{gathered}
$$

takes into account the spanwise and streamwise spacings at the Reynolds number of interest to predict the array-average Nusselt number. Figure 1.23 shows the array-average Nusselt numbers predicted by Equation 1.3 with respect to S1/d or S2/d at array Reynolds numbers of 10,000 and 25,000 . Figure 1.23 shows that array-average Nusselt number for a given $\mathrm{S} 1 / \mathrm{d}$ decreases with an increase in S2/d. It also shows that array-average Nusselt number for a given S2/d does not change with a change in $\mathrm{S} 1 / \mathrm{d}$ confirming that array-average Nusselt number is more dependent on S2/d (streamwise spacing) than S1/d (spanwise spacing).

As shown in Figure 1.24, the correlation is in good agreement with results from the literature for arrays within the designated geometry range. When compared to the results obtained by Metzger et al. [1982a] for an $\mathrm{S} 1 / \mathrm{d}=2.5, \mathrm{~S} 2 / \mathrm{d}=1.5, \mathrm{H} / \mathrm{d}=1$ array, the correlation fell within $6 \%$ at every Reynolds number. The correlation was within $10 \%$ of the results obtained by Metzger et al. [1982a] and within 7\% of the results obtained by Chyu et al. [1998] for an $\mathrm{S} 1 / \mathrm{d}=2.5, \mathrm{~S} 2 / \mathrm{d}=2.5, \mathrm{H} / \mathrm{d}=1$ array. Table 1.4 lists the correlations developed to predict the average pin, average endwall, and array-average Nusselt numbers for the geometries presented in this paper. The highlighted sections represent correlations that were developed using the average pin Nusselt number correlation shown by Equation 1.2.

\section{Effect of Pin Aspect Ratio on Endwall Heat Transfer}

The effects of pin aspect ratio on endwall heat transfer have not been widely studied. Limited research has been conducted on arrays with multiple aspect ratios to determine the direct effect of changing the dimension. This section focuses on the results obtained to briefly explore the effect that pin aspect ratio has on endwall heat transfer. Pin heat transfer was not measured for the array with $\mathrm{H} / \mathrm{d}=0.5$ because the endwall Nusselt numbers have a dominant effect on the 
array-average Nusselt numbers at very low aspect ratios and provide a reasonable prediction of array heat transfer.

Augmentation $\left(\mathrm{Nu} / \mathrm{Nu}_{0}\right)$ contour plots for the $\mathrm{S} 1 / \mathrm{d}=2, \mathrm{~S} 2 / \mathrm{d}=1.73$ array at aspect ratios of $\mathrm{H} / \mathrm{d}=0.5$ and $\mathrm{H} / \mathrm{d}=1$ are shown in Figure 1.25. It is important to note that every contour in Figure 1.25 encompasses the same physical area even though the pin diameter is twice as large in the $\mathrm{H} / \mathrm{d}=0.5$ array. Figure 1.25 shows that augmentation is slightly higher in the $\mathrm{H} / \mathrm{d}=1$ array at both Reynolds numbers. Lower augmentation and more localized pin wakes are observed in the array with $\mathrm{H} / \mathrm{d}=0.5$. The reason for the lower augmentation in the $\mathrm{H} / \mathrm{d}=0.5$ array is that the duct height relative to the pin diameter is low which suppresses the pin wakes and prevents wake interaction between pins. The wakes are more localized because they are unable to spread and interact with the wakes from other pins. Recall that Brigham and VanFossen [1984] concluded that combined pin and endwall augmentation decreased with decreased aspect ratio for arrays with $H / d>2$. The data presented here suggests that the endwall augmentation continues to decrease with decreased aspect ratio even when $\mathrm{H} / \mathrm{d}<2$. The augmentation behavior in the wakes of the pin fins for both geometries shown in Figure 1.25 is very different. The augmentation in the pin wakes for the $\mathrm{H} / \mathrm{d}=0.5$ array is lower than the surrounding areas while the augmentation in the pin wakes for the $\mathrm{H} / \mathrm{d}=1$ array shows no distinct difference from the surrounding area. This wake effect occurs because the pin diameter used in the $\mathrm{H} / \mathrm{d}=0.5$ array is twice as large as the pin diameter used for the $\mathrm{H} / \mathrm{d}=1$ array. The wider pins create higher local flow blockage resulting in lower velocities in the wakes of the pin fins. Contour plots for every geometry tested are shown in Appendix C.

The average endwall Nusselt numbers $\left(\overline{\overline{\mathrm{Nu}}}_{\mathrm{d}, \mathrm{e}}\right)$ for the $\mathrm{S} 1 / \mathrm{d}=2, \mathrm{~S} 2 / \mathrm{d}=1.73$ array at aspect ratios of $\mathrm{H} / \mathrm{d}=0.5$ and $\mathrm{H} / \mathrm{d}=1$ are shown in Figure 1.26. Lower endwall Nusselt numbers were observed across the range of Reynolds numbers $\left(\operatorname{Re}_{\mathrm{d}}\right)$ for the geometry with the higher aspect ratio which indicates a different heat transfer mechanism between the two aspect ratios. The $\mathrm{H} / \mathrm{d}=0.5$ geometry shows a slightly higher dependence on Reynolds number at higher Reynolds numbers. The Nusselt numbers do not collapse when presented with respect to array Reynolds number $\left(\mathrm{Re}_{\mathrm{d}}\right)$, which uses the maximum velocity as the scaling velocity. The conclusion to be drawn is that velocity alone does not scale the endwall heat transfer results at low aspect ratios. Increased knowledge of the turbulence in the arrays may be needed to determine the scaling factor required to collapse the endwall heat transfer results. It is possible that this information can only be obtained by measuring localized turbulence levels within the pin fin array. 
Figure 1.27 shows the Nusselt number development through the array for the $\mathrm{H} / \mathrm{d}=0.5$ and $\mathrm{H} / \mathrm{d}=1$ geometries both having $\mathrm{S} 1 / \mathrm{d}=2$ and $\mathrm{S} 2 / \mathrm{d}=1.73$. The ratio of channel Reynolds number $(\mathrm{Re})$ to pin Reynolds number $\left(\mathrm{Re}_{\mathrm{d}}\right)$ is smaller for the $\mathrm{H} / \mathrm{d}=1$ array which is why the Nusselt numbers for corresponding Reynolds numbers are so much larger for the $\mathrm{H} / \mathrm{d}=0.5$ geometry in Figure 1.27. The Nusselt number in both arrays becomes fully developed between rows three and four which indicates that Nusselt number development is independent of aspect ratio.

Figure 1.28 shows the array-average Nusselt numbers for the $\mathrm{S} 1 / \mathrm{d}=2, \mathrm{~S} 2 / \mathrm{d}=1.73$ array with aspect ratios of $\mathrm{H} / \mathrm{d}=0.5$ and $\mathrm{H} / \mathrm{d}=1$. The array-average results for the $\mathrm{H} / \mathrm{d}=1$ geometry were calculated by taking an area-average of the endwall and pin Nusselt numbers obtained for that array. The average pin Nusselt number correlation, shown by Equation 1.2, was used along with the measured endwall results to obtain the array-average Nusselt numbers for the $H / d=0.5$ geometry. The average pin Nusselt number correlation was used because the difference in pin Nusselt numbers between arrays with different spacings was negligible. The assumption was made that the difference in average pin Nusselt number between arrays with different aspect ratios would also be negligible. In addition, the area devoted to the pin compared to the endwall is negligible in an array with $\mathrm{H} / \mathrm{d}=0.5$ and therefore does not greatly affect the array-average Nusselt number. The array-average Nusselt numbers in Figure 1.28 agree better than the endwall Nusselt numbers (seen in Figure 1.25). Figure 1.28 shows that arrays with small aspect ratios $(\mathrm{H} / \mathrm{d}<1)$ exhibit the same array-average heat transfer which is consistent with the conclusion by Brigham and VanFossen [1984] that array-average heat transfer is independent of aspect ratio when $\mathrm{H} / \mathrm{d}<2$.

\section{Conclusions}

Pin and endwall heat transfer measurements across multiple row arrays placed at different spanwise and streamwise spacings were made. The effect of pin aspect ratio was also explored. For each case studied, measurements were made using an infrared thermography technique which allowed for spatially resolved results to be obtained and endwall heat transfer patterns to be observed.

The pin Nusselt numbers obtained for different array geometries were in good agreement which indicated that average pin Nusselt numbers were more dependent on Reynolds number 
than pin spacing. A correlation to predict average pin Nusselt numbers based on pin Reynolds number was developed from the pin Nusselt number results.

Experiments were conducted to determine the independent effects that spanwise and streamwise spacings have on Nusselt number through multiple row arrays of pin fins. The general trends showed that the convective heat transfer in an array of pin fins increased with decreased spanwise and streamwise pin spacings. The effect was more dependent on streamwise spacing than spanwise spacing. A correlation to predict Nusselt number based on spanwise spacing, streamwise spacing, and Reynolds number was developed and validated against results in the literature. Although previous studies on pin spacing effects have been limited, the results obtained in this study agree with the results in the literature. Nusselt number development through the array was also found to be dependent on the ratio of streamwise to spanwise spacing. If the streamwise spacing was larger than the spanwise spacing, the Nusselt number reached a fully developed value farther upstream in the array because of the combined effect of direct wake impingement from upstream rows and flow acceleration between pins. When streamwise spacing was smaller than spanwise spacing, the Nusselt number reached a higher fully developed value farther downstream in the array because direct wake impingement from upstream rows was postponed until the flow reached the third and fourth rows of the array.

Endwall results were obtained to determine the effect of pin aspect ratio on Nusselt number. Endwall augmentation decreased with aspect ratio between pin aspect ratios of 0.5 and one. Array-average Nusselt numbers were calculated for both aspect ratios studied and showed that the array-average Nusselt number $\left(\mathrm{Nu}_{\mathrm{d}}\right)$ was almost identical for both cases which leads to the conclusion that changing pin fin aspect ratio has little effect on array-average Nusselt number at pin aspect ratios less than one.

The ratio of pin-to-endwall Nusselt number is a widely studied topic, which has yielded no solid conclusions other than that the Nusselt number on the pin is greater than that on the endwall. The results obtained for this study showed that pin to endwall Nusselt number ratio depended on Reynolds number as well as pin spacing. This ratio ranged from 1.85 at the lowest Reynolds number and widest pin spacing to 1.4 at the highest Reynolds number and tightest pin spacing.

The results obtained for the wide range of geometries tested in this study improves the understanding of convective heat transfer in low aspect ratio pin fin arrays for turbine blade and 
vane trailing edge applications. Engineers can now use these results to design more efficient cooling geometries to improve the overall heat transfer in turbine airfoils. The spatially resolved heat transfer results shown by the contours also provide useful information regarding pin wake behavior on the array endwalls. The observed heat transfer patterns along with the quantitative results provide a great deal of information that could lead to the design of more efficient cooling methods. 


\section{Acknowledgments}

The authors would like to acknowledge Pratt \& Whitney for supporting this research. In particular the authors would like to thank Atul Kohli and George Suljak for their technical feedback and support. The authors also thank Mike Barringer for assisting in writing this paper.

\section{References}

Kays, W.M., Crawford, M.E., 1980, “Convective Heat and Mass Transfer," $2^{\text {nd }}$ Edition. New York, New York: McGraw-Hill Book Company, Inc.

Lau, S.C., Kim, Y.S., and Han, J.C., 1985, "Effects of Fin Configuration and Entrance Length on Local Endwall Heat/Mass Transfer in a Pin Fin Channel,” ASME Paper 85-WA/HT-62.

Armstrong, J., and Winstanley, D., 1988, "A Review of Staggered Array Pin Fin Heat Transfer for Turbine Cooling Applications," ASME Journal of Turbomachinery, vol. 110, pp. 94-103.

Metzger, D.E., Berry, R.A., and Bronson, J.P., 1982a, "Developing Heat Transfer in Rectangular Ducts with Staggered Arrays of Short Pin Fins," ASME Journal of Heat Transfer, vol. 104, pp. 700-706.

Yeh, J.J., and Chyu, M.K., 1998, “Heat Transfer of Staggered Pin Fin Arrays,” Masters Presentations/Papers and Bennett Poster Competition, Carnegie Mellon University.

Lyall, M.E., Thole, K.A., Kohli, A., 2006, "Heat Transfer from Low Aspect Ratio Pin Fins," ASME Turboexpo

Uzol, O., and Camci, C., 2005, "Heat Transfer, Pressure Loss and Flow Field Measurements Downstream of Staggered Two-Row Circular and Elliptical Pin Fin Arrays," ASME Journal of Heat Transfer, vol. 127, pp. 458-471.

Metzger, D.E., Fan, Z.X., Shepard, W.B., 1982c, "Pressure Loss and Heat Transfer Through Multiple Rows of Short Pin Fins," Heat Transfer 1982, vol. 3, U. Grigull et al., eds., Hemisphere, Washington, pp. 137-142.

Simoneau, R.J., and VanFossen, G.J., 1984, "Effect of Location in an Array on Heat Transfer to a Short Cylinder in Crossflow," ASME Journal of Heat Transfer, vol. 106, pp. 42-48.

Brigham, B.A., and VanFossen, G.J., 1984, "Length-to-Diameter Ratio and Row Number Effects in Short Pin Fin Heat Transfer," ASME Journal of Engineering for Gas Turbines and Power, vol. 106, pp. 241-245.

VanFossen, G.J., 1982, "Heat Transfer Coefficients for Staggered Arrays of Short Pin Fins," ASME Paper 81-GT-75. 
Metzger, D.E., Fan, C.S., Haley, S.W., 1984, "Effects of Pin Shape and Array Orientation on Heat Transfer and Pressure Loss in Pin Fin Arrays," ASME Journal of Engineering for Gas Turbines and Power, vol. 106, pp. 252-257.

Chyu, M.K., Hsing, Y.C., Shih, T.I.-P., and Natarajan, V., 1998, "Heat Transfer Contributions of Pins and Endwall in Pin-Fin Arrays: Effects of Thermal Boundary Condition Modeling," ASME Paper 98-GT-175.

Chyu, M.K., 1990, "Heat Transfer and Pressure Drop for Short Pin-Fin Arrays with Pin-Endwall Fillet," ASME Journal of Heat Transfer, vol. 112, pp. 926-932.

Ames, F.E., Dvorak, L.A., and Morrow, M.J., 2005, "Turbulent Augmentation of Internal Convection Over Pins in Staggered Pin Fin Arrays,” ASME Paper GT2005-53889.

Metzger, D.E., and Haley, S.W., 1982b, "Heat Transfer Experiments and Flow Visualization for Arrays of Short Pin Fins,” ASME Paper 82-GT-138.

Hwang, J., and Lui, C., 2001, "Measurement of endwall heat transfer and pressure drop in a pinfin wedge duct," International Journal of Heat and Mass Transfer, vol 45, pp. 877-889.

Ames F.E., Dvorak L.A., 2006, "Turbulent transport in pin fin arrays: Experimental data and predictions," Journal of Turbomachinery-Transactions of the ASME vol. 128 (1), pp. 71-81

Moffat, R.J., 1988, "Uncertainty Analysis in the Planning of an Experiment," Jounal of Fluids Engineering, vol. 107, pp. 173-181.

Zukauskas, A.A., 1972, "Heat Transfer from Tubes in Crossflow," Advances in Heat Transfer, vol. 8, pp. 93-160. 
Table 1.1. Array Nusselt Number Dependence on Reynolds Number from Literature

\begin{tabular}{|c|c|c|c|c|c|c|}
\hline Investigator & S1/d & S2/d & H/d & Test & Arrangement & $\begin{array}{c}\mathbf{b} \\
\overline{\overline{N u}_{d}}=a^{2} e_{d}^{b}\end{array}$ \\
\hline \multirow[t]{2}{*}{ Chyu [1990] } & 2.5 & 2.5 & 1 & Pin & Staggered & 0.511 \\
\hline & 2.5 & 2.5 & 1 & Pin & In-line & 0.537 \\
\hline \multirow{6}{*}{$\begin{array}{l}\text { Chyu et al. } \\
\text { [1998] }\end{array}$} & 2.5 & 2.5 & 1 & Pin & Staggered & 0.585 \\
\hline & 2.5 & 2.5 & 1 & Pin & In-line & 0.658 \\
\hline & 2.5 & 2.5 & 1 & Endwall & Staggered & 0.582 \\
\hline & 2.5 & 2.5 & 1 & Endwall & In-line & 0.759 \\
\hline & 2.5 & 2.5 & 1 & $\begin{array}{l}\text { Array- } \\
\text { average }\end{array}$ & Staggered & 0.583 \\
\hline & 2.5 & 2.5 & 1 & $\begin{array}{l}\text { Array- } \\
\text { average }\end{array}$ & In-line & 0.733 \\
\hline \multirow{2}{*}{$\begin{array}{l}\text { Hwang et al. } \\
\text { [2001] }\end{array}$} & 2.5 & 2.5 & $1.3-3.6$ & Endwall & Staggered & 0.646 \\
\hline & 2.5 & 2.5 & $1.3-3.6$ & Endwall & In-line & 0.537 \\
\hline \multirow[t]{2}{*}{$\begin{array}{l}\text { Metzger et } \\
\text { al. [1982a] }\end{array}$} & 2.5 & 1.5 & 1 & $\begin{array}{l}\text { Array- } \\
\text { average }\end{array}$ & Staggered & 0.707 \\
\hline & 2.5 & 2.5 & 1 & $\begin{array}{l}\text { Array- } \\
\text { average }\end{array}$ & Staggered & 0.728 \\
\hline $\begin{array}{l}\text { Uzol and } \\
\text { Camci } \\
\text { [2005] }\end{array}$ & 2 & 2 & 1.5 & Endwall & Staggered & 0.7 \\
\hline \multirow{6}{*}{$\begin{array}{l}\text { Yeh and } \\
\text { Chyu [1998] }\end{array}$} & 2.8 & 2.6 & 1 & Pin & Staggered & 0.5554 \\
\hline & 2.8 & 2.6 & 2.8 & Pin & Staggered & 0.5799 \\
\hline & 2.8 & 2.6 & 1 & Endwall & Staggered & 0.6341 \\
\hline & 2.8 & 2.6 & 2.8 & Endwall & Staggered & 0.7107 \\
\hline & 2.8 & 2.6 & 1 & $\begin{array}{l}\text { Array- } \\
\text { average }\end{array}$ & Staggered & 0.6247 \\
\hline & 2.8 & 2.6 & 2.8 & $\begin{array}{l}\text { Array- } \\
\text { average }\end{array}$ & Staggered & 0.6747 \\
\hline
\end{tabular}


Table 1.2. First Row Nusselt Number Correlations

\begin{tabular}{|l|c|c|}
\hline \multirow{2}{*}{ Studies } & \multicolumn{2}{c|}{ First Row Correlations, $\overline{\mathbf{N u}}_{\mathbf{d}}=\mathbf{a R e}_{\mathbf{d}}{ }^{\mathbf{b}}$} \\
\cline { 2 - 3 } & $\mathbf{a}$ & $\mathbf{b}$ \\
\hline Metzger et al. [1982a], 1,000 $\leq \operatorname{Re}_{\mathrm{d}} \leq 10,000$ & 0.140 & 0.611 \\
\hline Metzger et al. [1982a], 10,000 $\leq \operatorname{Re}_{\mathrm{d}} \leq 100,000$ & 0.022 & 0.831 \\
\hline Chyu [1990] & 0.330 & 0.550 \\
\hline Hwang et al. [2001] & 0.125 & 0.651 \\
\hline
\end{tabular}

Table 1.3. Multiple Row Geometries Tested for the Present Study

\begin{tabular}{|c|c|c|}
\hline $\mathbf{S 1 / d}$ & $\mathbf{S 2} / \mathbf{d}$ & H/d \\
\hline 2 & 1.73 & 1 \\
\hline 2 & 3.46 & 1 \\
\hline 2 & 1.73 & 0.5 \\
\hline 4 & 1.73 & 1 \\
\hline 4 & 3.46 & 1 \\
\hline
\end{tabular}

Table 1.4. Correlations from Present Study

\begin{tabular}{|c|c|c|c|c|c|c|c|c|}
\hline \multicolumn{10}{|c|}{$\overline{\mathbf{N u}}_{\mathbf{d}}=\mathbf{a R e}_{\mathbf{d}} \mathbf{b}$} \\
\hline \multicolumn{2}{|c|}{ Geometry } & \multicolumn{2}{c|}{ Pin } & \multicolumn{2}{c|}{ Endwall } & \multicolumn{2}{c|}{$\begin{array}{c}\text { Array- } \\
\text { average }\end{array}$} \\
\hline S1/d & S2/d & H/d & a & b & a & b & a & b \\
\hline 2 & 1.73 & 1 & 0.387 & 0.576 & 0.111 & 0.665 & 0.195 & 0.623 \\
\hline 2 & 3.46 & 1 & 0.430 & 0.564 & 0.252 & 0.573 & 0.288 & 0.570 \\
\hline 4 & 1.73 & 1 & 0.430 & 0.564 & 0.110 & 0.676 & 0.156 & 0.647 \\
\hline 4 & 3.46 & 1 & 0.495 & 0.552 & 0.119 & 0.649 & 0.149 & 0.632 \\
\hline 2 & 1.73 & 0.5 & 0.430 & 0.564 & 0.086 & 0.700 & 0.134 & 0.662 \\
\hline
\end{tabular}




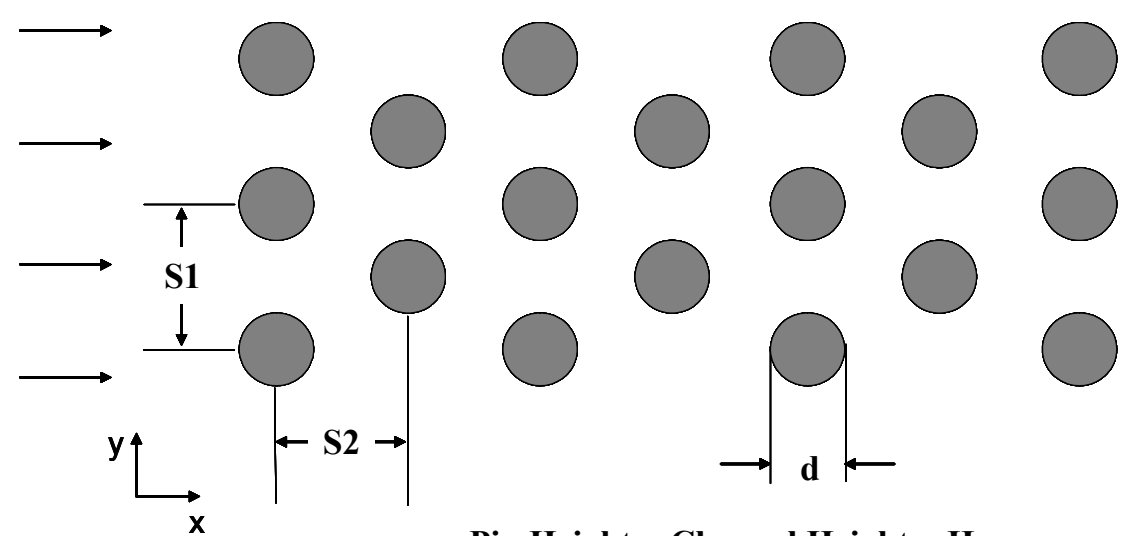

Pin Height $=$ Channel Height $=\mathbf{H}$

Figure 1.1. Schematic showing the spacing definitions used in the tested pin fin arrays.

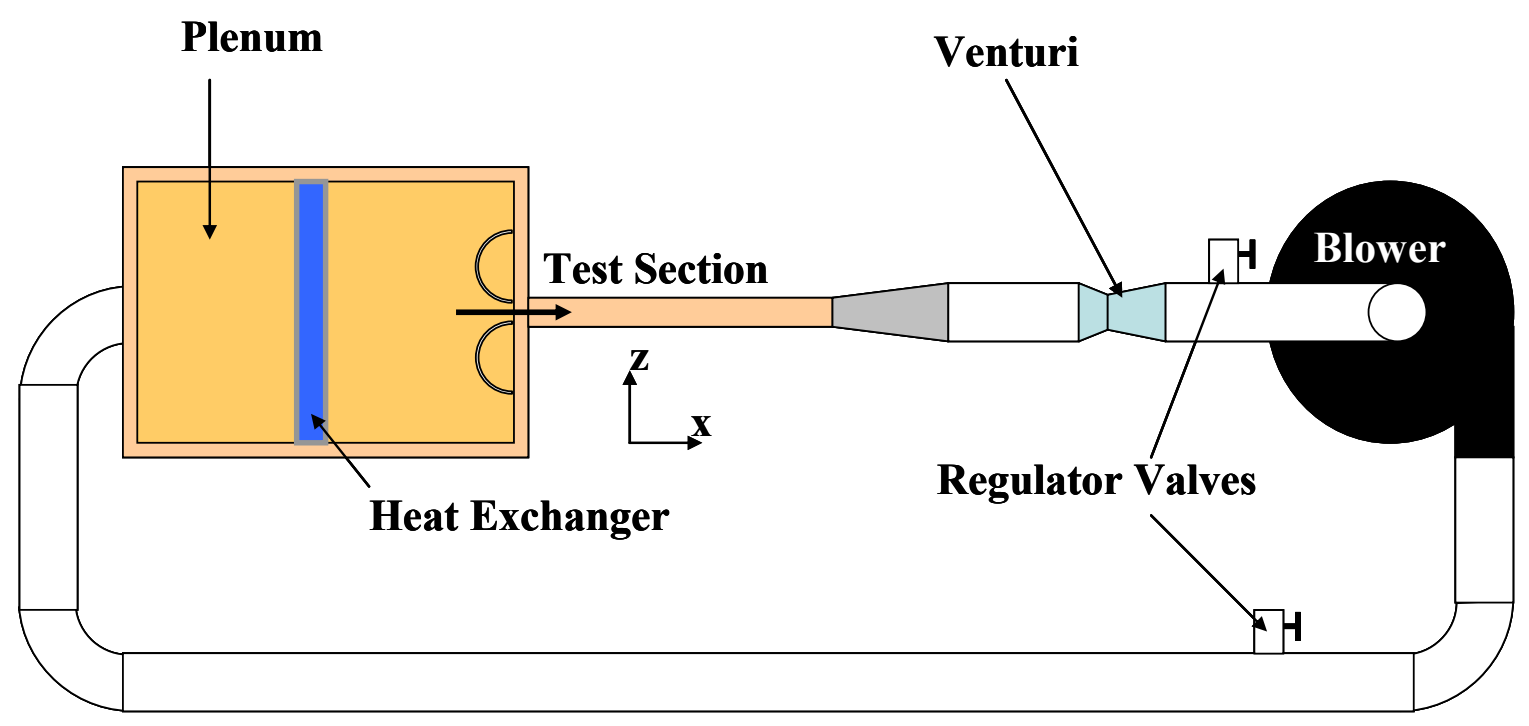

Figure 1.2. Schematic of the closed loop test facility used for pin fin array testing. 


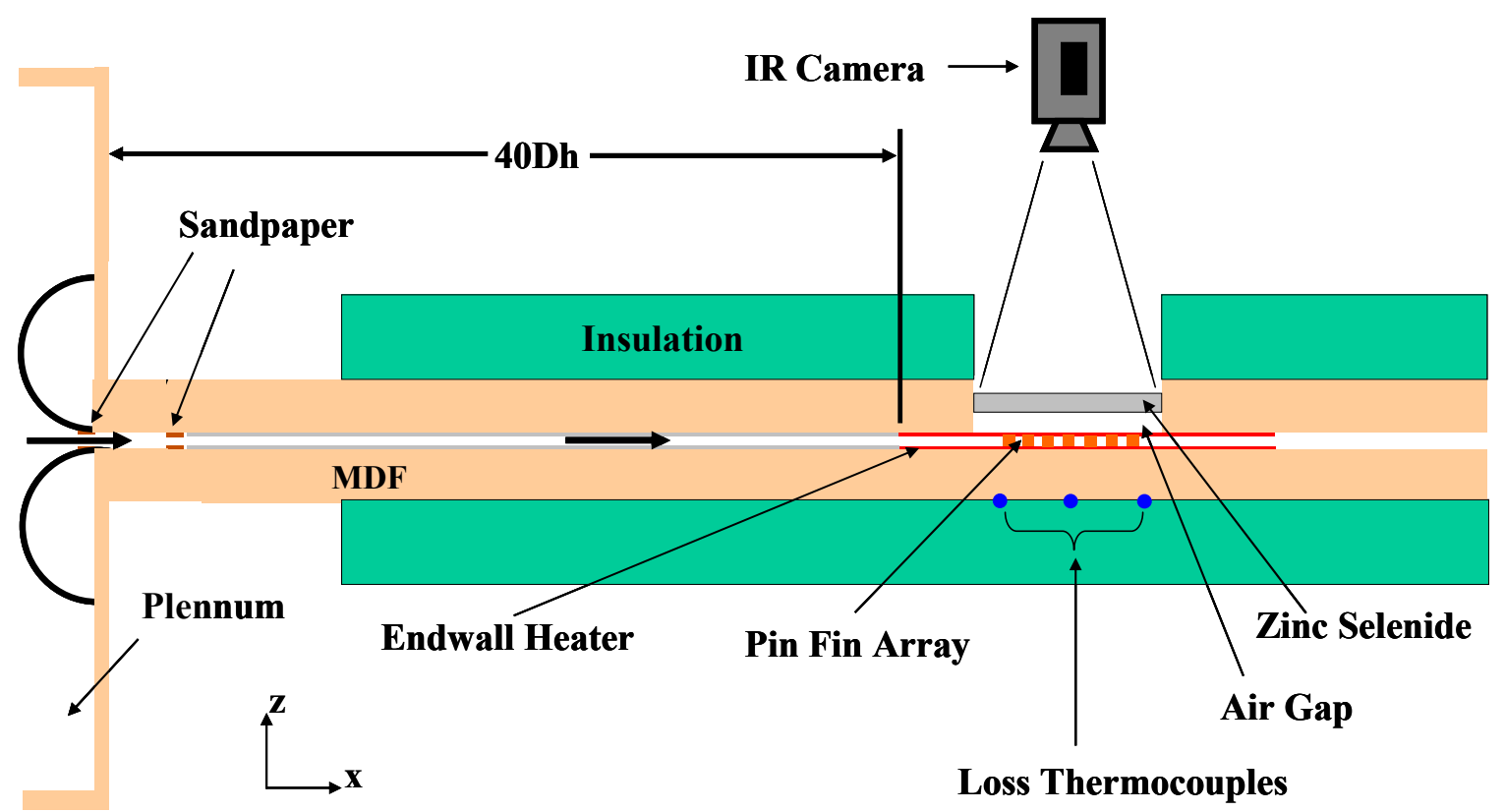

Figure 1.3. Schematic of the test section used for pin fin array testing.

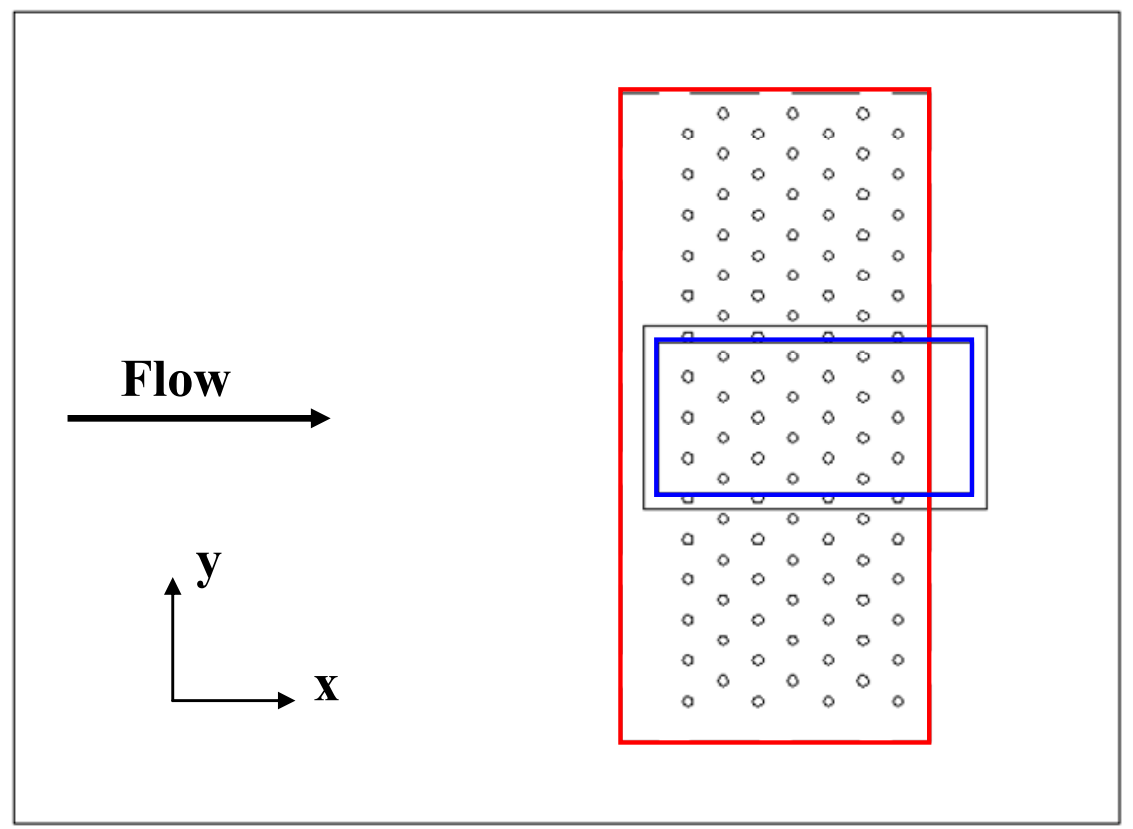

Figure 1.4. Schematic of the $S 1 / d=4, S 2 / d=3.46, H / d=1$ seven row array as placed in the test section. 


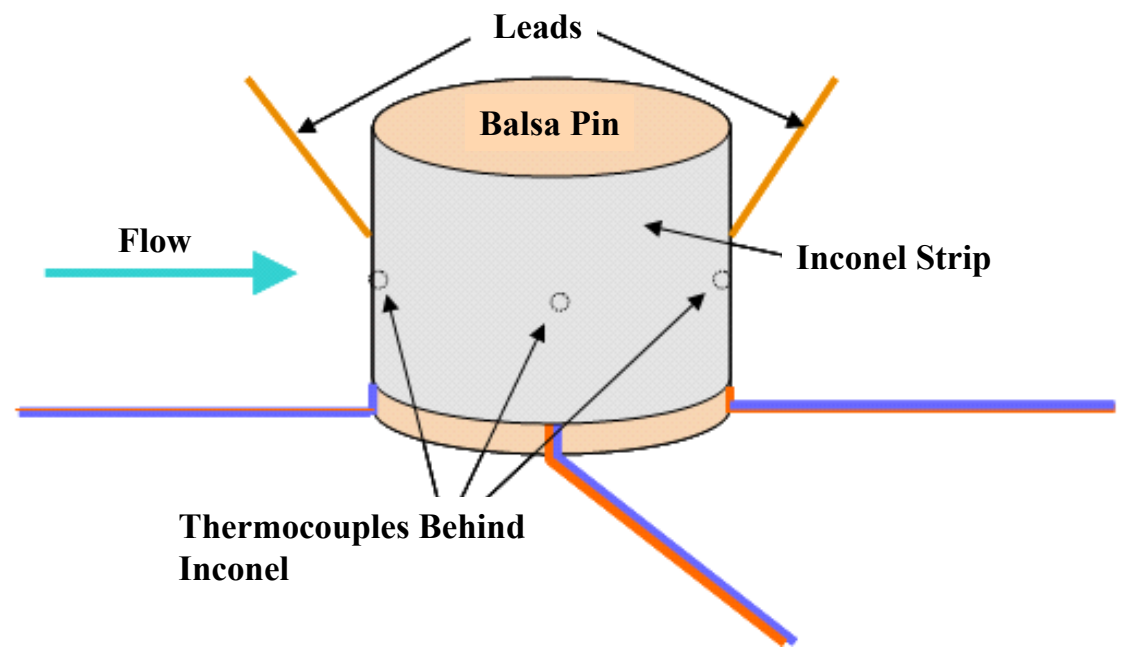

Figure 1.5. Schematic of the instrumented pin fin used for pin heat transfer tests.

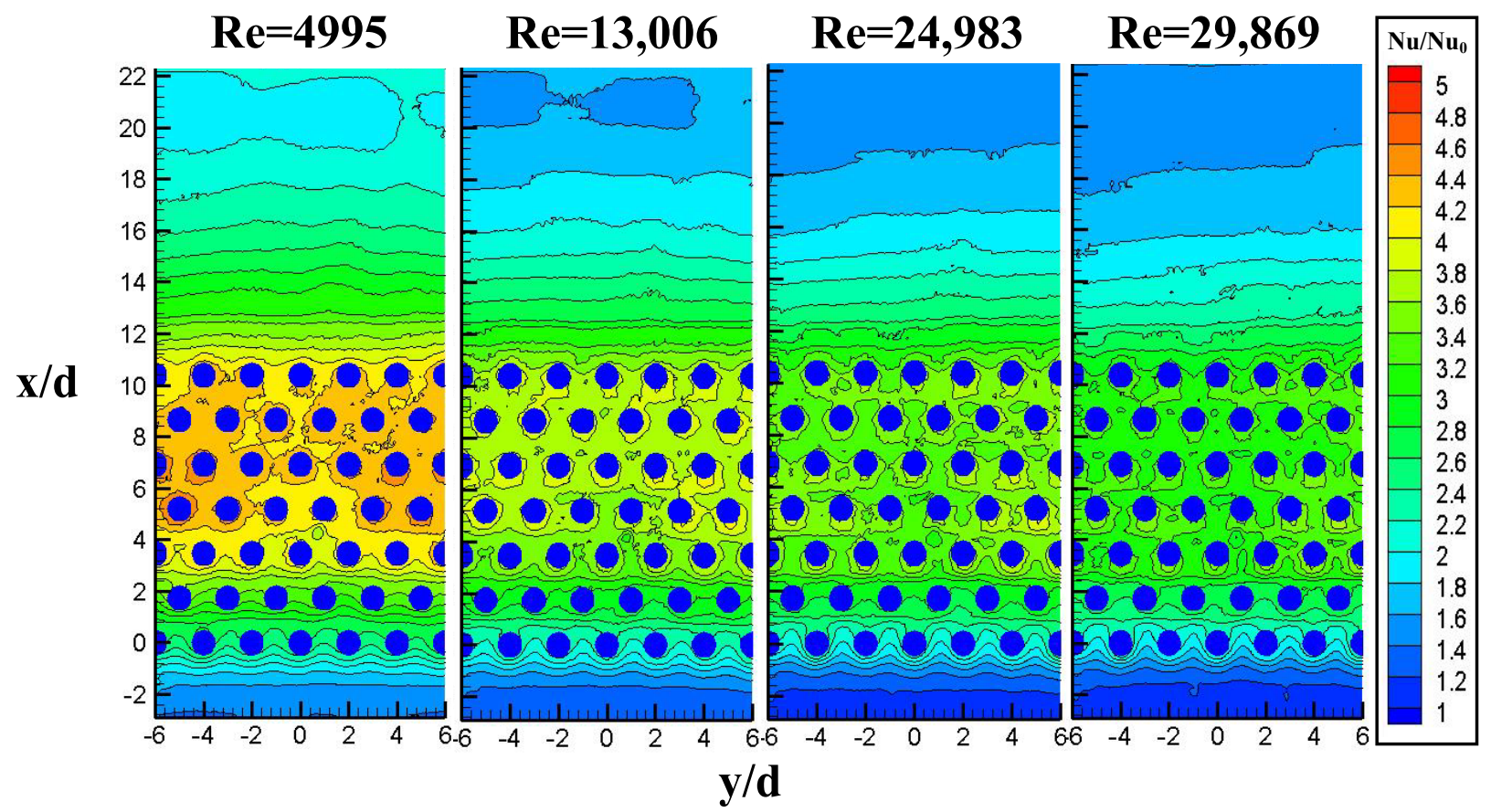

Figure 1.6. Endwall contour plots of Nusselt number augmentation for the $S 1 / d=2$, $\mathrm{S} 2 / \mathrm{d}=1.73, \mathrm{H} / \mathrm{d}=1$ geometry. 


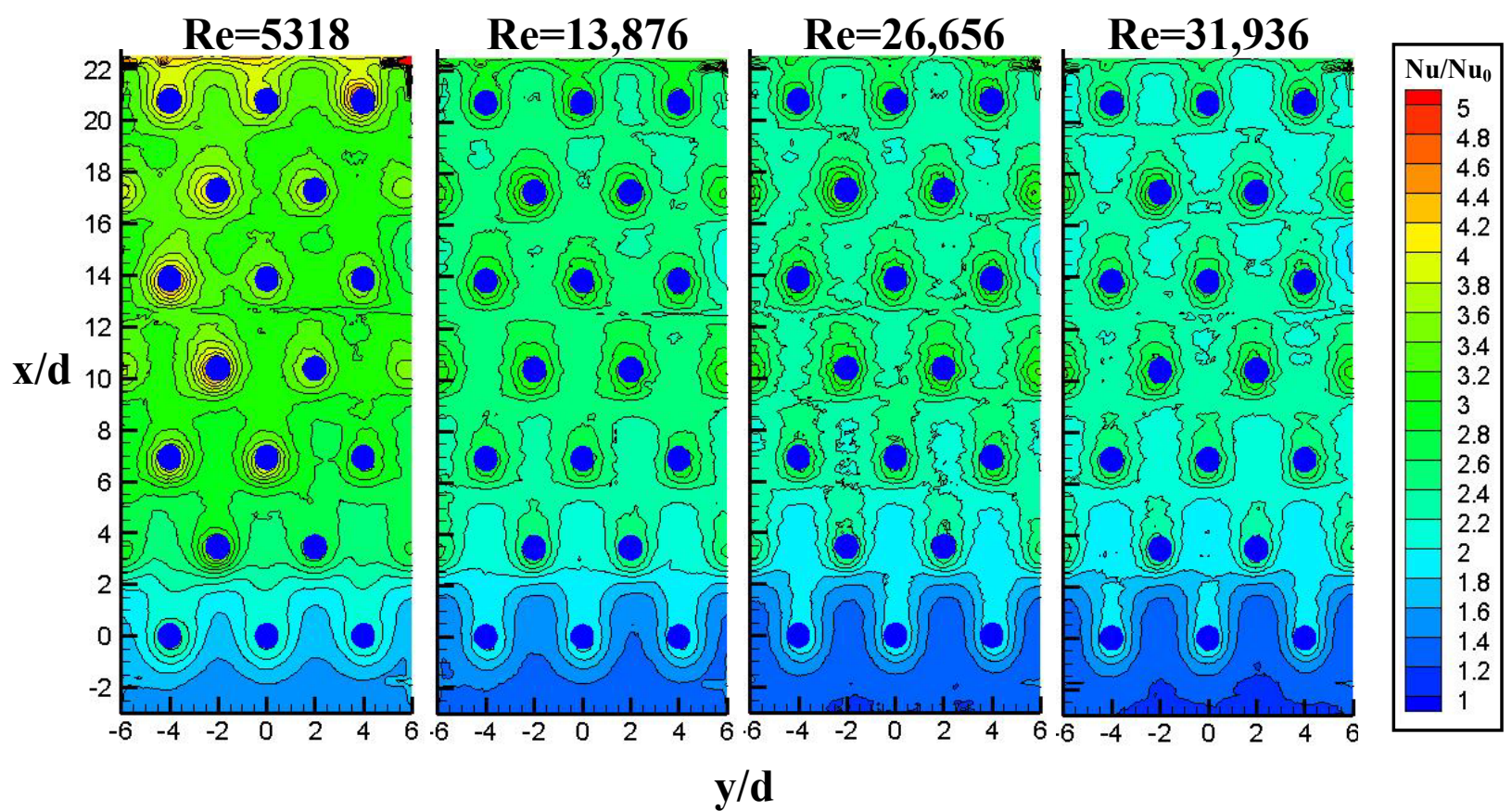

Figure 1.7. Endwall contour plots of Nusselt number augmentation for the $S 1 / d=4$, $\mathrm{S} 2 / \mathrm{d}=3.46, \mathrm{H} / \mathrm{d}=1$ geometry.

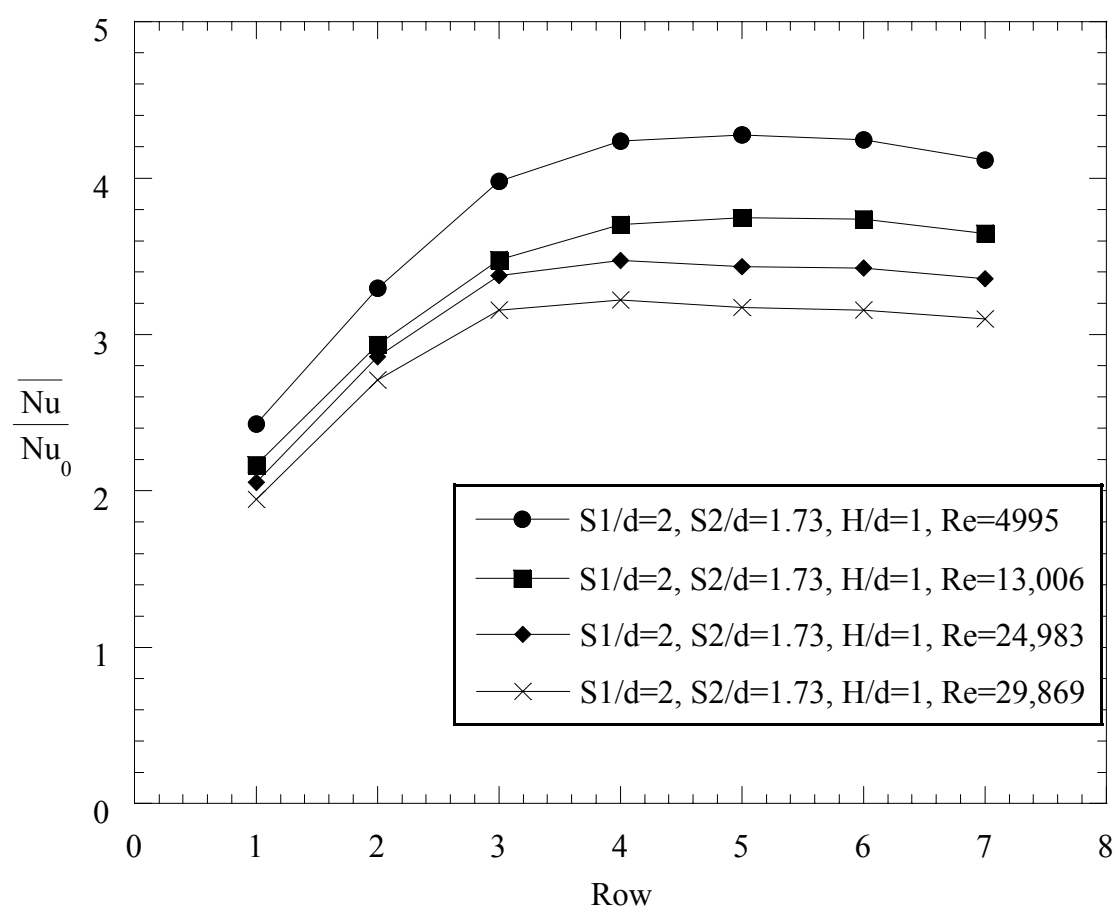

Figure 1.8. Row-resolved endwall augmentation values for the $S 1 / d=2, S 2 / d=1.73$, $H / d=1$ array. 


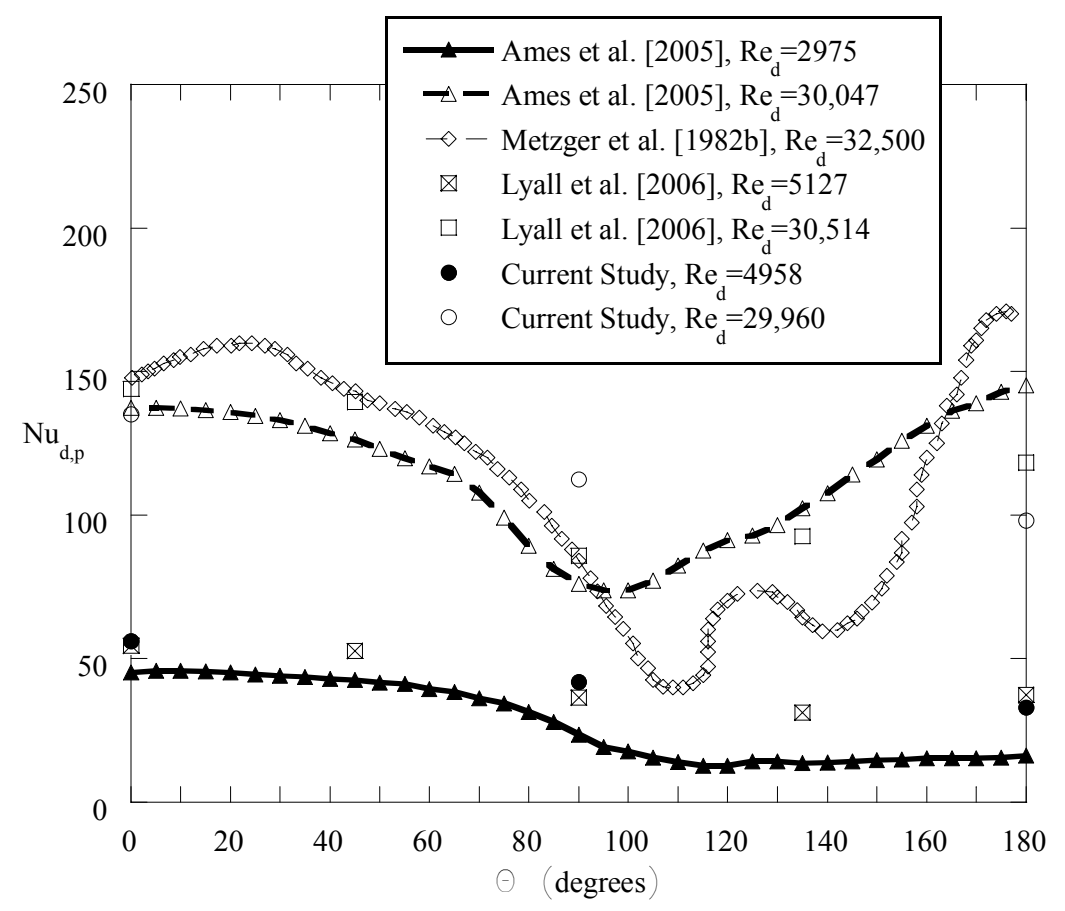

Figure 1.9. Midline pin Nusselt numbers found in the literature for a pin placed in the first row of a multiple row array.

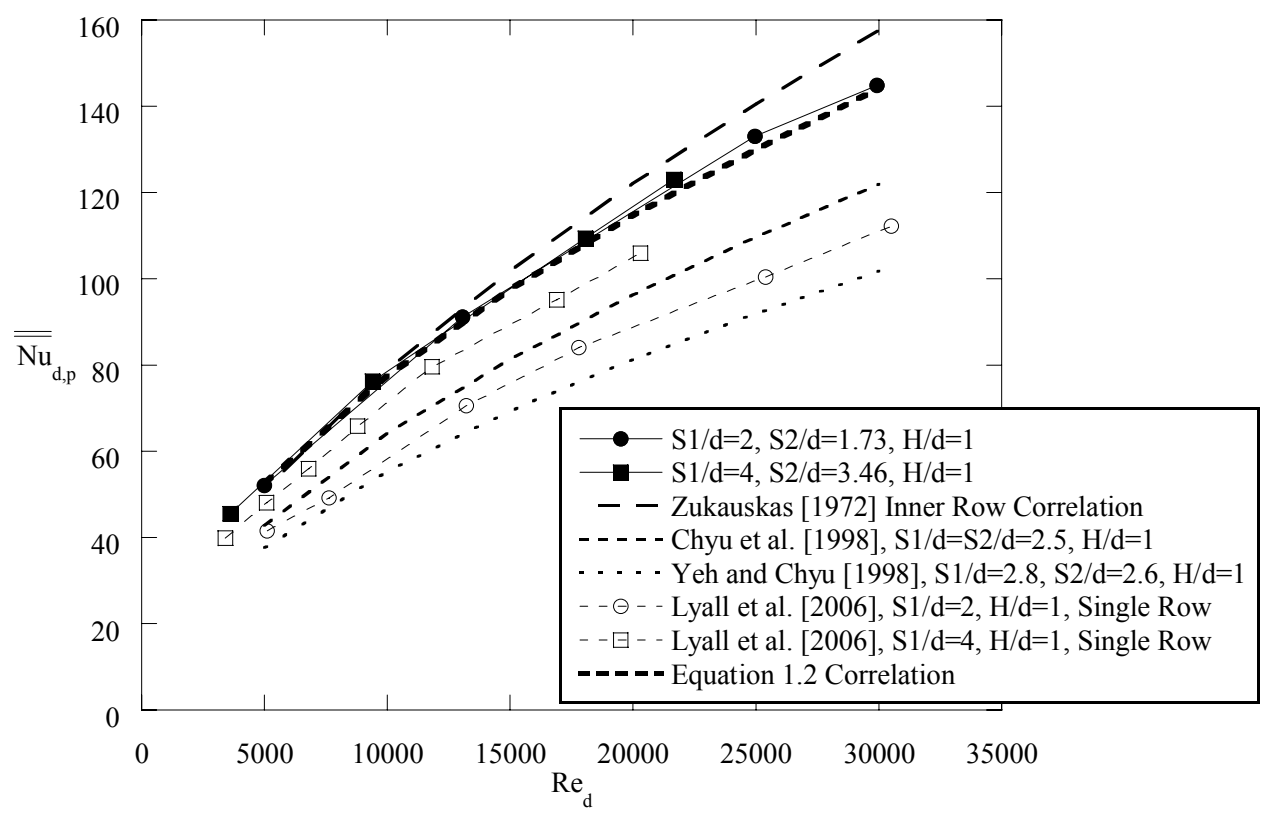

Figure 1.10. Average pin Nusselt numbers for the $S 1 / d=2, S 2 / d=1.73, H / d=1$ and $\mathrm{S} 1 / \mathrm{d}=4, \mathrm{~S} 2 / \mathrm{d}=3.46, \mathrm{H} / \mathrm{d}=1$ geometries compared with results from the literature. 


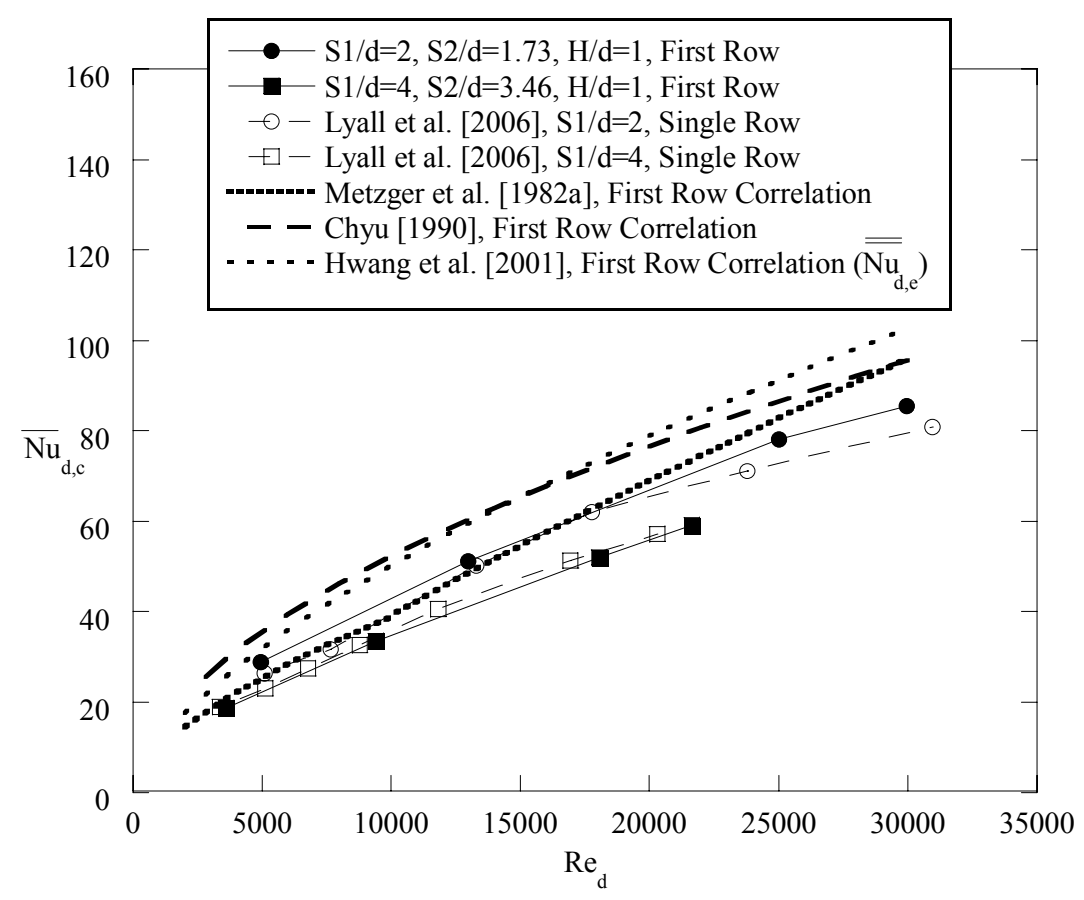

Figure 1.11. First row combined pin and endwall Nusselt number results plotted with results from the literature.

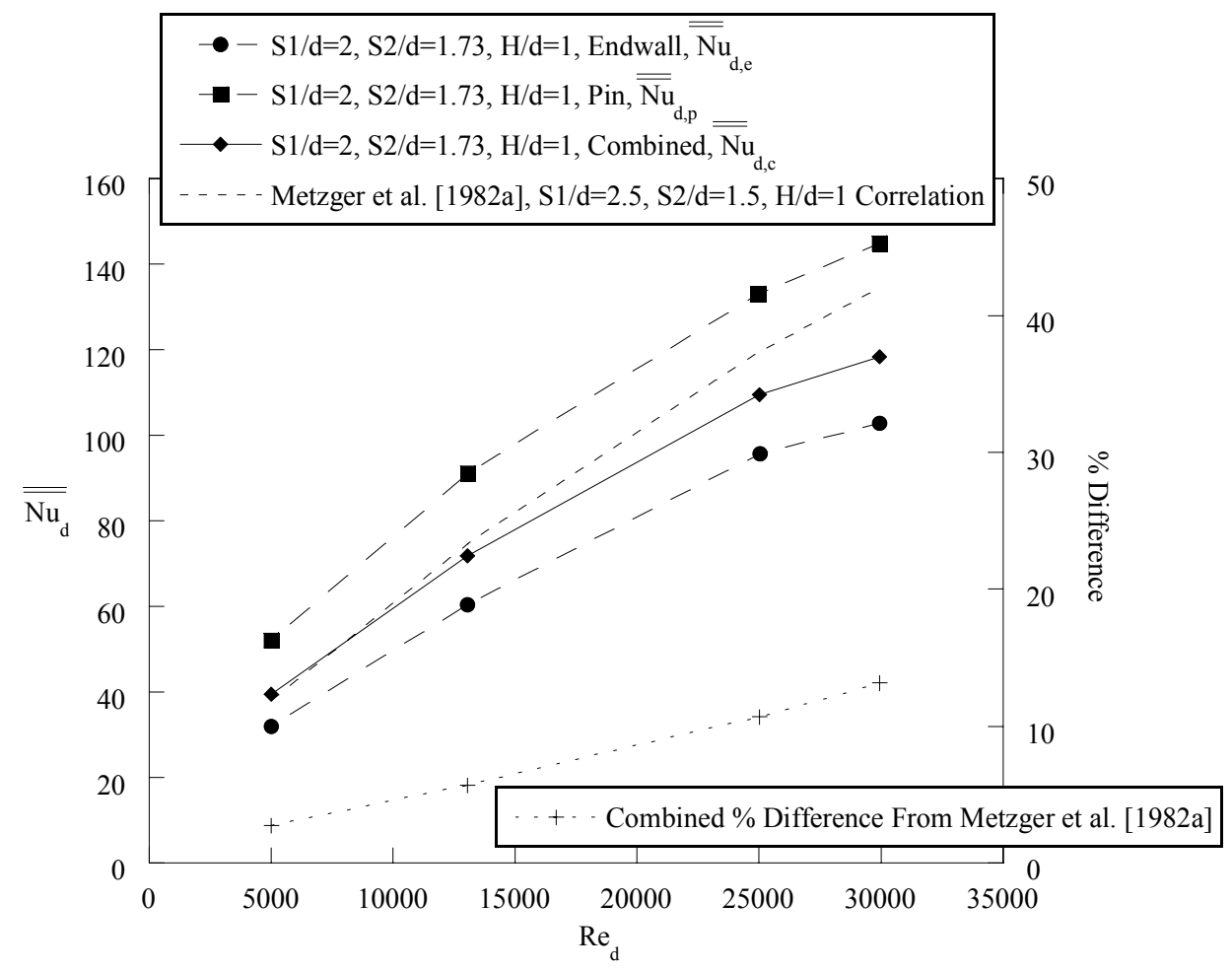

Figure 1.12. Pin, endwall, and array-average Nusselt number versus pin Reynolds number for an $\mathrm{S} 1 / \mathrm{d}=2, \mathrm{~S} 2 / \mathrm{d}=1.73, \mathrm{H} / \mathrm{d}=1$ array compared with Metzger et al. [1982a]. 


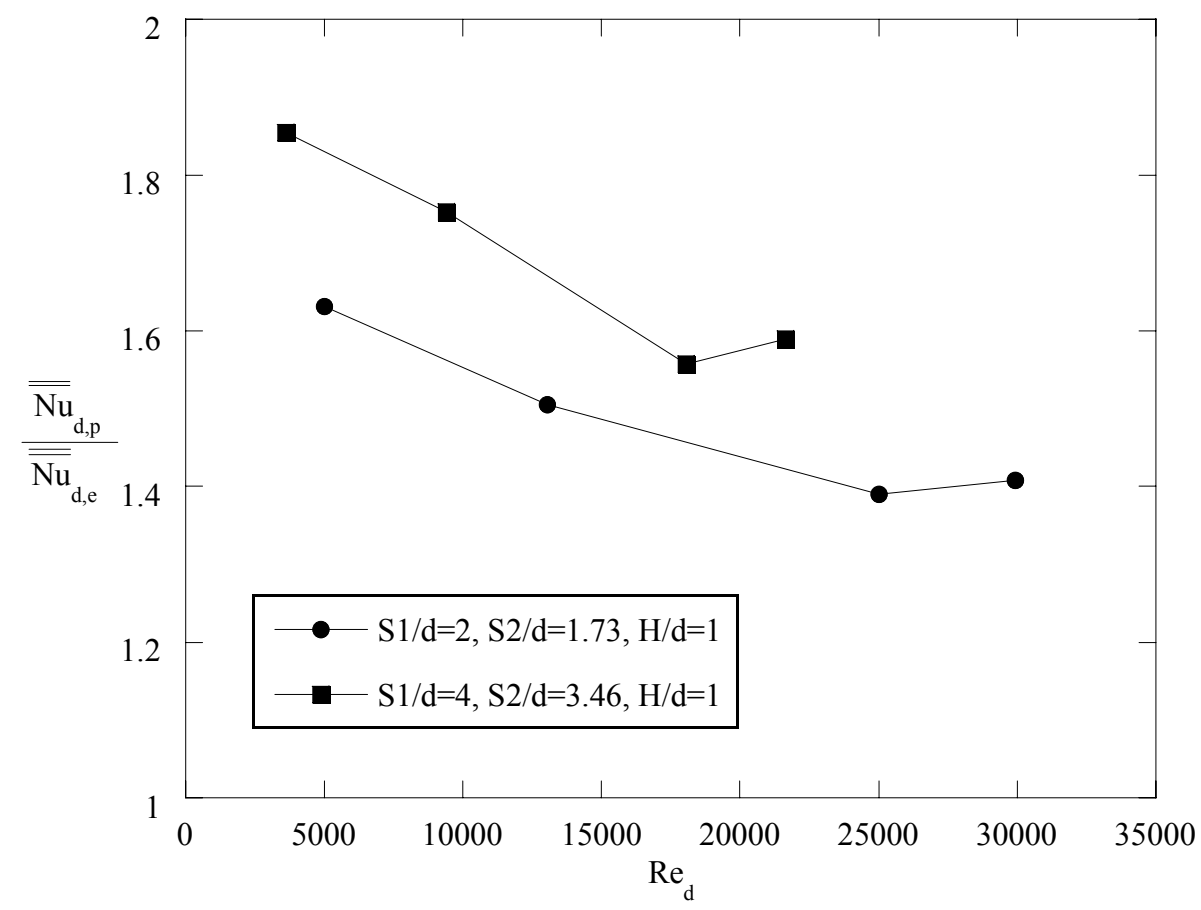

Figure 1.13. Pin-to-endwall Nusselt number as a function of pin Reynolds number.

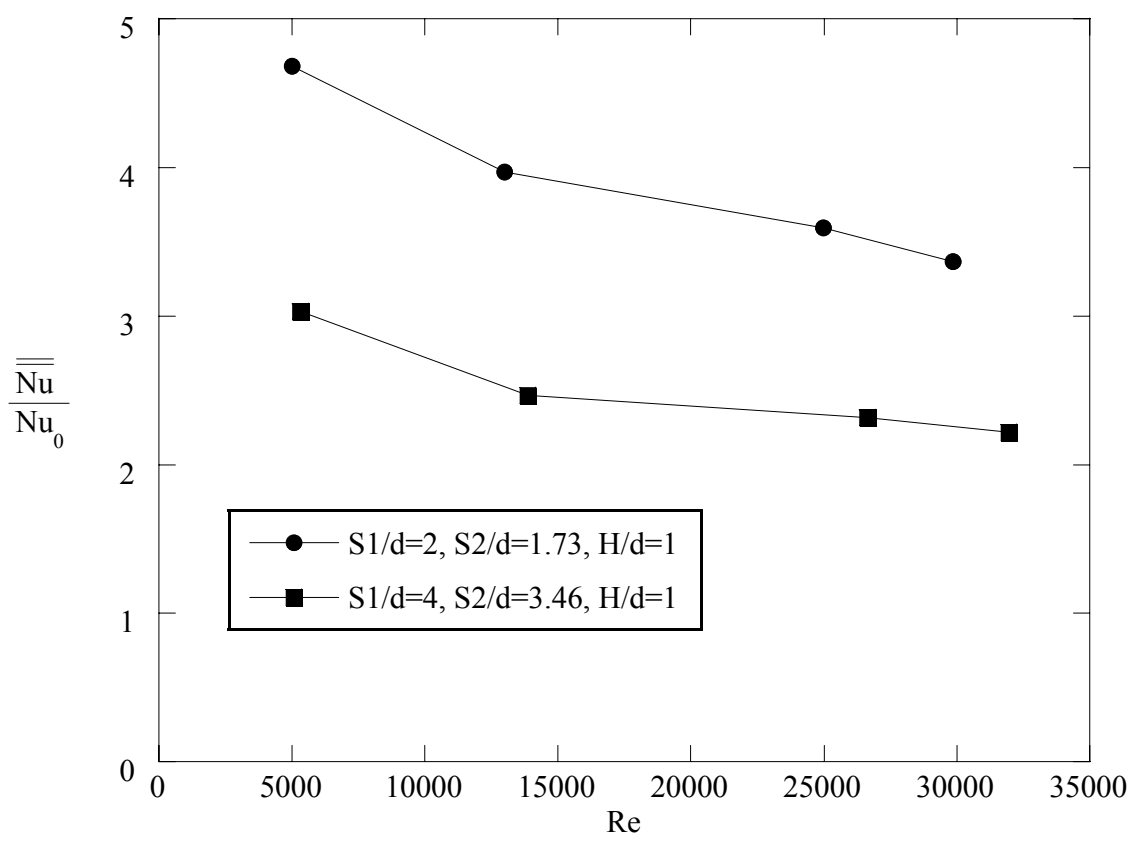

Figure 1.14. Array-average Nusselt number augmentation versus Reynolds number for the $\mathrm{S} 1 / \mathrm{d}=2, \mathrm{~S} 2 / \mathrm{d}=1.73, \mathrm{H} / \mathrm{d}=1$ and $\mathrm{S} 1 / \mathrm{d}=4, \mathrm{~S} 2 / \mathrm{d}=3.46, \mathrm{H} / \mathrm{d}=1$ geometries. 


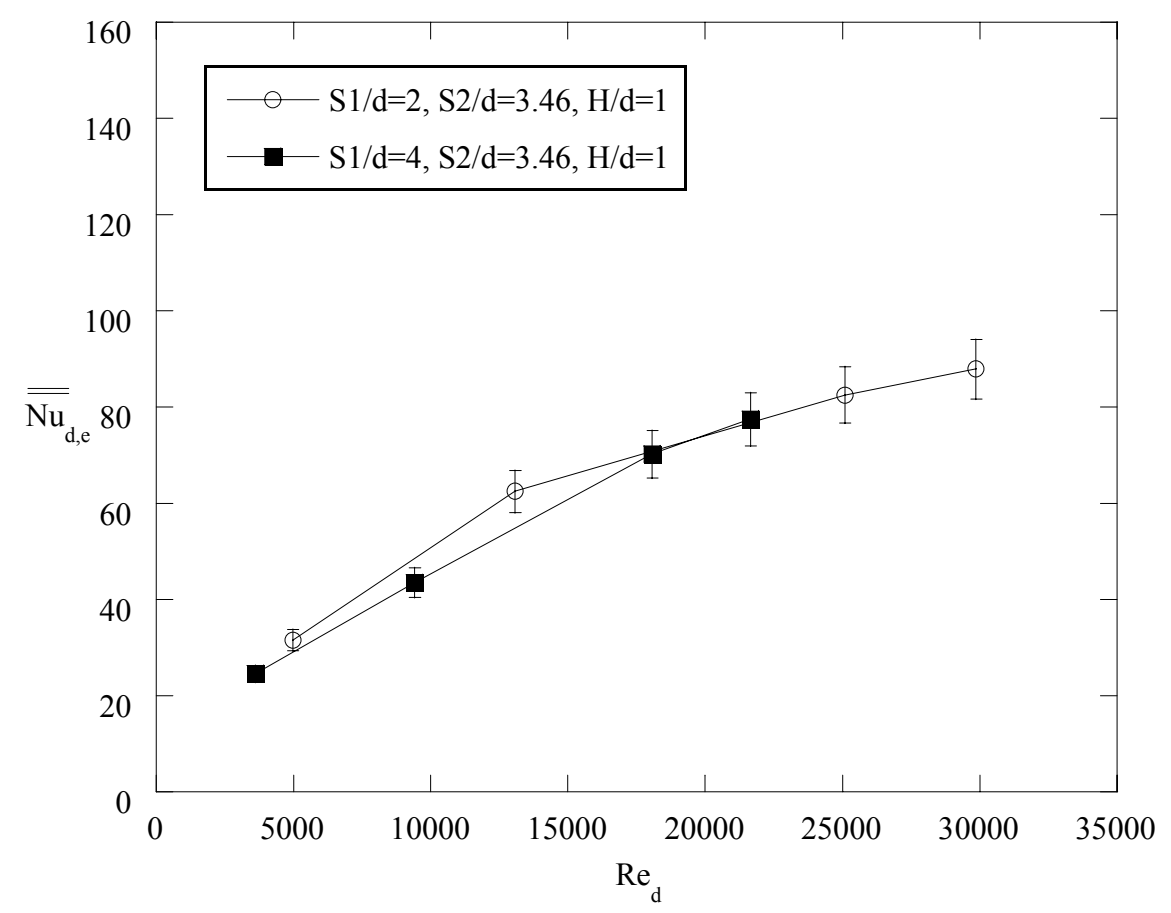

Figure 1.15. Average endwall Nusselt numbers for $\mathrm{S} 1 / \mathrm{d}=2, \mathrm{~S} 2 / \mathrm{d}=3.46, \mathrm{H} / \mathrm{d}=1$ and $\mathrm{S} 1 / \mathrm{d}=4, \mathrm{~S} 2 / \mathrm{d}=3.46, \mathrm{H} / \mathrm{d}=1$ geometries.

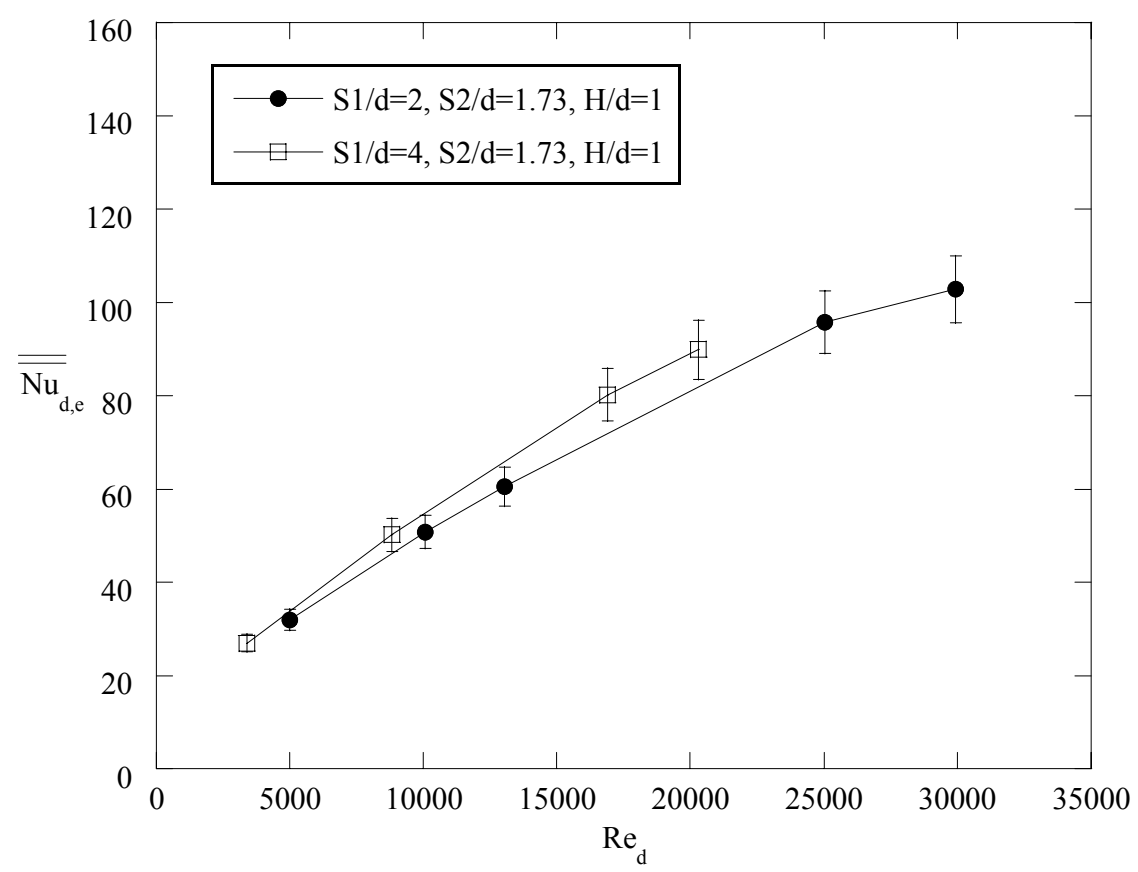

Figure 1.16. Average endwall Nusselt numbers for $\mathrm{S} 1 / \mathrm{d}=2, \mathrm{~S} 2 / \mathrm{d}=1.73, \mathrm{H} / \mathrm{d}=1$ and $\mathrm{S} 1 / \mathrm{d}=4, \mathrm{~S} 2 / \mathrm{d}=1.73, \mathrm{H} / \mathrm{d}=1$ geometries. 


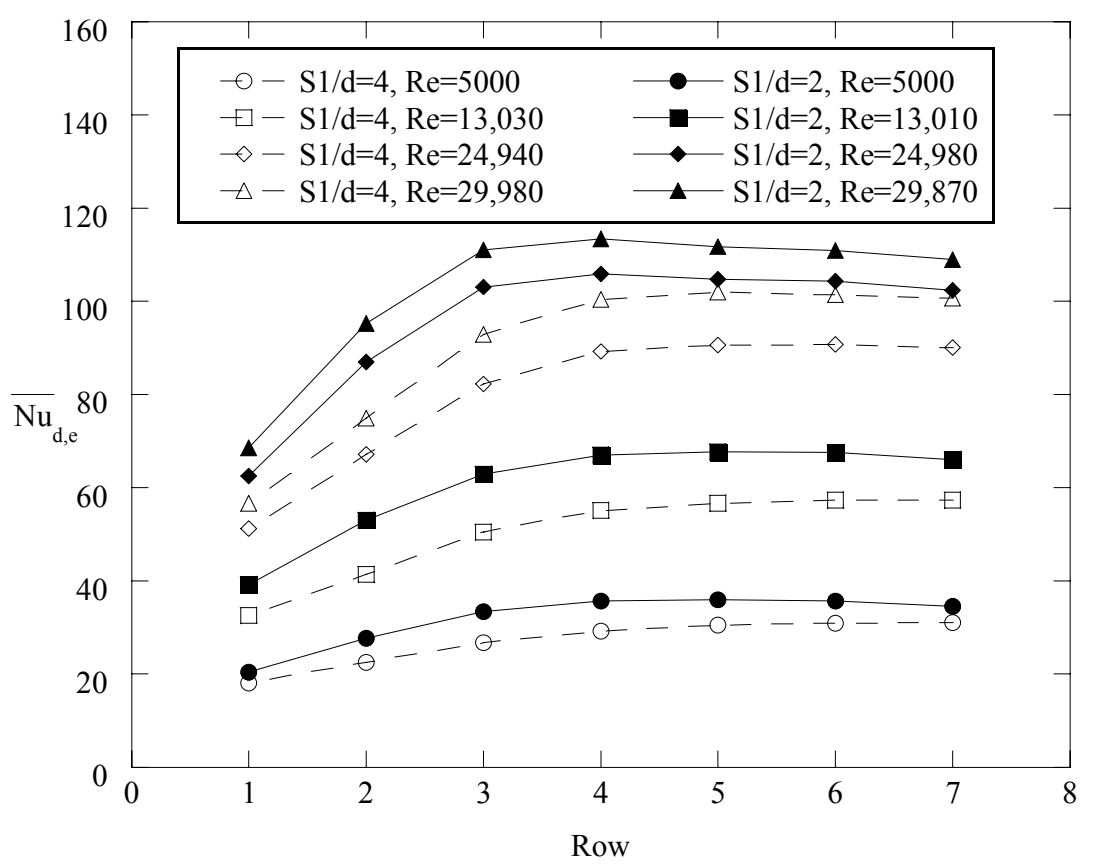

Figure 1.17. Endwall row average Nusselt numbers for the $S 1 / d=2, S 2 / d=1.73, H / d=1$ and $\mathrm{S} 1 / \mathrm{d}=4, \mathrm{~S} 2 / \mathrm{d}=1.73, \mathrm{H} / \mathrm{d}=1$ geometries.

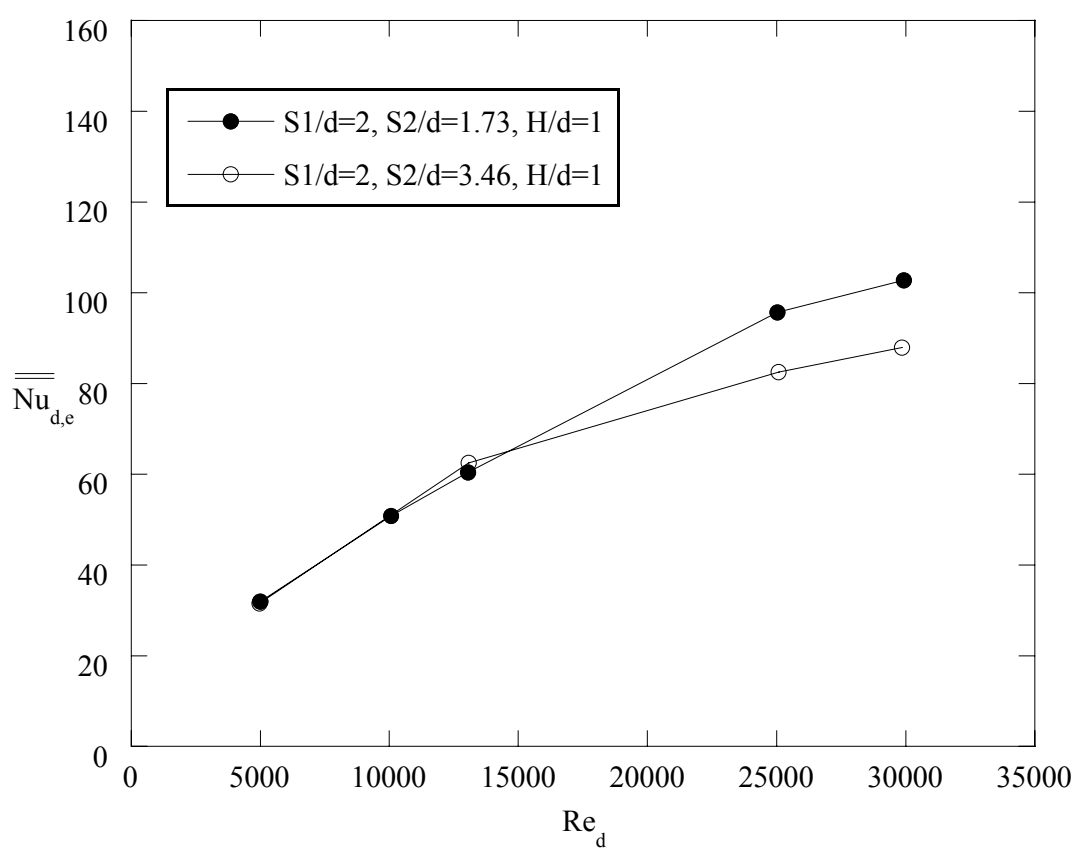

Figure 1.18. Average endwall Nusselt numbers for $S 1 / d=2, S 2 / d=1.73, H / d=1$ and $\mathrm{S} 1 / \mathrm{d}=2, \mathrm{~S} 2 / \mathrm{d}=3.46, \mathrm{H} / \mathrm{d}=1$ geometries. 


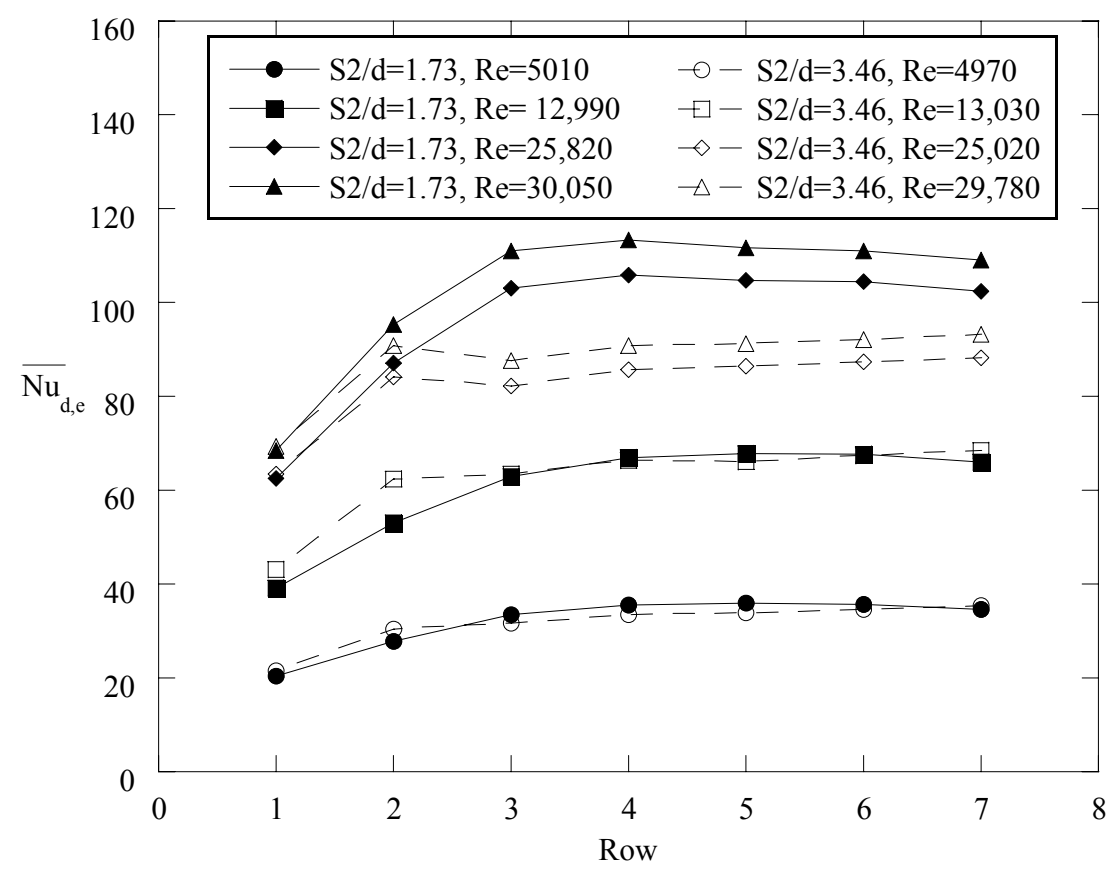

Figure 1.19. Row-resolved endwall Nusselt numbers for the $\mathrm{S} 1 / \mathrm{d}=2, \mathrm{~S} 2 / \mathrm{d}=1.73, \mathrm{H} / \mathrm{d}=1$ and $\mathrm{S} 1 / \mathrm{d}=2, \mathrm{~S} 2 / \mathrm{d}=3.46, \mathrm{H} / \mathrm{d}=1$ geometries.

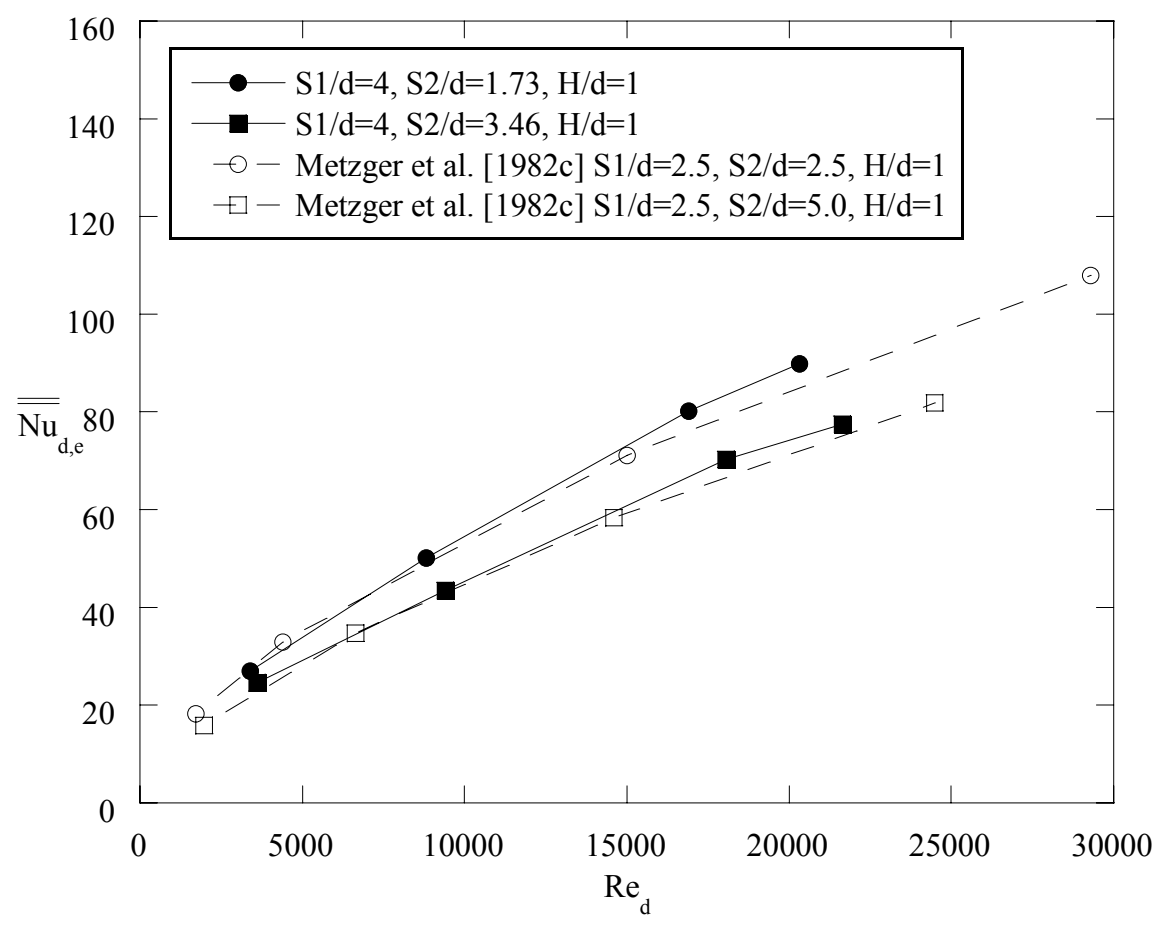

Figure 1.20. Average endwall Nusselt number for $\mathrm{S} 1 / \mathrm{d}=4, \mathrm{~S} 2 / \mathrm{d}=1.73, \mathrm{H} / \mathrm{d}=1$ and $\mathrm{S} 1 / \mathrm{d}=4, \mathrm{~S} 2 / \mathrm{d}=3.46, \mathrm{H} / \mathrm{d}=1$ geometries. 


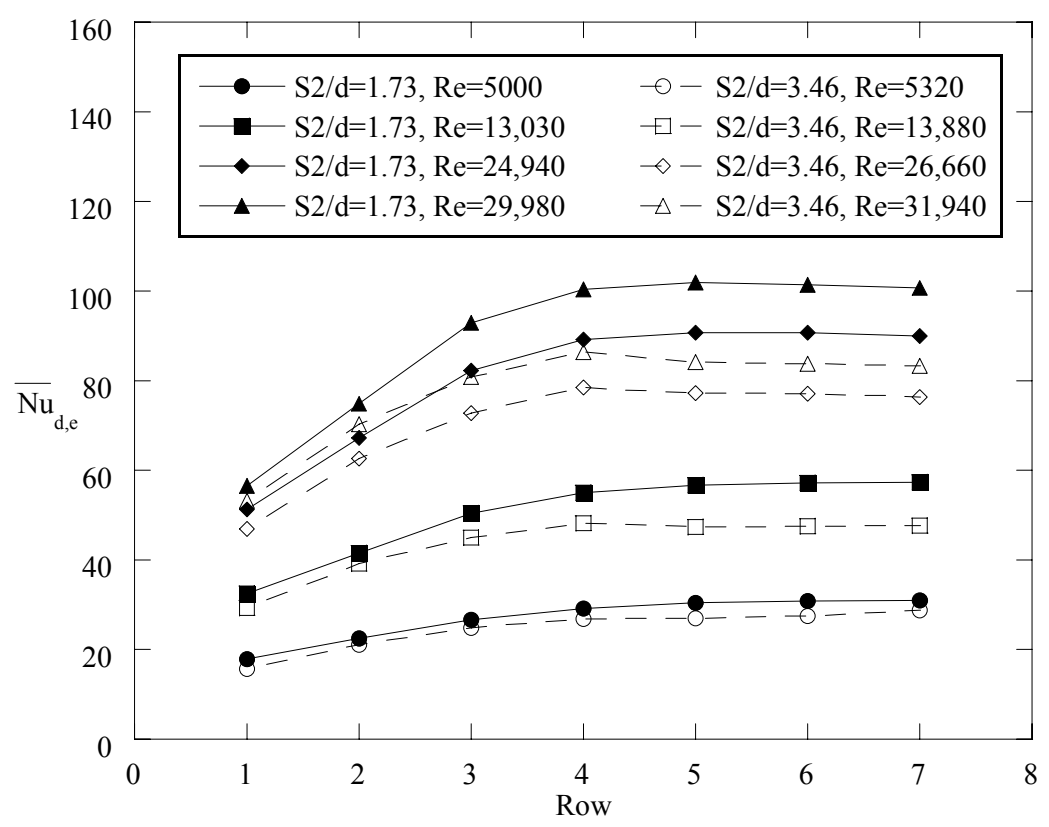

Figure 1.21. Row-resolved endwall Nusselt numbers for the $\mathrm{S} 1 / \mathrm{d}=4, \mathrm{~S} 2 / \mathrm{d}=1.73, \mathrm{H} / \mathrm{d}=1$ and $\mathrm{S} 1 / \mathrm{d}=4, \mathrm{~S} 2 / \mathrm{d}=3.46, \mathrm{H} / \mathrm{d}=1$ geometries.

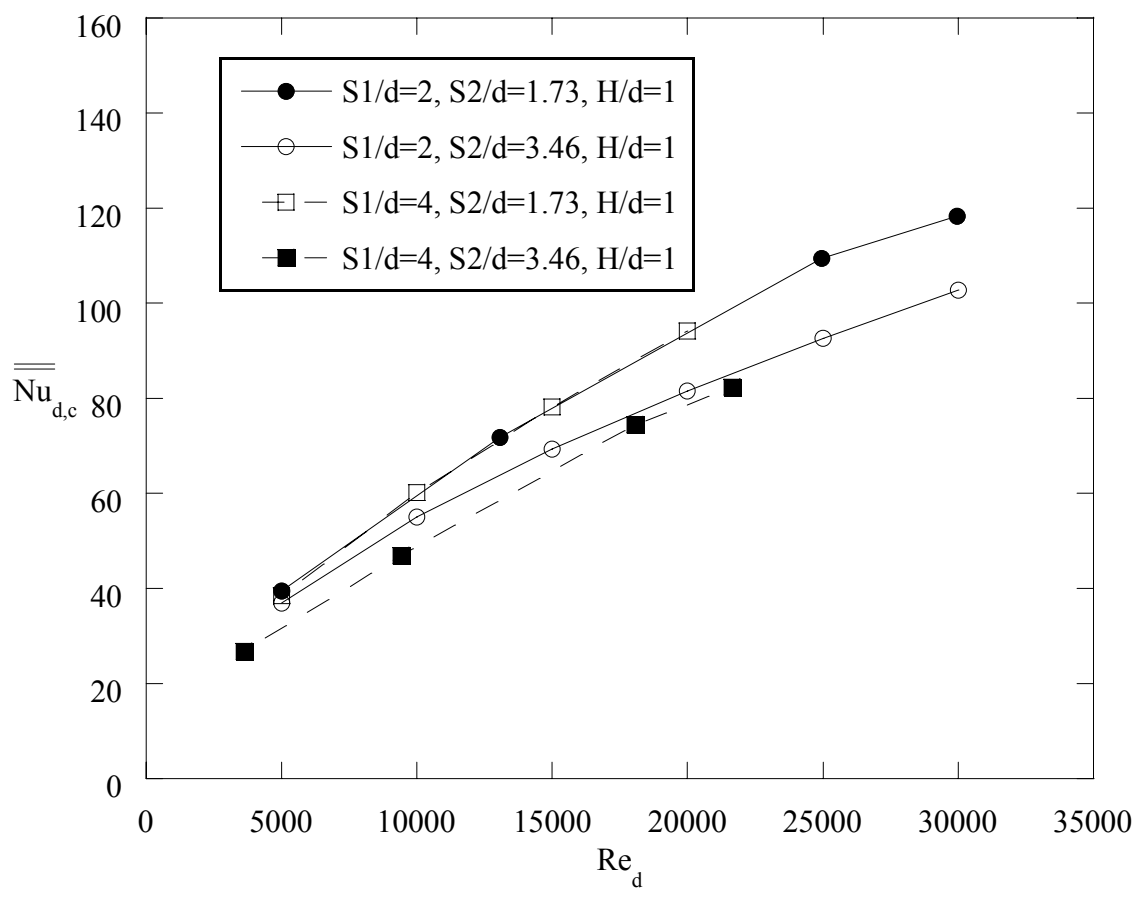

Figure 1.22. Array-average Nusselt numbers for all geometries with $\mathrm{H} / \mathrm{d}=1$. 


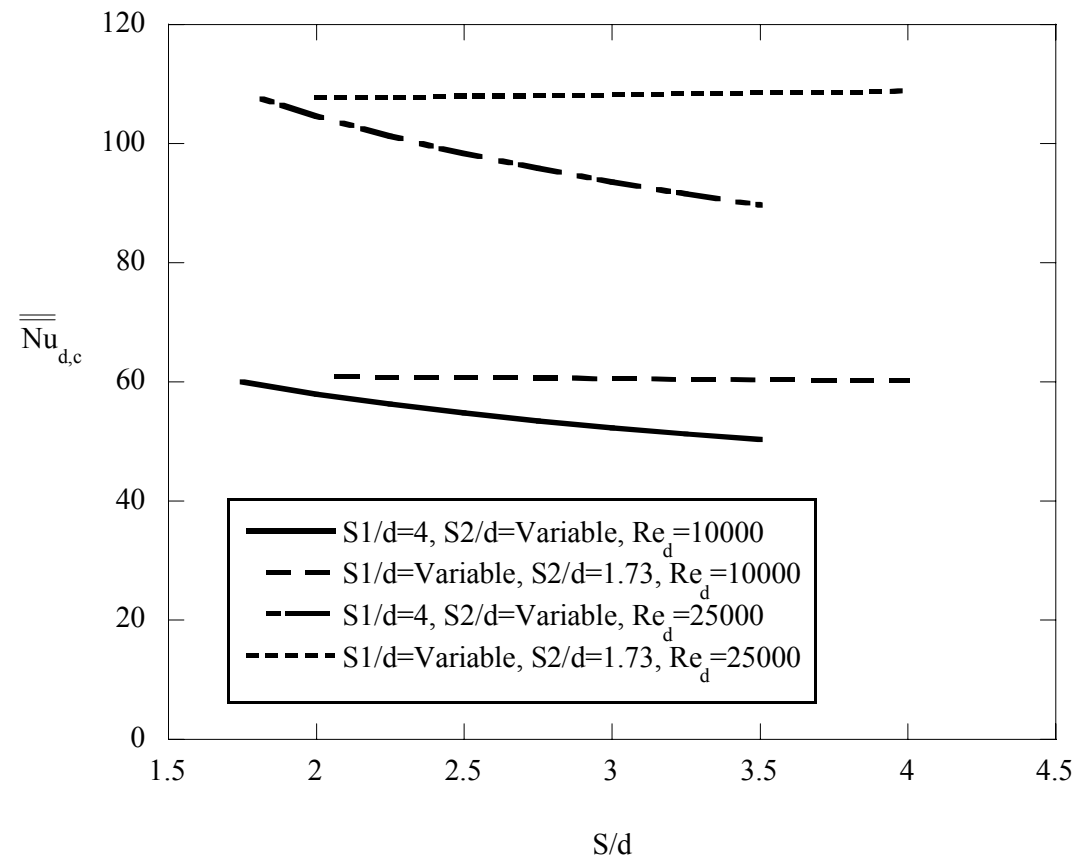

Figure 1.23. Array-average Nusselt numbers predicted by Equation 1.3 plotted with respect to $\mathrm{S} 1 / \mathrm{d}$ or $\mathrm{S} 2 / \mathrm{d}$.

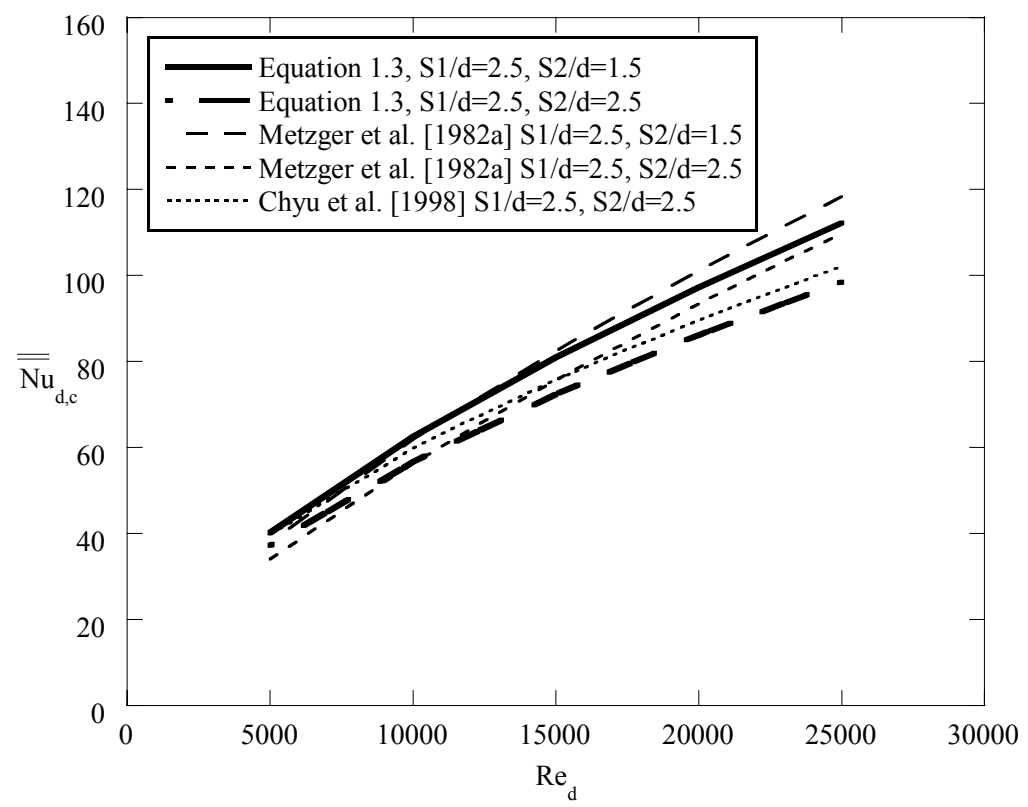

Figure 1.24. Array-average Nusselt number correlation (Equation 1.3) plotted with relevant correlations from the literature all having $\mathrm{H} / \mathrm{d}=1$. 

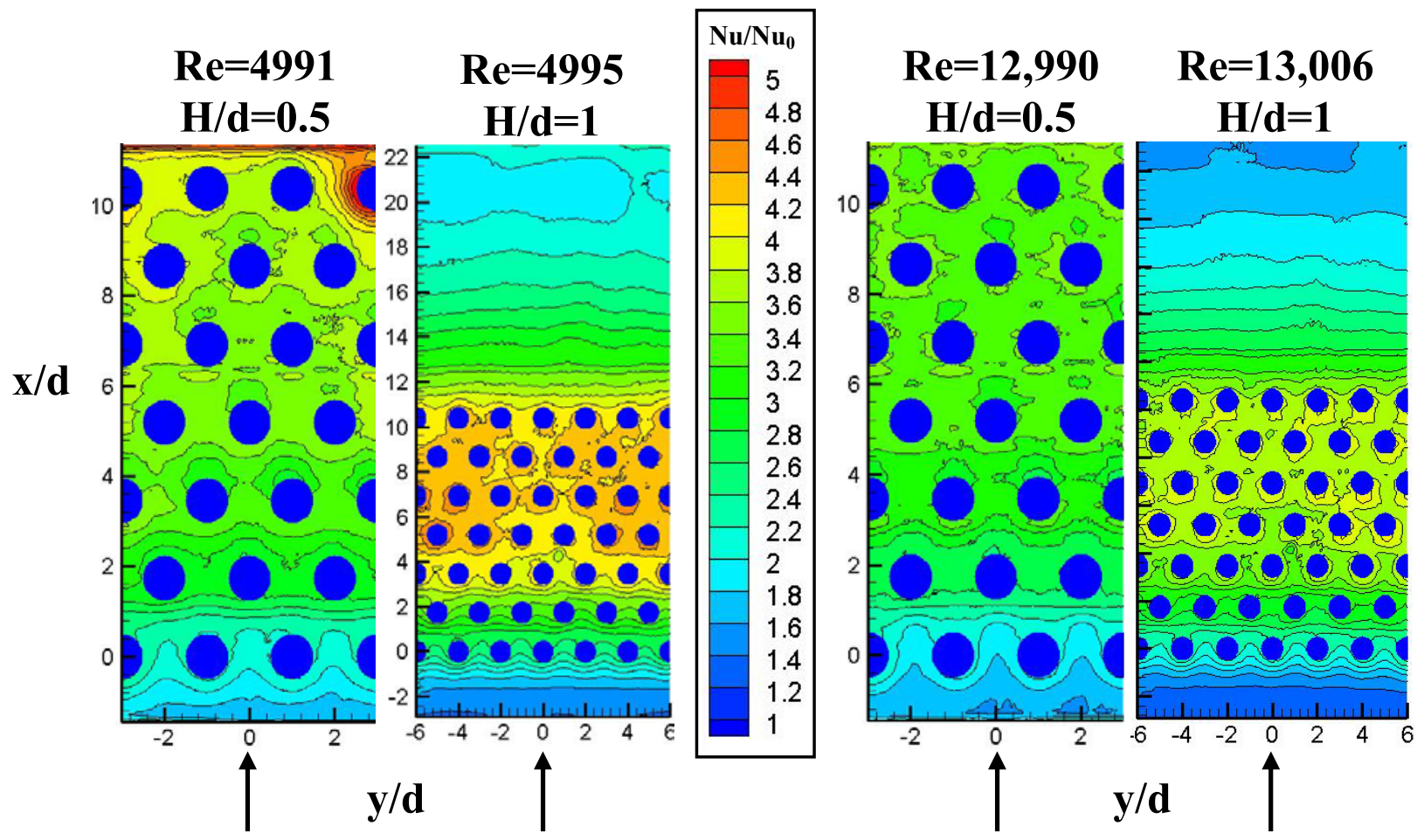

Figure 1.25. Contour plots comparing Nusselt number augmentation for the $\mathrm{S} 1 / \mathrm{d}=2$, $\mathrm{S} 2 / \mathrm{d}=1.73, \mathrm{H} / \mathrm{d}=0.5$ and $\mathrm{S} 1 / \mathrm{d}=2, \mathrm{~S} 2 / \mathrm{d}=1.73, \mathrm{H} / \mathrm{d}=1$ geometries.

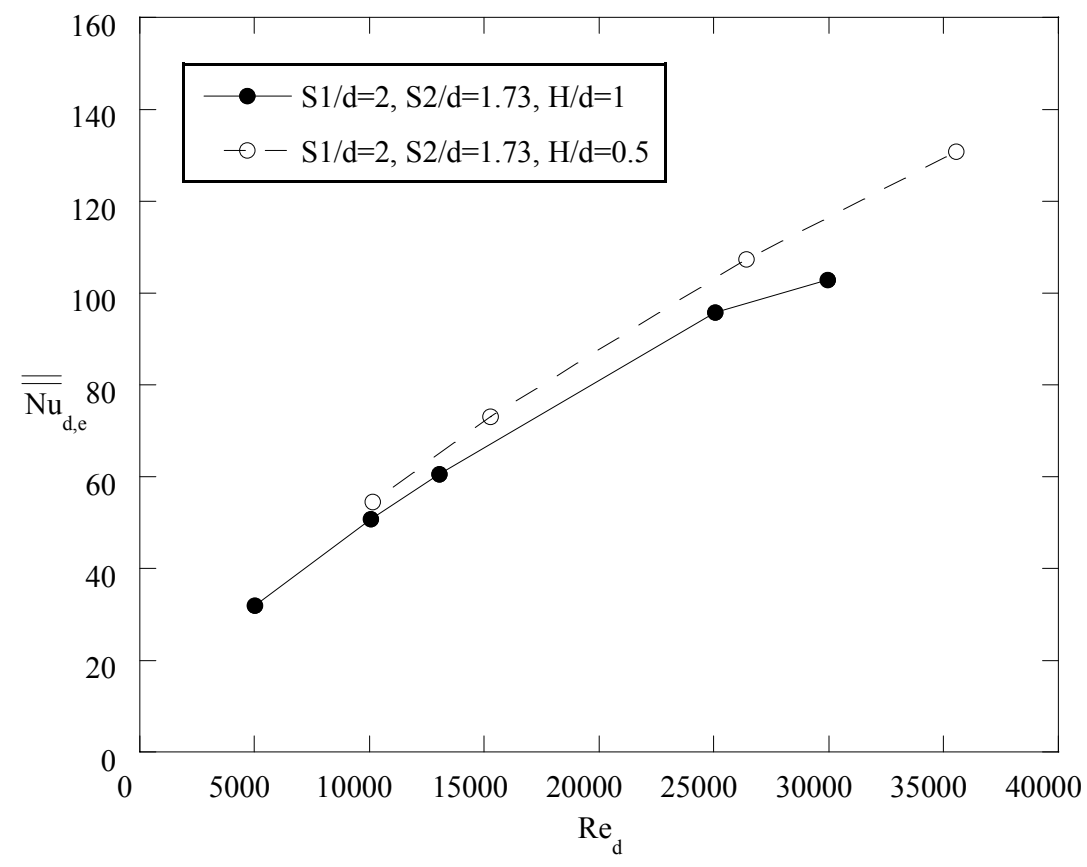

Figure 1.26. Average endwall Nusselt numbers for $\mathrm{S} 1 / \mathrm{d}=2, \mathrm{~S} 2 / \mathrm{d}=1.73, \mathrm{H} / \mathrm{d}=1$ and $\mathrm{S} 1 / \mathrm{d}=2, \mathrm{~S} 2 / \mathrm{d}=1.73, \mathrm{H} / \mathrm{d}=0.5$ geometries. 


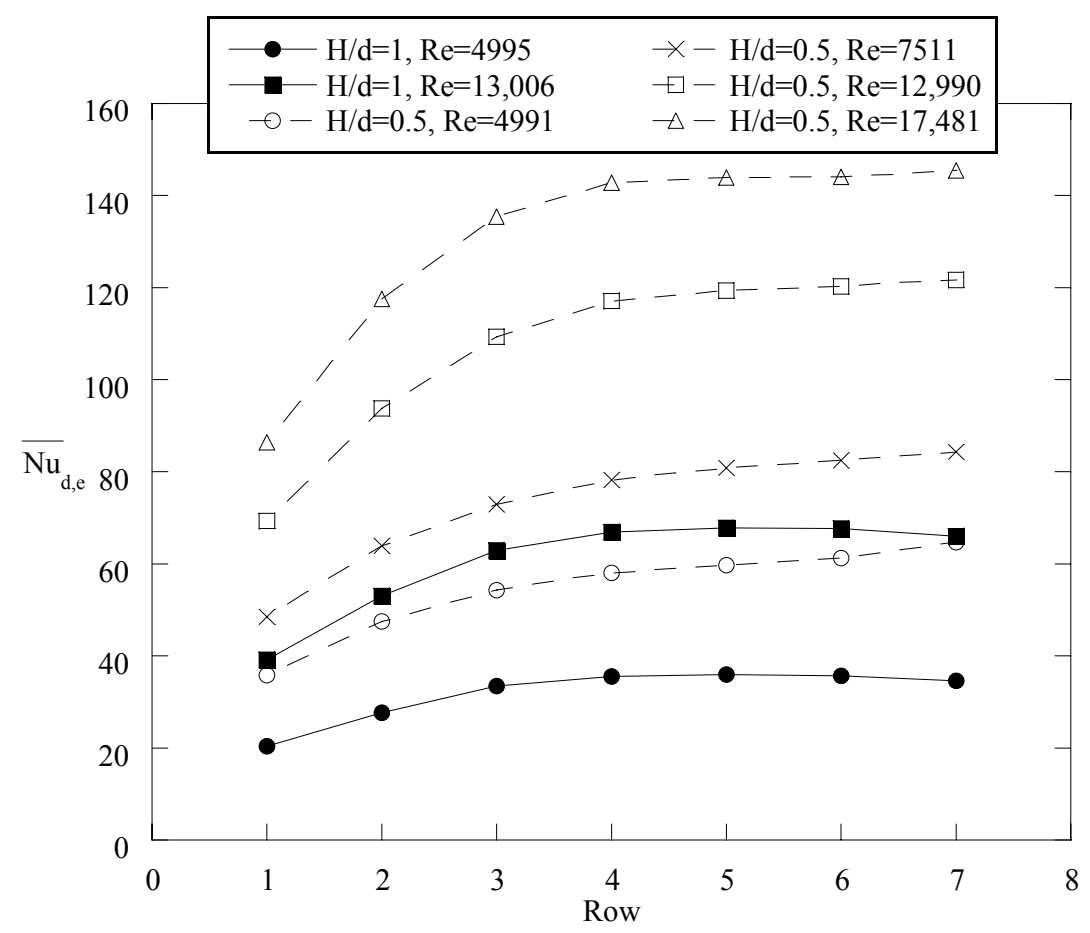

Figure 1.27. Row-resolved endwall Nusselt numbers for $\mathrm{S} 1 / \mathrm{d}=2, \mathrm{~S} 2 / \mathrm{d}=1.73, \mathrm{H} / \mathrm{d}=1$ and $\mathrm{S} 1 / \mathrm{d}=2, \mathrm{~S} 2 / \mathrm{d}=1.73, \mathrm{H} / \mathrm{d}=0.5$ geometries.

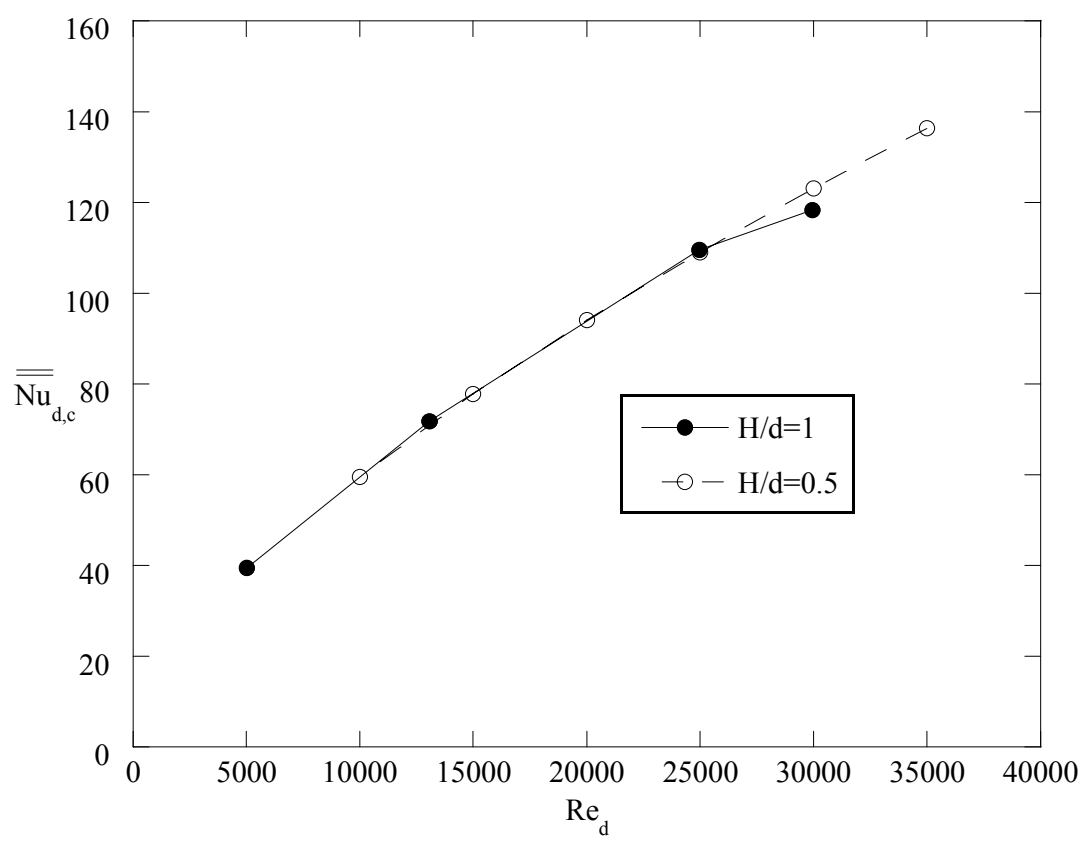

Figure 1.28. Array-average Nusselt numbers for the $\mathrm{S} 1 / \mathrm{d}=2, \mathrm{~S} 2 / \mathrm{d}=1.73, \mathrm{H} / \mathrm{d}=0.5$ and $\mathrm{S} 1 / \mathrm{d}=2, \mathrm{~S} 2 / \mathrm{d}=1.73, \mathrm{H} / \mathrm{d}=1$ geometries. 


\title{
Paper 2
}

\section{Heat Transfer from Multiple Row Arrays of Low Aspect Ratio Pin Fins with Different Flow Incidence Angles}

\begin{abstract}
The study of internal cooling for turbine blades is a necessary task because of the high turbine inlet temperatures that must be achieved in order to maximize the specific thrust of a gas turbine engine. Because of the way that pin fin arrays are arranged in internal cooling channels, they sometimes experience different flow incidence angles. Pin fin arrays were tested to determine the effect of changing flow incidence angles on heat transfer from pin fin arrays. The effect of changing the pin aspect ratio was also studied for arrays with different flow incidence angles. Experiments were conducted through a range of Reynolds numbers between 5000 and 30,000. Results indicated that pin spacing and flow incidence angle had little to no effect on average pin Nusselt number. Less wake interaction between pins was observed on the endwalls of arrays with flow incidence angles of $30^{\circ}$ due to decreased flow obstruction. In some cases there was a noticeable difference in array-average Nusselt number between arrays with flow incidence angles and arrays with perpendicular flow. The arrays with a flow incidence angle of $30^{\circ}$ yielded lower array-average Nusselt numbers than arrays with perpendicular flow. As pin spacing was increased, the effect of flow incidence angle decreased. As aspect ratio decreased, the effect of flow incidence angle increased creating a larger heat transfer difference between flow incidence angles.
\end{abstract}




\section{Nomenclature}

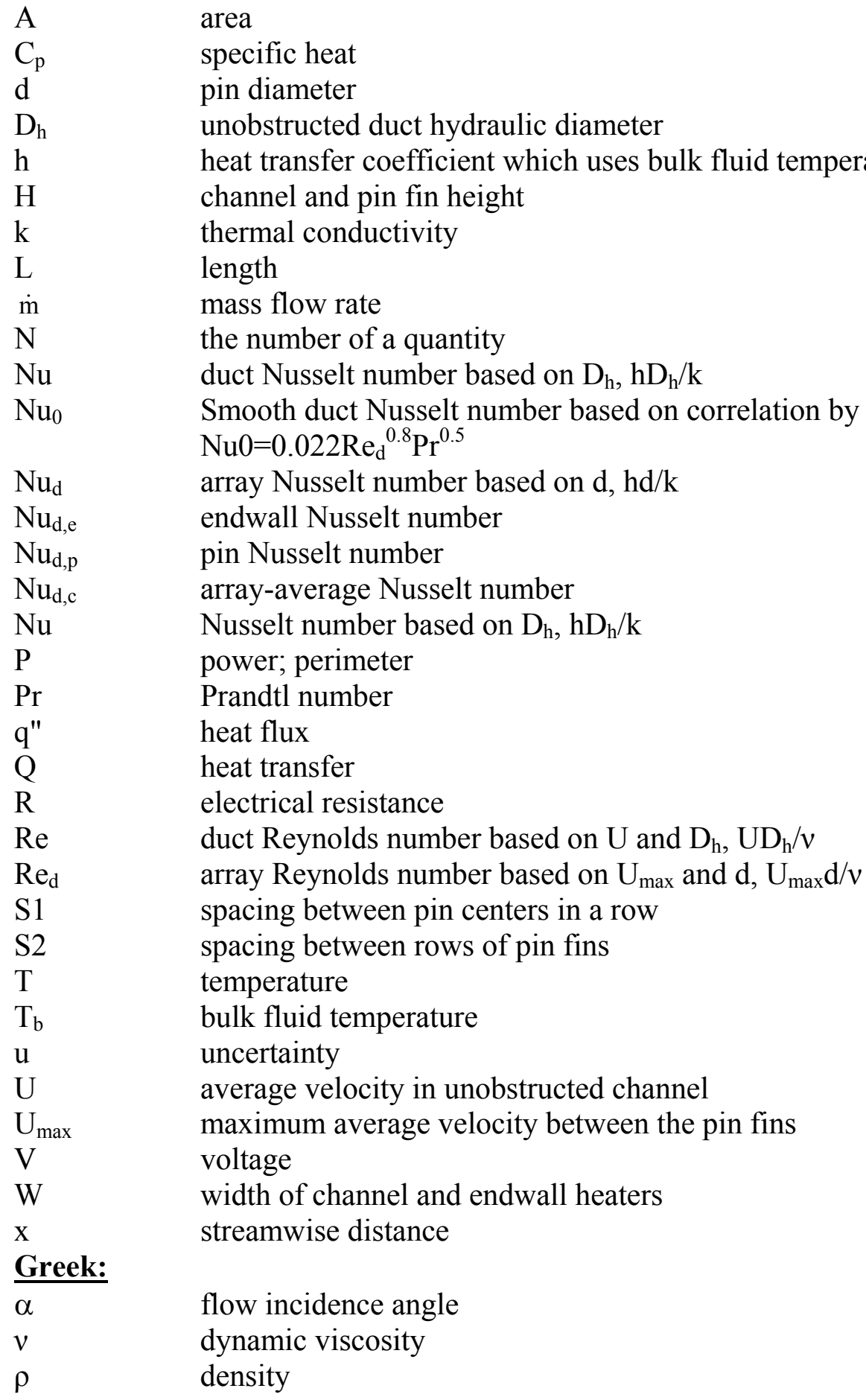

\section{Subscripts:}

\begin{tabular}{|c|c|}
\hline$\overline{\text { variable }}$ & spanwise averaged value \\
\hline varial & area aver \\
\hline $\begin{array}{l}0 \\
\mathrm{amb}\end{array}$ & $\begin{array}{l}\text { unobstructed duct baseline condi } \\
\text { ambient conditions }\end{array}$ \\
\hline
\end{tabular}




\section{Introduction}

Improved methods for internal and external cooling are necessary because the turbine inlet temperatures of today's gas turbines are higher than the melting point of the material used to construct the turbine airfoils. Coolant is extracted from the compressor and routed through internal cooling channels of each turbine airfoil. After internally cooling the airfoils, the coolant passes through film-cooling holes to provide external cooling for the part.

The design of internal cooling channels for the trailing edge of a turbine airfoil is a particularly difficult challenge. It is a challenge because the narrow channels in the trailing edge do not allow for film cooling so the internal cooling must be as effective as possible to account for the high external heat transfer coefficients associated with the mainstream core flow. The cooling channels in this region are generally narrow in order for the airfoil to maintain structural support. The most effective way to induce heat transfer in these types of channels is to insert staggered or in-line arrays of cylindrical pin fins with low aspect ratios (channel height-to-pin diameter). Pin fin arrays increase the wetted heat transfer area and turbulence levels to improve convection from the airfoil to the internal coolant air.

Because of the way pin fin arrays are placed in a trailing edge cooling channel, the flow typically does not enter every section of the array at the same incidence angle. As such, determining the effects of changing flow incidence angle on pin fin array heat transfer is of great interest. This paper presents the experimental studies that were conducted to gain a better understanding of the heat transfer characteristics across multiple rows of triangularly spaced pins placed at different flow incidence angles. The effects related to the pin fin heat transfer as well as the effects related to the heat transfer on the duct walls, also known as endwalls, are discussed in this study. The effect of changing the pin aspect ratio was also studied for arrays with different flow incidence angles. All geometries included in this study consist of seven rows of triangularly spaced pin fins which means that the pin fins are placed in an equilateral triangle arrangement with respect to one another. 


\section{Review of Relevant Literature}

Many improvements in the cooling methods for turbine airfoils have been made since the 1950's. Numerous studies have been made to test different arrangements of pin fin arrays. The following section discusses the results from the available literature related to the effects of flow incidence angle and aspect ratio on Nusselt number.

Evenko et al. [1976] studied the heat transfer of long cylinder tube banks. They found evidence to suggest that arranging the tube banks with a flow incidence angle could slightly increase the heat transfer in some cases. They defined a relative angle as the ratio of the flow incidence angle to the angle that would create an in-line pin layout. The highest heat transfer was measured in the array arranged at a relative angle of 0.66 . The in-line array arrangement yielded lower Nusselt numbers than the array with perpendicular flow.

Metzger et al. [1984] tested circular and oval pins at different orientations to the flow. They tested the effects of flow incidence angle on circular pin fin arrays with a spanwise spacing of 2.5, a streamwise spacing of 1.5, and an aspect ratio of one. The flow incidence angles tested were $0^{\circ}, 13^{\circ}, 26^{\circ}$, and $40^{\circ}$. They found that Nusselt number increased with flow incidence angle at angles less than $40^{\circ}$. The $40^{\circ}$ arrangement was essentially an in-line layout and yielded the lowest Nusselt numbers. Although Metzger et al. [1984] found that arranging the array at an intermediate flow incidence angle slightly improved Nusselt number, they concluded that the array orientation had a small effect on Nusselt number for circular pin fins.

Several investigators have studied the heat transfer through in-line versus staggered pin fin arrays. The heat transfer relationship between in-line and staggered arrays is similar to the relationship between arrays with flow incidence angles and arrays with no flow incidence angle and is, therefore, relevant to the current study. Simoneau and VanFossen [1984], Chyu et al. [1998], and Hwang et al. [2001] all concluded that staggered arrays have higher array average heat transfer than in-line arrays.

Simoneau and VanFossen [1984] measured pin Nusselt numbers using a single heated pin placed in both in-line and staggered arrays. The heat transfer for the in-line case showed little difference when the number of upstream rows was changed; however, the results for the staggered arrays were affected by the number of upstream rows. The Nusselt numbers in the downstream rows of the staggered array were higher than the Nusselt numbers in the downstream rows of the in-line array. Simoneau and VanFossen [1984] also measured spanwise 
turbulence levels through staggered and in-line arrays. Although the average turbulence intensity between in-line and staggered arrays was similar, the turbulence profiles measured in the staggered array were more complex experiencing more peaks and valleys in the turbulence levels across the span of the array. The effects of using in-line versus staggered arrays of pin fins were also studied by Chyu et al. [1998]. They found that a staggered array produced higher array-average Nusselt numbers than an in-line array, which is consistent with the findings of Simoneau and VanFossen [1984]. Hwang et al. [2001] studied endwall Nusselt numbers for staggered and in-line pin fin arrays located in a wedged duct with varying channel height. They determined that the staggered array had a higher array-average Nusselt number than the in-line array across the whole range of Reynolds numbers tested which is consistent with the findings of Evenko et al. [1976] and Metzger et al. [1984].

Multiple studies have been conducted to determine the effects of changing pin aspect ratio on array-average heat transfer. Brigham and VanFossen [1984] and Yeh and Chyu [1998] both found that heat transfer decreases with a decrease in pin aspect ratio.

Brigham and VanFossen [1984] studied the effects of aspect ratio on array-average Nusselt number augmentation. They found that the Nusselt number augmentation relative to an open duct decreased with decreasing aspect ratio at aspect ratios greater than two. Below an aspect ratio of two, the augmentation remained the same between aspect ratios. Armstrong and Winstanley [1988] attributed the decreased augmentation with decreasing aspect ratio to the reduction in wetted area associated with the pins at low aspect ratios. As the aspect ratio is decreased, the endwall begins to account for most of the wetted heat transfer area. At higher aspect ratios, the pin Nusselt number, which is typically higher than the endwall Nusselt number, contributes more to the array-average Nusselt number.

Yeh and Chyu [1998] obtained results for two identically spaced arrays having aspect ratios of 1 and 2.8. They found that both arrays had the same development trend and observed that endwall Nusselt numbers for both arrays were very similar. They found that the array with an aspect ratio of one had a higher array-average Nusselt number at low Reynolds numbers than the array with an aspect ratio of 2.8. For the majority of the Reynolds number range, the array with an aspect ratio of 2.8 had higher array-average Nusselt numbers than the array with an aspect ratio of one. The decrease in the array-average Nusselt number with aspect ratio found by Yeh and Chyu [1998] is consistent with the findings of Brigham and VanFossen [1984]. 
The research available in the literature concerning the effects of flow incidence angle was limited. Studies by Evenko et al. [1976] showed that flow incidence angle had a slight effect on array heat transfer. They obtained results to show that array heat transfer could be increased by increasing the flow incidence angle of the array to a certain extent. The flow incidence angle that created an in-line pin arrangement actually decreased the array heat transfer. Similar conclusions were made by Metzger et al. [1984] in that array heat transfer could be increased by changing the flow incidence angle to a certain extent. Studies by Simoneau and VanFossen [1984], Chyu et al. [1998], and Hwang et al. [2001] also showed that heat transfer through in-line arrays was generally lower than heat transfer through staggered arrays which is consistent with the findings by Evenko et al. [1976] and Metzger et al. [1984].

Very limited studies have been conducted to explore the effect that flow incidence angle has on pin fin array heat transfer. The objective of the present work is to further explore the effects of flow incidence angle for staggered arrays of cylindrical pin fins with low aspect ratios. The present study also examines the effects of aspect ratio on the heat transfer in arrays with different flow incidence angles.

\section{Experimental Facility}

An experimental facility was constructed to measure the convective heat transfer characteristics of different pin fin array geometries. The facility provided the correct flow conditions to test scaled up models of pin fin arrays. To measure the array heat transfer characteristics copper pin fins having different spanwise spacings (S1/d), streamwise spacings $(\mathrm{S} 2 / \mathrm{d})$, aspect ratios $(\mathrm{H} / \mathrm{d})$, and flow incidence angles $(\alpha)$ were placed in a seven row triangularly spaced array and tested in the facility. In a triangularly spaced array, the pins are placed in an equilateral triangle orientation with respect to one another. Figure 2.1 shows a schematic of a pin fin arrangement defining the spacing parameters.

A closed loop facility similar to the one used by Lyall et al. [2006] was constructed. The flow moves in the clockwise direction through the facility shown in Figure 2.2. As flow entered the plenum, it first encountered a splash plate, which was used to prevent the inlet air from propagating through to the test section without mixing. The air then passed through a finned tube heat exchanger that was used to ensure a constant inlet air temperature to the test section. 
As the flow exited the plenum, it was directed through a rounded test section entrance constructed from sections of pipe to ensure uniform flow entering the duct.

Strips of sandpaper were added at the entrance of the test section, shown by Figure 2.3, to uniformly trip the boundary layer across the span of the channel. Flow developed for 40 hydraulic diameters upstream of the symmetrically heated channel walls. The first row of the pin fin array was placed four hydraulic diameters downstream of the leading edge of the heater. The test section of the facility was constructed as a parallel plate duct. With a width of $61 \mathrm{~cm}$ and a height of $0.95 \mathrm{~cm}$, the test section had a width-to-height ratio of 64:1.

Downstream of the test section, the flow passed through an extension that transitioned the flow from a rectangular duct to a round pipe. A venturi flowmeter was placed 15 pipe diameters downstream of the extension. A pipe length of eight pipe diameters was placed between the venturi and the blower to ensure accurate flow measurements.

A blower seen in Figure 2.2 was manually regulated to set the desired flow conditions for each individual test. Pressure regulating valves also shown in Figure 2.2 were installed on both the suction and the discharge sides of the blower. These valves were used to minimize the pressure difference between the inside and the outside of the test section. This was necessary because a thin flexible heater was used as the endwall of the pin fin array. A pressure differential between the test section and surroundings caused the pin fin array endwall to either compress inward or bow outward. If the pressure on the inside of the channel was higher than the ambient pressure, the heater would bubble out causing the pins to lose contact with the endwall heater. If the pressure on the inside of the channel was lower than the ambient pressure, the heater would compress in creating a non-uniform channel height through the array. The flowrate measurement was taken downstream of the test section and upstream of the pressure regulating valves to ensure an accurate measurement that was independent of the settings of the pressure regulating valves.

The experiments were set up to measure Nusselt numbers on the pin and endwall surfaces of arrays with different flow incidence angles. Rather than changing the angle of the coolant flow through the duct, the array of interest was arranged at the necessary angle relative to the flow as shown by Figure 2.4. Figure 2.4a shows the array layout during tests on an array with no flow incidence angle while Figure $2.4 \mathrm{~b}$ illustrates the array layout during tests on an array with a flow incidence angle of $30^{\circ}$. The large red boxes in Figure 2.4 represent the endwall heaters 
which are explained later in this section. A $17 \mathrm{~cm}$ by $33 \mathrm{~cm}$ rectangular section of the top endwall was visible from the outside of the channel so that temperature measurements could be made with an infrared (IR) camera. This rectangular section is shown by the blue rectangles in Figure 2.4. A zinc selenide window was placed between the back side of the heater and the foam insulation creating an insulating air gap outside of the heater. Zinc selenide was chosen because of its transparency to infrared. The air gap, window, and foam insulation minimized heat losses from the back side of the heater.

A constant heat flux boundary condition on the endwalls of the pin fin array was created by heaters that were placed along the walls of the test section seen in Figure 2.3. The constant heat flux boundary condition was used to simplify the experimental setup. The heat transfer coefficients that were measured using constant heat flux boundary conditions are similar to the heat transfer coefficients that would be measured using isothermal boundary conditions. They are similar because the flow conditions for the experiments in this study are highly turbulent for which the convection is driven by the eddy currents caused by the turbulence. The heaters were powered by individual power supplies and placed in series with a precision resistor that was used to make accurate heater current measurements. Net heat flux convected to the flow could be calculated knowing the power supplied to the heaters using Equation 2.1,

$$
\mathrm{q}_{\text {net }} "=\frac{\mathrm{P}-\mathrm{q}_{\text {loss }} "(2 \mathrm{~L} \cdot \mathrm{W})}{2 \mathrm{~L} \cdot \mathrm{W}+0.5 \mathrm{~N} \pi \cdot \mathrm{d}^{2}}
$$

where $\mathrm{P}$ is the total power to the heaters, qloss" is the calculated loss heat flux, L is the length of each heater, $\mathrm{W}$ is the width of each heater, $\mathrm{N}$ is the number of pins, and $\mathrm{d}$ is the pin diameter. The term in the denominator of Equation 2.1 represents the wetted heat flux area and includes the surface area of the pin fins as well as the endwalls exposed to the flow.

Three thermocouples were placed on the outside of the test section and were used to calculate the heat loss knowing the thermal resistance of the test section walls. The calculated losses were $5 \%$ at the lowest Reynolds number and decreased with increased Reynolds number. A more detailed loss heat flux analysis is provided in Appendix B. The heat transfer coefficient was calculated using the bulk fluid temperature as the reference temperature. This bulk fluid temperature was calculated using a simple energy balance knowing the inlet temperature and the cumulative heat which entered the flow up to the point of interest. 
Each test was allowed to reach steady-state before a section of insulation was removed from the zinc selenide window to take a series of infrared pictures of the back side of the endwall heater. Three thermocouples were placed in hot and cold locations on the back side of the heater and were used to calibrate the infrared images during data reduction. The emissivity of the back side of the heater was assumed to be 0.96 and the measured temperatures on the back side of the heater were corrected to account for the thickness of the heater itself. The heater was composed of an inconel strip arranged in a serpentine pattern and encapsulated in Kapton. A thin layer of copper was vacuum deposited to the back side of the heater to ensure an even heat flux distribution. Even with the multiple layers, each heater was only $254 \mu \mathrm{m}$ thick.

Pin heat transfer experiments were conducted with the use of two specially designed balsa wood pins. Figure 2.5 shows a schematic illustrating the parts of the balsa wood pins. Balsa wood was used because of its low thermal conductivity to minimize conduction losses through the pin. Each balsa pin was constructed to be the same size as a copper pin and was heated on the surface by an inconel strip. Three thermocouples were embedded on the outside surface of each balsa pin, but in thermal contact with the inside of the inconel strip. The thermocouples were placed at the leading edge, on the side, and at the trailing edge of the pin fin. Heat transfer coefficients were calculated at each thermocouple location and a circumferential average was calculated for each pin. Comparisons with the literature were made to verify that the three measurements around the pin gave a good average of pin heat transfer coefficients [Lyall, 2006]. During each test, both pins were placed in the row of interest on a non-conductive surface and averaged to obtain the heat transfer for the pins in that row. A two pin average was taken to decrease the uncertainty of the overall result. Each row was tested for a range of Reynolds numbers between 5000 and 30,000.

\section{Uncertainty Analysis}

An uncertainty analysis was conducted using the methods by Moffat [1988]. Uncertainty values were calculated for low and high Reynolds number cases. At each Reynolds number, uncertainties were calculated for low and high Nusselt numbers. The Reynolds number uncertainty was $4.0 \%$ at a Reynolds number of 5000 and $2.5 \%$ at a Reynolds number of 30,000. The uncertainty for the pin Nusselt number $\left(\mathrm{Nu}_{\mathrm{d}, \mathrm{p}}\right)$ was below 5.5\% for every case. The duct Nusselt number $(\mathrm{Nu})$ calculated on the endwall had a higher uncertainty than the pin Nusselt 
number because of the uncertainty associated with the calibration of the infrared images. The highest duct Nusselt number uncertainty was 13\%. The duct Nusselt number uncertainty was reflected in the Nusselt number augmentation $\left(\mathrm{Nu} / \mathrm{Nu}_{0}\right)$ uncertainty which also was as high as $13 \%$ in the worst case. The array-average Nusselt number uncertainty was less than $8 \%$ for all cases which is comparable to experimental uncertainties by other researchers. A more detailed uncertainty analysis is shown in Appendix A.

\section{Test Matrix and Data Analysis}

Because of geometric constraints, pin fin arrays are typically placed in the trailing edge cooling channels of turbine airfoils. Due to complicated geometric schemes, the coolant air within these trailing edge channels does not always flow perpendicular to the pin fin arrays. The heat transfer characteristics of pin fin arrays having flow incidence angles are of great interest to turbine airfoil designers. Table 2.1 shows the test matrix of the experiments conducted for this study on the effects of flow incidence angles on heat transfer in pin fin arrays. The table illustrates the different geometries tested along with the different flow incidence angles associated with each geometry. Every array tested had seven rows of pin fins. The "Pin Layout" column in Table 2.1 shows the different array configurations and their relative flow incidence angles.

Two Reynolds number and Nusselt number definitions were used in this study to characterize the flow conditions and the endwall and pin heat transfer. The endwall heat transfer is characterized in two ways throughout this paper. The duct Nusselt number augmentation $\left(\mathrm{Nu} / \mathrm{Nu}_{0}\right)$ is the ratio of duct Nusselt number $(\mathrm{Nu})$ to the empty duct Nusselt number $\left(\mathrm{Nu}_{0}\right)$ at the same Reynolds number and is used to characterize the endwall heat transfer in all contour plots. The duct Nusselt number is the non-dimensional heat transfer coefficient which uses the duct hydraulic diameter as the characteristic length. The duct Reynolds number $(\mathrm{Re})$ is defined by the bulk fluid velocity through the duct and uses the duct hydraulic diameter as the characteristic length. The duct Reynolds number is typically used in conjunction with the duct Nusselt number. The endwall heat transfer is most commonly characterized by the array Nusselt number $\left(\mathrm{Nu}_{\mathrm{d}}\right)$ throughout the literature and is used here to draw comparisons between the pin $\left(\mathrm{Nu}_{\mathrm{d}, \mathrm{p}}\right)$ and endwall $\left(\mathrm{Nu}_{\mathrm{d}, \mathrm{e}}\right)$ heat transfer at various geometries. The array Nusselt number is a nondimensional heat transfer coefficient and uses the pin diameter as the characteristic length. The 
array Reynolds number $\left(\mathrm{Re}_{\mathrm{d}}\right)$ is defined by the maximum fluid velocity through the array and also uses the pin diameter as the characteristic length. The array Reynolds number is typically used in conjunction with the array Nusselt number to characterize the flow.

The data reduction process for arrays having non-zero flow incidence angles was more complicated than the data reduction process for arrays with perpendicular flow incidence angles. For every array studied the row-resolved Nusselt numbers were calculated first. The endwall Nusselt number for each row was calculated by taking a spanwise average of the Nusselt numbers from half of a row spacing $(0.5 \mathrm{X})$ upstream to half of a row spacing downstream of the location of interest. The average endwall Nusselt numbers $\left(\overline{\overline{\mathrm{Nu}}}_{\mathrm{d}, \mathrm{e}}\right)$ were then calculated by averaging the row-resolved results from all rows in the array. The red boxes in Figure 2.6a show the row areas over which the row-resolved endwall Nusselt numbers were taken for arrays with no flow incidence angle. It is important to note that the data encompassing each pin footprint were not included in this average and are represented by the blue circles in the contour plots. For arrays with flow incidence angles, the data was analyzed in two different ways before a common convention was chosen. The first method is illustrated by the red boxes (Figure 2.6a), which represent the row areas for the rows oriented perpendicular to the coolant flow. The second method is illustrated by the yellow boxes (Figure 2.6b) which represent the row areas for the rows oriented at an angle relative to the coolant flow. The row-average method illustrated by the red boxes did not properly identify the effects of the flow incidence angle on the array heat transfer. To properly determine the independent effect of flow incidence angle on array heat transfer, row-averages of the rows oriented at angles relative to the flow were calculated as shown by the yellow boxes in Figure 2.6b.

Row-resolved pin Nusselt numbers were obtained by averaging the Nusselt numbers obtained by the two instrumented balsa pins for each row. The pin Nusselt numbers for every row were then averaged over the seven rows to obtain the average pin Nusselt number at every flow condition. After the average Nusselt numbers were calculated for the pin $\left(\overline{\overline{\mathrm{Nu}}}_{\mathrm{d}, \mathrm{p}}\right)$ and endwall $\left(\overline{\overline{\mathrm{Nu}}}_{\mathrm{d}, \mathrm{e}}\right)$ surfaces, the array-averaged Nusselt number $\left(\overline{\overline{\mathrm{Nu}}}_{\mathrm{d}, \mathrm{c}}\right)$ was then calculated by taking an area-average of both. 


\section{Baseline Experimental Results}

Before an understanding of the effects of flow incidence angle on pin fin array heat transfer can be accomplished, a good understanding of the general effects on heat transfer in arrays with no flow incidence angle must be developed. This section describes the strongest effects on pin and endwall heat transfer in arrays with no flow incidence angle. The effects of Reynolds number, pin spacing, and aspect ratio on array heat transfer are described in this section. The relationship between pin and endwall heat transfer is presented here as well. A more detailed analysis of the effects described in this section is discussed in Paper 1.

Contour plots of Nusselt number augmentation were developed from the spatially resolved endwall temperatures. Figure 2.7 shows Nusselt number augmentation contour plots for the $\mathrm{S} 1 / \mathrm{d}=2, \mathrm{~S} 2 / \mathrm{d}=1.73$ and $\mathrm{S} 1 / \mathrm{d}=4, \mathrm{~S} 2 / \mathrm{d}=3.46$ arrays having no flow incidence angle and an $\mathrm{H} / \mathrm{d}=1$. Contours are shown for both geometries at approximate duct Reynolds numbers of 5000 and 30,000. The contours are oriented such that the flow moves from bottom to top. The vertical axes show the non-dimensional streamwise distance, $\mathrm{x} / \mathrm{d}$, where $\mathrm{x}$ is the streamwise distance measured from the first row and $\mathrm{d}$ is the pin diameter. The horizontal axes show the non-dimensional spanwise distance, $\mathrm{y} / \mathrm{d}$, where $\mathrm{y}$ is the spanwise distance measured from the center of each image. The contour plots all represent the same physical area. Appendix C shows contour plots for every tested geometry.

Figure 2.7 shows that augmentation decreases with Reynolds number. This decrease is observed because, at low Reynolds numbers, adding pin fins greatly increases the turbulence while at high Reynolds numbers the turbulence is only slightly increased relative to the turbulence induced by the high Reynolds number in an empty duct. Figure 2.7 also shows that augmentation in the $\mathrm{S} 1 / \mathrm{d}=2$ array is higher than in the $\mathrm{S} 1 / \mathrm{d}=4$ array because the $\mathrm{S} 1 / \mathrm{d}=2$ array experiences more pin wake interaction than the $\mathrm{S} 1 / \mathrm{d}=4$ array. The pin wake interaction is one of the main driving mechanisms behind convection through pin fin arrays.

Figure 2.7 also shows that Reynolds number has an effect on Nusselt number augmentation upstream of the array. The augmentation levels directly upstream of the arrays at $\mathrm{Re}=5000$ are higher than the augmentation levels directly upstream of the arrays at $\mathrm{Re}=30,000$. Nusselt number augmentation levels are expected to be equal to one upstream of the array where the flow is unaffected by the pin fins; however, the available data is limited because of the infrared window size constraint. Higher levels of augmentation directly upstream of the array 
for the $\mathrm{Re}=5000$ case indicate that the pin fins have a larger effect on upstream augmentation at low Reynolds numbers than at high Reynolds numbers.

Figure 2.8 shows the average endwall Nusselt numbers $\left(\overline{\overline{\mathrm{Nu}}}_{\mathrm{d}, \mathrm{e}}\right)$ measured for the $\mathrm{S} 1 / \mathrm{d}=2$, $\mathrm{S} 2 / \mathrm{d}=1.73$ having $\mathrm{H} / \mathrm{d}=0.5$ and $\mathrm{H} / \mathrm{d}=1$ along with the $\mathrm{S} 1 / \mathrm{d}=4, \mathrm{~S} 2 / \mathrm{d}=3.46$ array having $\mathrm{H} / \mathrm{d}=1$. Figure 2.8 illustrates the effect that Reynolds number, pin spacing, and aspect ratio have on endwall Nusselt number through arrays of triangularly spaced pin fins. The results in Figure 2.8 show that as array Reynolds number $\left(\operatorname{Re}_{\mathrm{d}}\right)$ increases, the endwall Nusselt number increases as well. The increase in endwall Nusselt number occurs because the velocity through the array increases with Reynolds number which increases the heat transfer coefficients through the array. Pin wake interaction is also stronger at high Reynolds numbers. Figure 2.8 also shows that the array with the wider pin spacing $(\mathrm{S} 1 / \mathrm{d}=4)$ experiences lower heat transfer. As mentioned previously, the pin wake interaction decreases with increased pin spacing creating a less effective arrangement for heat transfer. The endwall Nusselt numbers for the $\mathrm{S} 1 / \mathrm{d}=2, \mathrm{~S} 2 / \mathrm{d}=1.73$ array with $\mathrm{H} / \mathrm{d}=0.5$ is also shown in Figure 2.8 . The endwall results from the two identically spaced arrays with different aspect ratios (H/d) illustrate the effect of aspect ratio on endwall heat transfer at low aspect ratios. As the aspect ratio is decreased, the endwall Nusselt numbers increase. The conclusion drawn in Paper 1 regarding the effect that aspect ratio has on endwall heat transfer was that the velocity alone does not scale the endwall heat transfer results at low aspect ratios. It was determined that increased knowledge of the local turbulence levels in each array may be needed to determine the scaling factor required to collapse the endwall heat transfer data at different aspect ratios.

The effects of flow incidence angle and pin spacing on average pin Nusselt number $\left(\overline{\overline{\mathrm{Nu}}}_{\mathrm{d}, \mathrm{p}}\right)$ were also studied. Figure 2.9 shows the circumferential average of the pin Nusselt number for the $\mathrm{S} 1 / \mathrm{d}=2, \mathrm{~S} 2 / \mathrm{d}=1.73$ and $\mathrm{S} 1 / \mathrm{d}=4, \mathrm{~S} 2 / \mathrm{d}=3.46$ arrays with no flow incidence angle as well as the Nusselt number for the $\mathrm{S} 1 / \mathrm{d}=4, \mathrm{~S} 2 / \mathrm{d}=3.46$ array with a flow incidence angle of $30^{\circ}$. All three geometries presented in Figure 2.9 have an $\mathrm{H} / \mathrm{d}=1$. The averaged pin Nusselt numbers for all three geometries are well within the experimental uncertainty of one another indicated by the error bars in Figure 2.9. A correlation to predict average pin Nusselt numbers based on array Reynolds number $\left(\operatorname{Re}_{\mathrm{d}}\right)$ was developed and is shown by Equation 2.2 


$$
\begin{gathered}
\overline{\overline{\mathrm{Nu}}}_{\mathrm{d}, \mathrm{p}}=0.43 \operatorname{Re}_{\mathrm{d}} 0.564 \\
2 \leq \mathrm{S} / \mathrm{d} \leq 4 ; 1.73 \leq \mathrm{X} / \mathrm{d} \leq 3.46 ; \mathrm{H} / \mathrm{d}=1 ; 0^{\circ} \leq \alpha \leq 30^{\circ}
\end{gathered}
$$

Note that the correlation in Equation 2.2 was used to predict the average pin Nusselt numbers in geometries for which pin Nusselt numbers were not measured.

The ratio of pin-to-endwall Nusselt number $\left(\overline{\overline{\mathrm{Nu}}}_{\mathrm{d}, \mathrm{p}} / \overline{\overline{\mathrm{Nu}}}_{\mathrm{d}, \mathrm{e}}\right)$ was calculated for the three arrays (shown in Figure 2.9) in which pin Nusselt numbers were measured. Figure 2.10 shows that the pin-to-endwall Nusselt number ratio depends more on Reynolds number and pin spacing than array angle. The ratio is highest at the lowest Reynolds number and the widest pin spacing. The ratio for the $\mathrm{S} 1 / \mathrm{d}=4, \mathrm{~S} 2 / \mathrm{d}=3.46$ arrays are very similar in trend and magnitude. The $\mathrm{S} 1 / \mathrm{d}=4$, $\mathrm{S} 2 / \mathrm{d}=3.46, \alpha=30^{\circ}$ ratio is higher than the $\mathrm{S} 1 / \mathrm{d}=4, \mathrm{~S} 2 / \mathrm{d}=3.46, \alpha=0^{\circ}$ ratio at the lowest Reynolds number but then falls slightly for the rest of the Reynolds number range. The pin-to-endwall ratios for all three geometries show a high Reynolds number dependence at the low Reynolds numbers. They gradually decrease through the rest of the range before slightly increasing at the highest Reynolds number. Paper 1 discusses the comparison between the results obtained in the present study and the results found in the literature concerning the pin-to-endwall Nusselt number ratio.

\section{Effect of Flow Incidence Angle on Array Heat Transfer}

Spatially resolved Nusselt numbers were measured on the endwalls of triangularly spaced arrays placed at different flow incidence angles. As previously stated, the effect of flow incidence angle is of interest because pin fin arrays do not always experience perpendicular flow $\left(\alpha=0^{\circ}\right)$ when placed in the cooling channels of turbine airfoils. Endwall Nusselt numbers were obtained for an $\mathrm{S} 1 / \mathrm{d}=2, \mathrm{~S} 2 / \mathrm{d}=1.73$ array set at flow incidence angles of $0^{\circ}$ and $30^{\circ}$. Endwall Nusselt numbers were also obtained for an $\mathrm{S} 1 / \mathrm{d}=4, \mathrm{~S} 2 / \mathrm{d}=3.46$ array at flow incidence angles of $0^{\circ}, 15^{\circ}$, and $30^{\circ}$. All arrays presented in this section have $\mathrm{H} / \mathrm{d}=1$.

Figure 2.11 shows Nusselt number augmentation contour plots for the $\mathrm{S} 1 / \mathrm{d}=4, \mathrm{~S} 2 / \mathrm{d}=3.46$ array at flow incidence angles of $0^{\circ}$ and $30^{\circ}$ and approximate Reynolds numbers of 5000 and 30,000 . Note that the contour plots all represent the same physical area. Figure 2.11 shows that

augmentation decreases with Reynolds number for both arrays similar to the results presented in the previous section. The decrease in augmentation with increased Reynolds number occurs 
because, relative to an open channel, adding pin fins increases the turbulence more at low Reynolds numbers than at high Reynolds numbers. At a given Reynolds number, the average augmentation level for arrays with different flow incidence angles is very similar; however, the flow patterns through the $\alpha=30^{\circ}$ array are different than the flow patterns through the array with no flow incidence angle. A triangularly spaced staggered array at a flow incidence angle of $\alpha=30^{\circ}$ experiences similar flow patterns as an in-line array. The contours clearly show that the pins create less flow blockage through the array with a flow incidence angle of $\alpha=30^{\circ}$. The array with the flow incidence angle of $\alpha=30^{\circ}$ provides a direct path for the flow to pass through the array with minimum blockage. The low augmentation levels through the in-line channels, shown in Figures $2.11 \mathrm{~b}$ and $2.11 \mathrm{~d}$, may indicate that the flow is less turbulent through the direct flow paths. The in-line array arrangement also suppresses the wake interaction between pins.

Figure 2.12 shows a series of contour plots for the $\mathrm{S} 1 / \mathrm{d}=4, \mathrm{~S} 2 / \mathrm{d}=3.46$ array with flow incidence angles of $0^{\circ}, 15^{\circ}$, and $30^{\circ}$ at Reynolds numbers of $13,876,13,009$, and 13,019 respectively. The contour plots in Figure 2.12 illustrate the differences in flow behavior between all three flow incidence angles. The $\alpha=15^{\circ}$ case behaves more like the $\alpha=0^{\circ}$ case because the flow has no direct path through the array contrary to the $\alpha=30^{\circ}$ case. The augmentation levels through the $\alpha=0^{\circ}$ and $\alpha=15^{\circ}$ arrays indicate higher wake interaction between pins than the $\alpha=30^{\circ}$ case because the wakes from each pin spread out and impact adjacent pins in downstream rows.

Figure 2.13 shows the incidence angle effectiveness ratios $\left(\overline{\overline{\mathrm{Nu}}}_{\mathrm{d}, \mathrm{c}} / \overline{\overline{\mathrm{Nu}}}_{\mathrm{d}, \mathrm{c}, \alpha=0}\right)$ for the array-average Nusselt numbers through the $\mathrm{S} 1 / \mathrm{d}=2, \mathrm{~S} 2 / \mathrm{d}=1.73$ and $\mathrm{S} 1 / \mathrm{d}=4, \mathrm{~S} 2 / \mathrm{d}=3.46$ arrays. The incidence angle effectiveness ratio is the ratio of the array-average Nusselt number to the array-average Nusselt number for the same array with a flow incidence angle of $\alpha=0^{\circ}$. Figure 2.13 shows that the incidence angle effectiveness ratios are less than one for both array spacings tested at $\alpha=30^{\circ}$. The incidence angle effectiveness ratio is lower for the $\mathrm{S} 1 / \mathrm{d}=2$ array indicating that the flow incidence angle has a larger effect on arrays with tighter pin spacings. The larger effect at tighter pin spacings is a result of the difference in pin wake interaction between high and low pin spacings. As previously explained, when a triangularly spaced array is placed at an $\alpha=30^{\circ}$ flow incidence angle, the heat transfer patterns are similar to those of an in-line array. The results presented in Figure 2.13 are consistent with the findings by Chyu et al. [1998] who concluded that staggered arrays had higher heat transfer than in-line arrays. After measuring Nusselt numbers for arrays at multiple angles, Metzger et al. [1984] concluded that the $40^{\circ}$ 
angled array, which was essentially an in-line array for their geometry, yielded lower Nusselt numbers than the array set perpendicular to the flow $(\alpha=0)$. The incidence angle effectiveness ratio for the $\mathrm{S} 1 / \mathrm{d}=4$ array at $\alpha=15^{\circ}$ is slightly higher than one indicating a slight improvement in heat transfer over the $\alpha=0^{\circ}$; however, the improvement is so small that no conclusions regarding the intermediate flow incidence angle can be drawn from the observation.

Figure 2.14 shows endwall Nusselt number development through the $\mathrm{S} 1 / \mathrm{d}=4$ array at flow incidence angles of $\alpha=0^{\circ}, \alpha=15^{\circ}$, and $\alpha=30^{\circ}$. The flow is characterized by the duct Reynolds number $(\mathrm{Re})$ in Figure 2.14. At the low Reynolds number all three array geometries show a gradual increase in Nusselt number through the array. At the high Reynolds number the $\alpha=0^{\circ}$ and $\alpha=15^{\circ}$ arrays show almost identical development trends reaching a maximum Nusselt number at row four before gradually decreasing through the remainder of the array. Metzger et al. [1982] and Yeh and Chyu [1998] observed similar trends in their data. Their measured Nusselt number reached a maximum value and declined through the remainder of the array. The array with $\alpha=30^{\circ}$ shows a different trend reaching a fully developed Nusselt number at row five. Unlike the trend seen in the $\mathrm{S} 1 / \mathrm{d}=2, \mathrm{~S} 2 / \mathrm{d}=1.73 \alpha=30^{\circ}$ array, the maximum Nusselt number in the $\mathrm{S} 1 / \mathrm{d}=4, \mathrm{~S} 2 / \mathrm{d}=3.46, \alpha=30^{\circ}$ array is not reached until the fifth row because of the Nusselt number behavior in the flow paths between the pins as illustrated by Figure 2.11. The Nusselt number augmentation patterns in Figure 2.11 show that augmentation gradually increases and is minimally affected by the pin wakes through the direct flow paths between the pin columns. The Nusselt number in the flow paths dominates the behavior of the $\mathrm{S} 1 / \mathrm{d}=4, \mathrm{~S} 2 / \mathrm{d}=3.46, \alpha=30^{\circ}$ array because the area affected by these flow paths is large. The same effect is not as strong in the $\mathrm{S} 1 / \mathrm{d}=2, \mathrm{~S} 2 / \mathrm{d}=1.73, \alpha=30^{\circ}$ array because the area affected by the direct flow paths is small compared to the area affected by the pin wakes.

Array-average Nusselt numbers for each $\mathrm{H} / \mathrm{d}=1$ geometry tested in this study are shown in Figure 2.15. The combined average Nusselt numbers were calculated using an area average of the pin and endwall Nusselt numbers. The geometries for which pin results were not measured utilized the correlation shown by Equation 2.2 to predict the pin Nusselt numbers. Figure 2.15 confirms that flow incidence angle has a larger effect on the $\mathrm{S} 1 / \mathrm{d}=2, \mathrm{~S} 2 / \mathrm{d}=1.73$ array than the $\mathrm{S} 1 / \mathrm{d}=4, \mathrm{~S} 2 / \mathrm{d}=3.46$ array with a noticeable difference between the $\alpha=0^{\circ}$ and $\alpha=30^{\circ}$ cases. All three $\mathrm{S} 1 / \mathrm{d}=4, \mathrm{~S} 2 / \mathrm{d}=3.46$ cases fall within experimental uncertainty of one another indicating a 
smaller flow incidence angle effect at wider pin spacings. In general, the effect of changing the flow incidence angle is noticeable, but small especially for arrays with wider pin spacings.

\section{Effect of Aspect Ratio on Array Heat Transfer for Arrays with Flow incidence Angles}

The effect the pin aspect ratio has been studied for arrays with different flow incidence angles. The previous section discussed the general effects of flow incidence angle on arrays with $\mathrm{H} / \mathrm{d}=1$. This section focuses on the effects of flow incidence angle on arrays with $\mathrm{H} / \mathrm{d}=0.5$.

Figure 2.16 shows Nusselt number augmentation contour plots for the $\mathrm{S} 1 / \mathrm{d}=2$, $\mathrm{S} 2 / \mathrm{d}=1.73, \alpha=30^{\circ}$ arrays with pin aspect ratios of $\mathrm{H} / \mathrm{d}=0.5$ and $\mathrm{H} / \mathrm{d}=1$ and approximate Reynolds numbers of 5000 and 17,500. As explained previously, the contours are oriented such that the flow moves from bottom to top. Normally, the contour plots all represent the same physical area; however, in this case the scales on the axes are different because the pin diameters between the $\mathrm{H} / \mathrm{d}=0.5$ and the $\mathrm{H} / \mathrm{d}=1$ cases are different. Rather than changing the pin height, the pin diameter was changed to create the arrays with $\mathrm{H} / \mathrm{d}=0.5$. Figure 2.16 shows that augmentation decreases with Reynolds number for both arrays similar to the results presented previously. Augmentation on the endwall of the $\mathrm{H} / \mathrm{d}=0.5$ array is lower than the augmentation on the endwall of the $\mathrm{H} / \mathrm{d}=1$ array. As explained in Paper 1, the lower augmentation in the $\mathrm{H} / \mathrm{d}=0.5$ arrays is a result of suppressed pin wake interaction at the lower pin aspect ratio. The wake interaction is suppressed in the $\mathrm{H} / \mathrm{d}=0.5$ case because the endwalls are much closer together than in the $\mathrm{H} / \mathrm{d}=1$ case preventing the wake from any one pin to spread and interact with wakes from other pins.

Figure 2.17 shows the incidence angle effectiveness ratios $\left(\overline{\overline{\mathrm{Nu}}}_{\mathrm{d}, \mathrm{c}} / \overline{\overline{\mathrm{Nu}}}_{\mathrm{d}, \mathrm{c}, \alpha=0}\right)$ for the array-average Nusselt numbers through every array tested in this study. Figure 2.17 shows that the incidence angle effectiveness ratios are lower for the $\mathrm{H} / \mathrm{d}=0.5$ array than the $\mathrm{H} / \mathrm{d}=1$ array. The ratio is lower for the $\mathrm{H} / \mathrm{d}=0.5$ array because the wake interaction between pins is suppressed more by increasing the flow incidence angle at $\mathrm{H} / \mathrm{d}=0.5$. Again, the wake interaction is lower in the $\mathrm{H} / \mathrm{d}=0.5$ array because the wake interaction is suppressed by the decreased channel height relative to the pin diameter.

The endwall Nusselt number development for the $\mathrm{H} / \mathrm{d}=0.5$ array at $\alpha=0^{\circ}$ and $\alpha=30^{\circ}$ is shown in Figure 2.18. The flow is characterized by the duct Reynolds number (Re) in Figure 2.18. The development trend is very similar between the $\alpha=0^{\circ}$ and the $\alpha=30^{\circ}$ arrays reaching a 
peak Nusselt number between rows three and four in both cases. The $\alpha=30^{\circ}$ array reaches a peak Nusselt number at row four and gradually decreases through the remainder of the array. Metzger et al. [1982] and Yeh and Chyu [1998] observed a similar decrease in their Nusselt number development. Ames et al. [2005] observed the same decrease in heat transfer after row four and said it was an indication of reduced local velocity.

Figure 2.19 shows the array-average Nusselt numbers for the $\mathrm{S} 1 / \mathrm{d}=2, \mathrm{~S} 2 / \mathrm{d}=1.73, \alpha=0^{\circ}$ and $\alpha=30^{\circ}$ arrays at aspect ratios of $\mathrm{H} / \mathrm{d}=0.5$ and $\mathrm{H} / \mathrm{d}=1$. Array-average results were obtained by calculating an area average of the pin and endwall Nusselt numbers. Of the geometries presented in Figure 2.19, the $\mathrm{H} / \mathrm{d}=1, \alpha=0^{\circ}$ array was the only one for which pin measurements were made. Pin results were not obtained for the $\mathrm{H} / \mathrm{d}=0.5$ geometry; however, being that the pin Nusselt numbers were in good agreement between arrays with different spacings and angles, it was assumed that the pin Nusselt numbers would not change significantly with decreased aspect ratio. Moreover, the pin contribution to the array-average Nusselt number is small for the $\mathrm{H} / \mathrm{d}=0.5$ array relative to the $\mathrm{H} / \mathrm{d}=1$ array. As discussed in the Paper 1 , the array-average Nusselt numbers for the arrays with perpendicular flow at both aspect ratios are almost identical which is consistent with the findings of Bringham and VanFossen [1984] who concluded that arrayaverage Nusselt number augmentations are the same for all arrays with the same spacings having $H / d<2$. The $\alpha=30^{\circ}$ array Nusselt numbers are lower for the $H / d=0.5$ array than for the $H / d=1$ array. As previously explained, the lower Nusselt numbers obtained for the $H / d=0.5 \alpha=30^{\circ}$ are a result of decreased wake interaction between pins due to a combined effect of flow incidence angle and aspect ratio.

\section{Conclusions}

Multiple row arrays of low aspect ratio pin fins are commonly placed in the internal cooling channels through the trailing edge of turbine airfoils. Pin and endwall heat transfer measurements across multiple row arrays with different flow incidence angles were deduced. The effect of pin aspect ratio on arrays with flow incidence angles was also explored. For each case studied, measurements were made using an infrared thermography technique which allowed for spatially resolved heat transfer coefficients on the endwall to be observed.

Contour plots showed similar augmentation levels between arrays with different flow incidence angles. The heat transfer patterns on the endwall; however, were very different 
between angled and non-angled cases. Arrays with flow incidence angles of $30^{\circ}$ exhibited less wake interaction between pins and provided a direct path for the flow to pass through the array.

Pin heat transfer was measured for two arrays with perpendicular flow and one array with a flow incidence angle of $30^{\circ}$. The pin Nusselt number for each geometry fell within experimental uncertainty which indicated that pin spacing and flow incidence angle had a negligible effect on pin heat transfer.

Endwall heat transfer was measured for a widely spaced array at flow incidence angles of $0^{\circ}, 15^{\circ}$, and $30^{\circ}$. The average endwall Nusselt numbers for all three flow incidence angles fell within experimental uncertainty indicating a negligible flow incidence angle effect. Endwall Nusselt numbers were also measured for a tightly spaced array with flow incidence angles of $0^{\circ}$ and $30^{\circ}$. The average endwall Nusselt numbers for the array with the flow incidence angle of $30^{\circ}$ were noticeably lower than for the array with perpendicular flow. The calculated arrayaverage Nusselt numbers for each geometry illustrated trends similar to those seen on the endwall. The array-average Nusselt numbers for the arrays indicated that flow incidence angle had a larger effect on arrays with tighter pin spacings.

The effects of aspect ratio on arrays with flow incidence angles were also explored. Identically spaced arrays were tested with different flow incidence angles and aspect ratios to explore the independent effects of each. The array-average Nusselt number results indicated that arrays with a low pin aspect ratio were more affected by flow incidence angle than arrays with a large pin aspect ratio. The larger effect at the lower aspect ratio is a result of decreased wake interaction between pins due to a combined effect of flow incidence angle and aspect ratio.

Arranging a triangular array with a flow incidence angle of $30^{\circ}$ produces effects similar to those observed for in-line arrays. The quantitative results from this study combined with the spatially resolved heat transfer patterns observed on the endwall should help turbine airfoil designers understand the heat transfer effects of flow incidence angle. In the event that a pin fin is arranged with an in-line layout due to the flow incidence angle, the pin spacing should be changed to prevent decreased heat transfer. The understanding of the effects presented in this paper leaves room for optimization based on the array geometry and coolant flow conditions such as flow incidence angle. 


\section{Acknowledgements}

The authors would like to acknowledge Pratt \& Whitney for supporting this research. In particular the authors would like to thank Atul Kohli and George Suljak for their technical feedback and support. The authors also thank Mike Barringer for assisting in writing this paper.

\section{References}

Kays, W.M., Crawford, M.E., 1980, “Convective Heat and Mass Transfer," $2^{\text {nd }}$ Edition. New York, New York: McGraw-Hill Book Company, Inc.

Evenko, V.I., and Anisin, A.K., 1976, "Increasing Efficiency of Heat Transfer by Bundles of Tubes in Transverse Flow," Teploenergetika, vol. 23 (7), pp. 37-40.

Metzger, D.E., Fan, C.S., Haley, S.W., 1984, "Effects of Pin Shape and Array Orientation on Heat Transfer and Pressure Loss in Pin Fin Arrays," ASME Journal of Engineering for Gas Turbines and Power, vol. 106, pp. 252-257.

Simoneau, R.J., and VanFossen, G.J., 1984, "Effect of Location in an Array on Heat Transfer to a Short Cylinder in Crossflow," ASME Journal of Heat Transfer, vol. 106, pp. 42-48.

Chyu, M.K., Hsing, Y.C., Shih, T.I.-P., and Natarajan, V., 1998, "Heat Transfer Contributions of Pins and Endwall in Pin-Fin Arrays: Effects of Thermal Boundary Condition Modeling," ASME Paper 98-GT-175.

Hwang, J., and Lui, C., 2001, "Measurement of endwall heat transfer and pressure drop in a pinfin wedge duct," International Journal of Heat and Mass Transfer, vol 45, pp. 877-889.

Brigham, B.A., and VanFossen, G.J., 1984, "Length-to-Diameter Ratio and Row Number Effects in Short Pin Fin Heat Transfer," ASME Journal of Engineering for Gas Turbines and Power, vol. 106, pp. 241-245.

Yeh, J.J., and Chyu, M.K., 1998, “Heat Transfer of Staggered Pin Fin Arrays,” Masters Presentations/Papers and Bennett Poster Competition, Carnegie Mellon University.

Armstrong, J., and Winstanley, D., 1988, "A Review of Staggered Array Pin Fin Heat Transfer for Turbine Cooling Applications,” ASME Journal of Turbomachinery, vol. 110, pp. 94-103.

Lyall, M.E., Thole, K.A., Kohli, A., 2006, "Heat Transfer from Low Aspect Ratio Pin Fins," ASME Turboexpo.

Lyall, M.E., 2006, “Heat Transfer from Low Aspect Ratio Pin Fins,” Master's Thesis, Virginia Tech. 
Moffat, R.J., 1988, "Uncertainty Analysis in the Planning of an Experiment," Journal of Fluids Engineering, vol. 107, pp. 173-181.

Metzger, D.E., Berry, R.A., and Bronson, J.P., 1982, "Developing Heat Transfer in Rectangular Ducts with Staggered Arrays of Short Pin Fins," ASME Journal of Heat Transfer, vol. 104, pp. 700-706.

Ames, F.E., Dvorak, L.A., and Morrow, M.J., 2005, "Turbulent Augmentation of Internal Convection Over Pins in Staggered Pin Fin Arrays," ASME Paper GT2004-53889. 
Table 2.1. Multiple Row Geometries Tested for Flow Incidence Angle Study

\begin{tabular}{|c|c|c|c|c|}
\hline $\mathbf{S 1 / d}$ & S2/d & H/d & $\alpha\left(^{\circ}\right)$ & Pin Layout \\
\hline 2 & 1.73 & 1 & $\mathbf{0}$ & $\longrightarrow: \because \because \because \because:$ \\
\hline 2 & 1.73 & 1 & 30 & $>\quad \because \because \because \because:$ \\
\hline 2 & 1.73 & 0.5 & $\mathbf{0}$ & $\rightarrow 0^{\circ}$ \\
\hline 2 & 1.73 & 0.5 & 30 & $>0_{0}^{0} 0_{0}^{0} 0_{0}^{0} 0_{0}^{0}$ \\
\hline 4 & 3.46 & 1 & 0 & $\because \circ$ \\
\hline 4 & 3.46 & 1 & 15 & $\rightarrow 0^{\circ} 0^{\circ}$ \\
\hline 4 & 3.46 & 1 & 30 & $\nearrow$ \\
\hline
\end{tabular}

Table 2.2. Correlations from Present Study

\begin{tabular}{|c|c|c|c|c|c|c|c|c|c|}
\hline \multicolumn{10}{|c|}{$\overline{\mathbf{N u}}_{\mathbf{d}}=\mathbf{a R e}_{\mathbf{d}}{ }^{\mathbf{b}}$} \\
\hline S1/d & S2/d & H/d & Angle (a) & $\mathbf{a}$ & $\mathbf{b}$ & $\mathbf{a}$ & $\mathbf{b}$ & $\mathbf{a}$ & $\mathbf{b}$ \\
\hline 2 & 1.73 & 1 & 0 & 0.387 & 0.576 & 0.111 & 0.665 & 0.195 & 0.623 \\
\hline 2 & 1.73 & 1 & 30 & 0.430 & 0.564 & 0.050 & 0.736 & 0.142 & 0.650 \\
\hline 4 & 3.46 & 1 & 0 & 0.495 & 0.552 & 0.119 & 0.649 & 0.149 & 0.632 \\
\hline 4 & 3.46 & 1 & 15 & 0.430 & 0.564 & 0.133 & 0.638 & 0.1592 & 0.6254 \\
\hline 4 & 3.46 & 1 & 30 & 0.427 & 0.563 & 0.092 & 0.673 & 0.118 & 0.654 \\
\hline 2 & 1.73 & 0.5 & 0 & 0.430 & 0.564 & 0.086 & 0.700 & 0.134 & 0.662 \\
\hline 2 & 1.73 & 0.5 & 30 & 0.430 & 0.564 & 0.049 & 0.737 & 0.096 & 0.682 \\
\hline
\end{tabular}




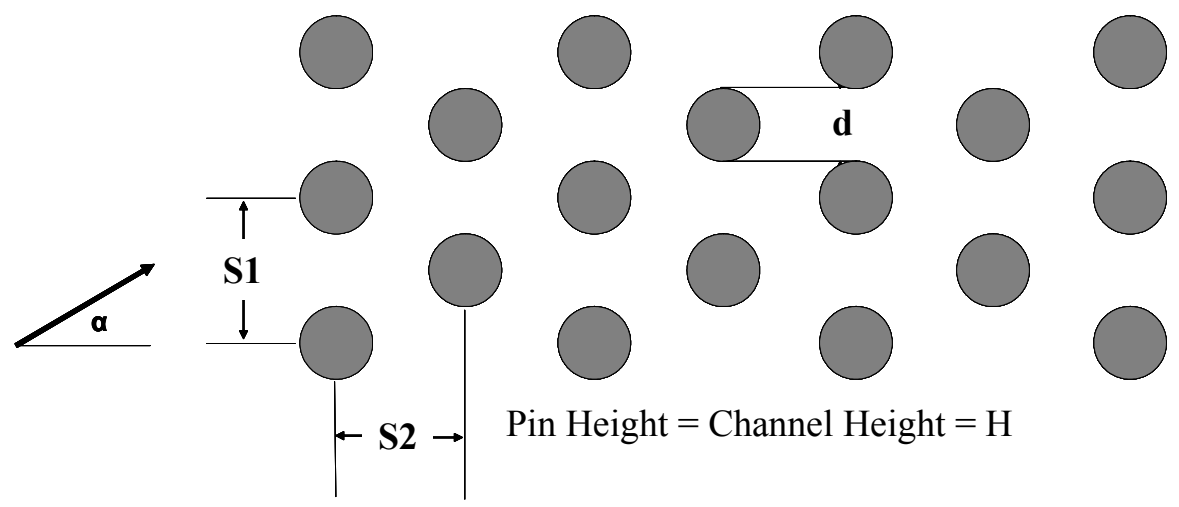

Figure 2.1. Schematic illustrating the spacing definitions of a pin fin array with flow incidence angle, $\alpha$.

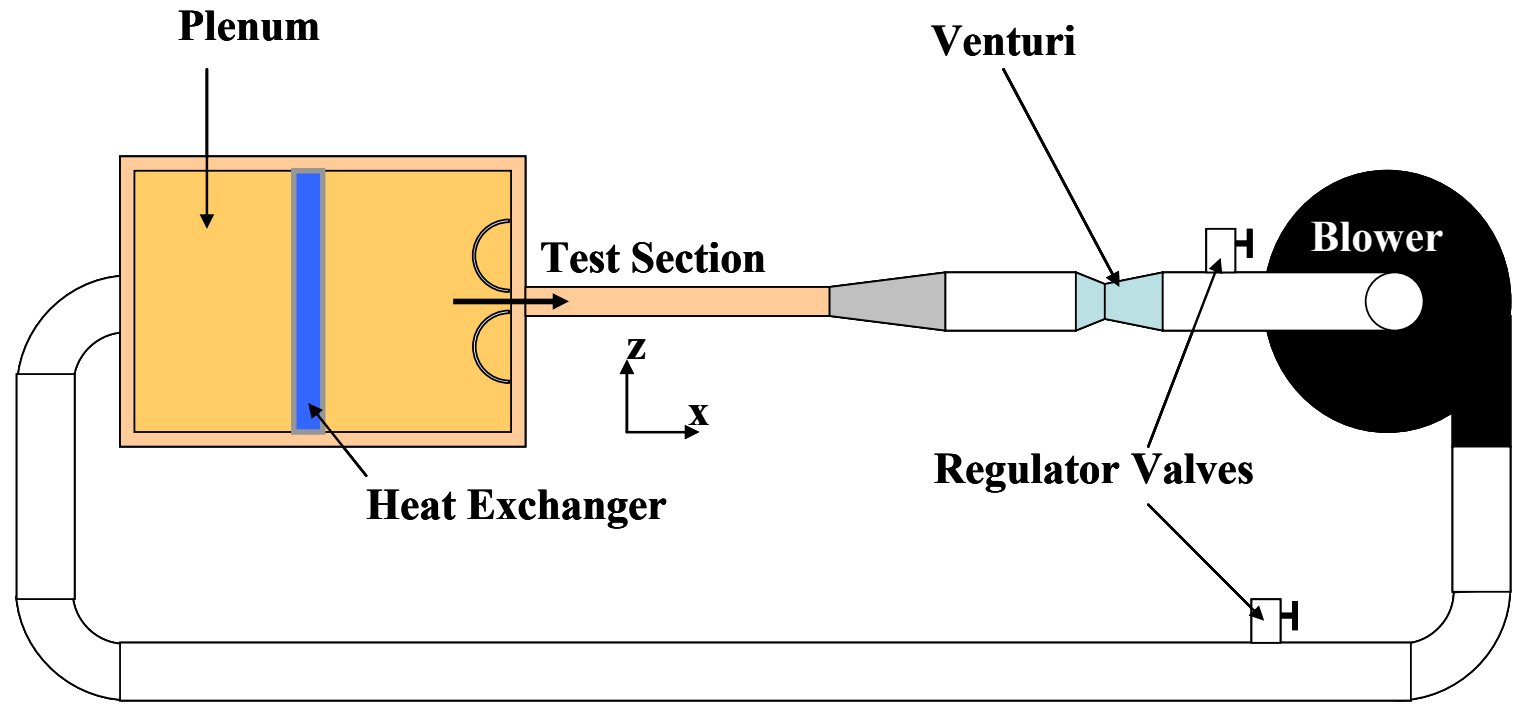

Figure 2.2 Schematic of the closed loop test facility used for pin fin array testing. 


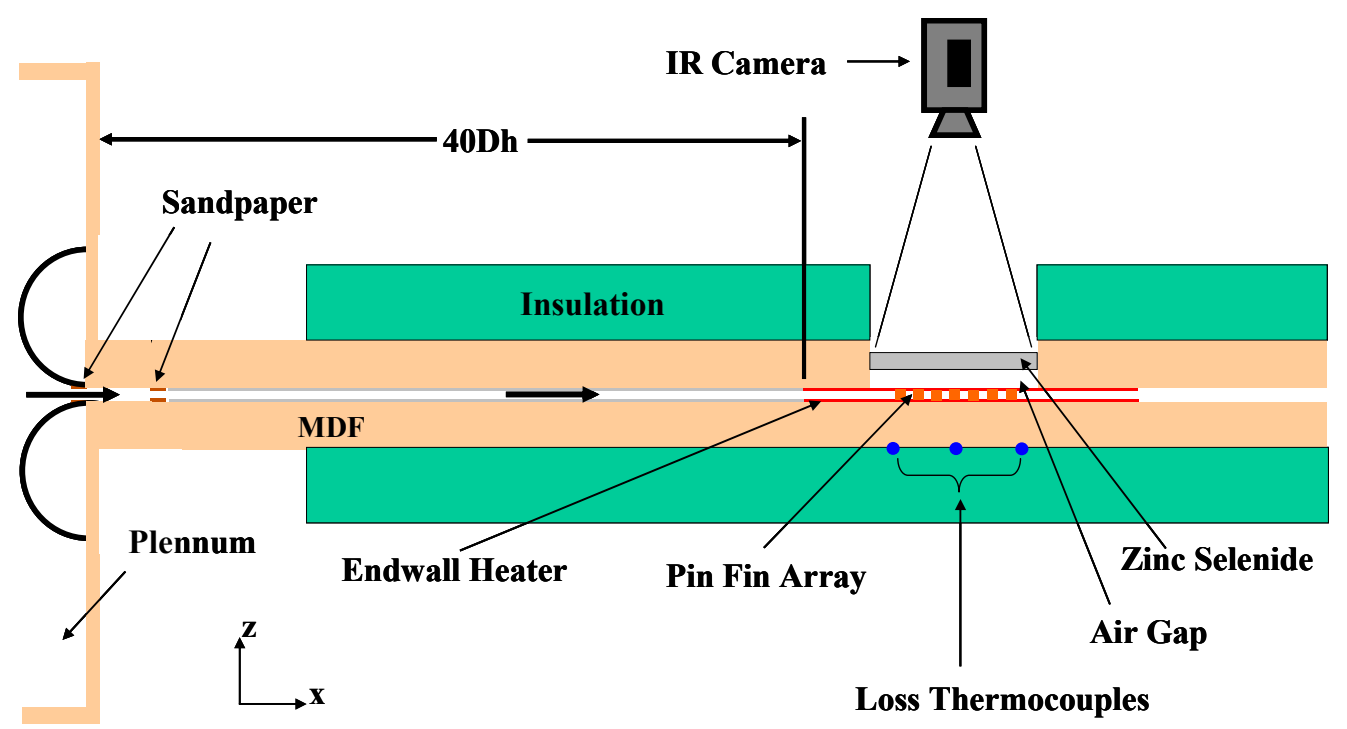

Figure 2.3. Schematic of the test section used for pin fin array testing.

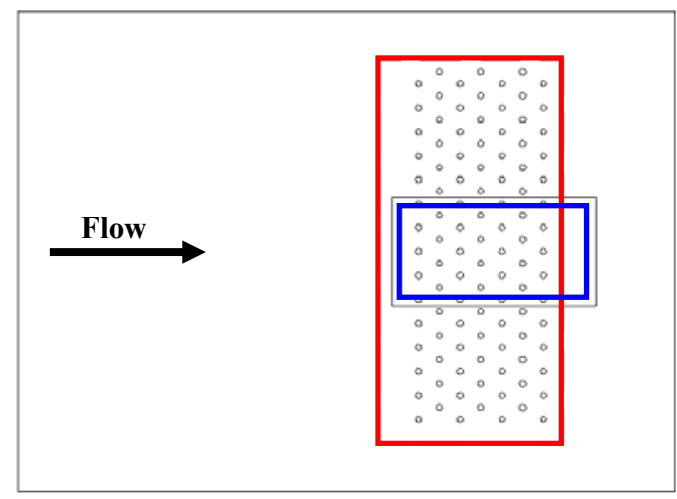

a) $\alpha=0^{\circ}$

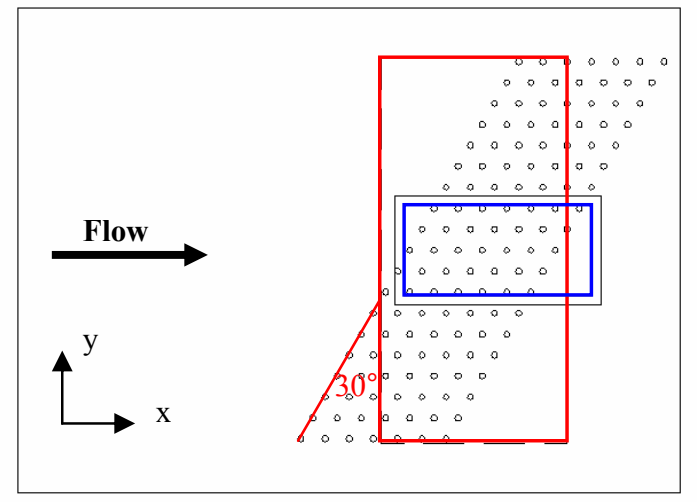

b) $\alpha=30^{\circ}$

Figure 2.4. Schematics showing an $S 1 / d=4, S 2 / d=3.46$ array at angles of a) $\alpha=0^{\circ}$ and b) $\alpha=30^{\circ}$. 


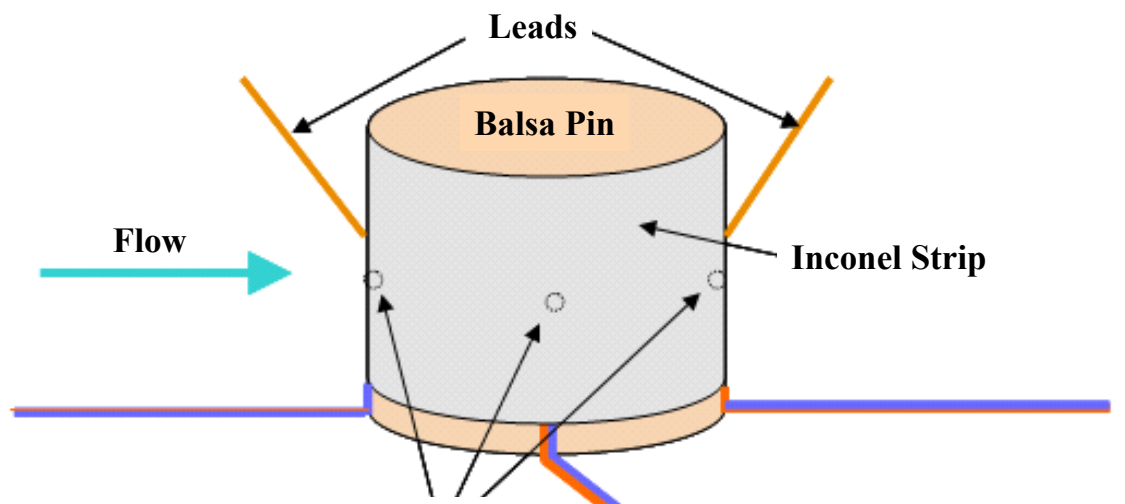

Thermocouples Behind Inconel

Figure 2.5. Schematic of an instrumented pin fin used for pin heat transfer tests.
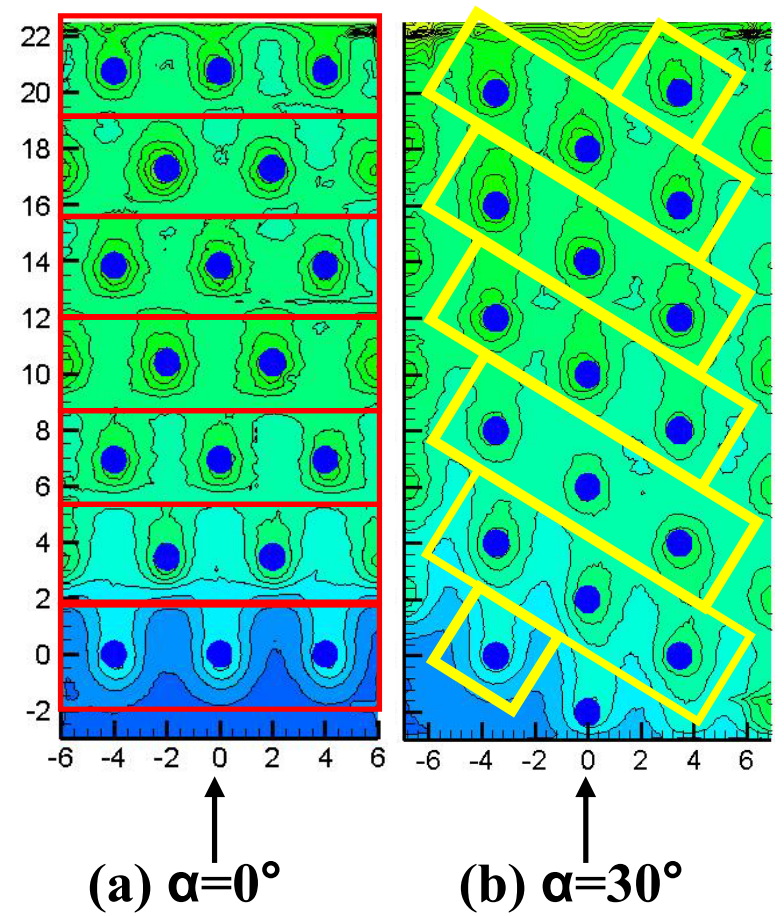

Figure 2.6. Row-by-row average areas shown on the augmentation contour plots for $S 1 / d=4$ arrays at $(a) \alpha=0^{\circ}$ (b) $\alpha=30^{\circ}$. 

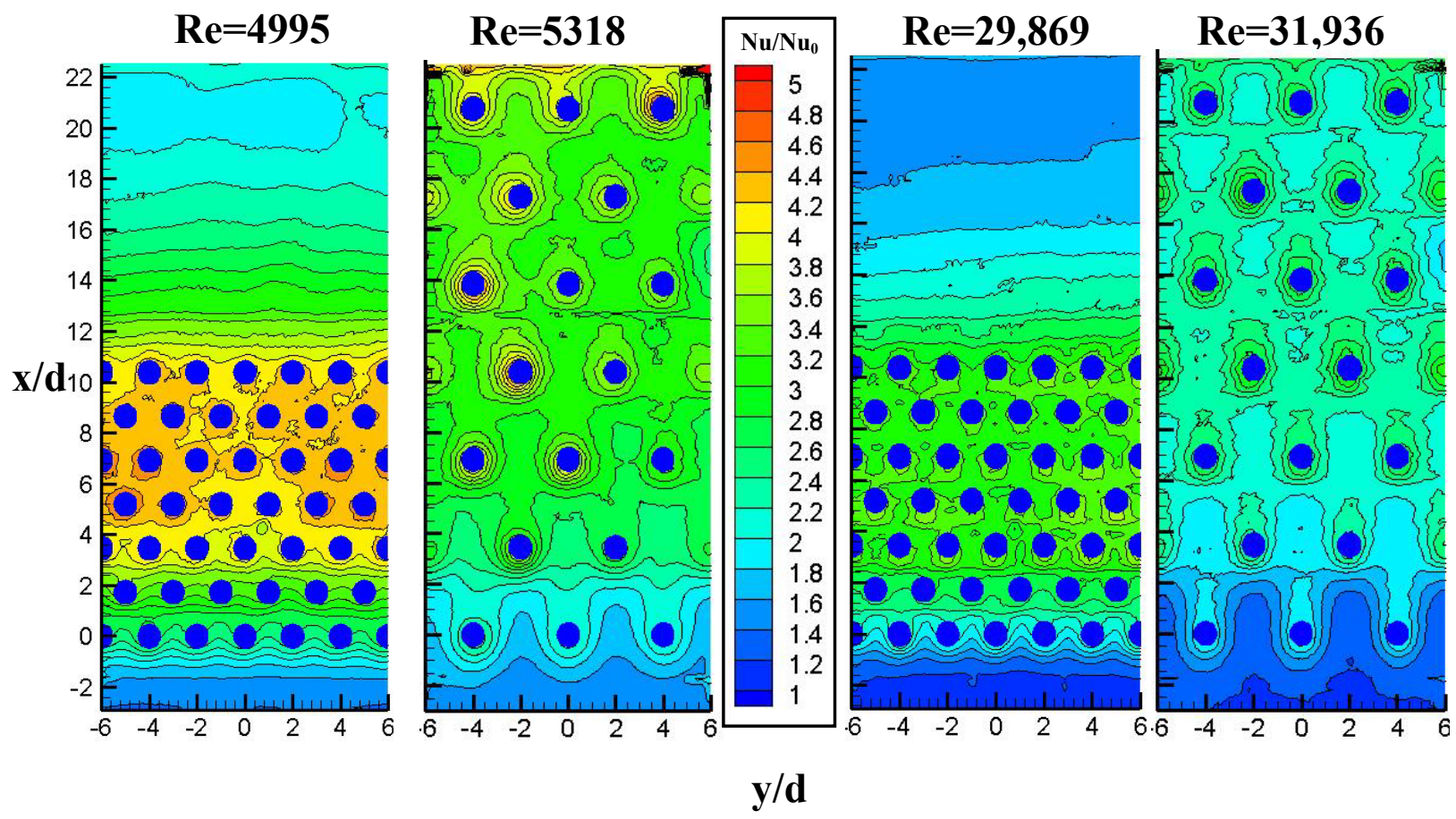

Figure 2.7. Nusselt number augmentation contour plots for the $S 1 / d=2, S 2 / d=1.73$ and $\mathrm{S} 1 / \mathrm{d}=4, \mathrm{~S} 2 / \mathrm{d}=3.46$ arrays having $\mathrm{H} / \mathrm{d}=1$.

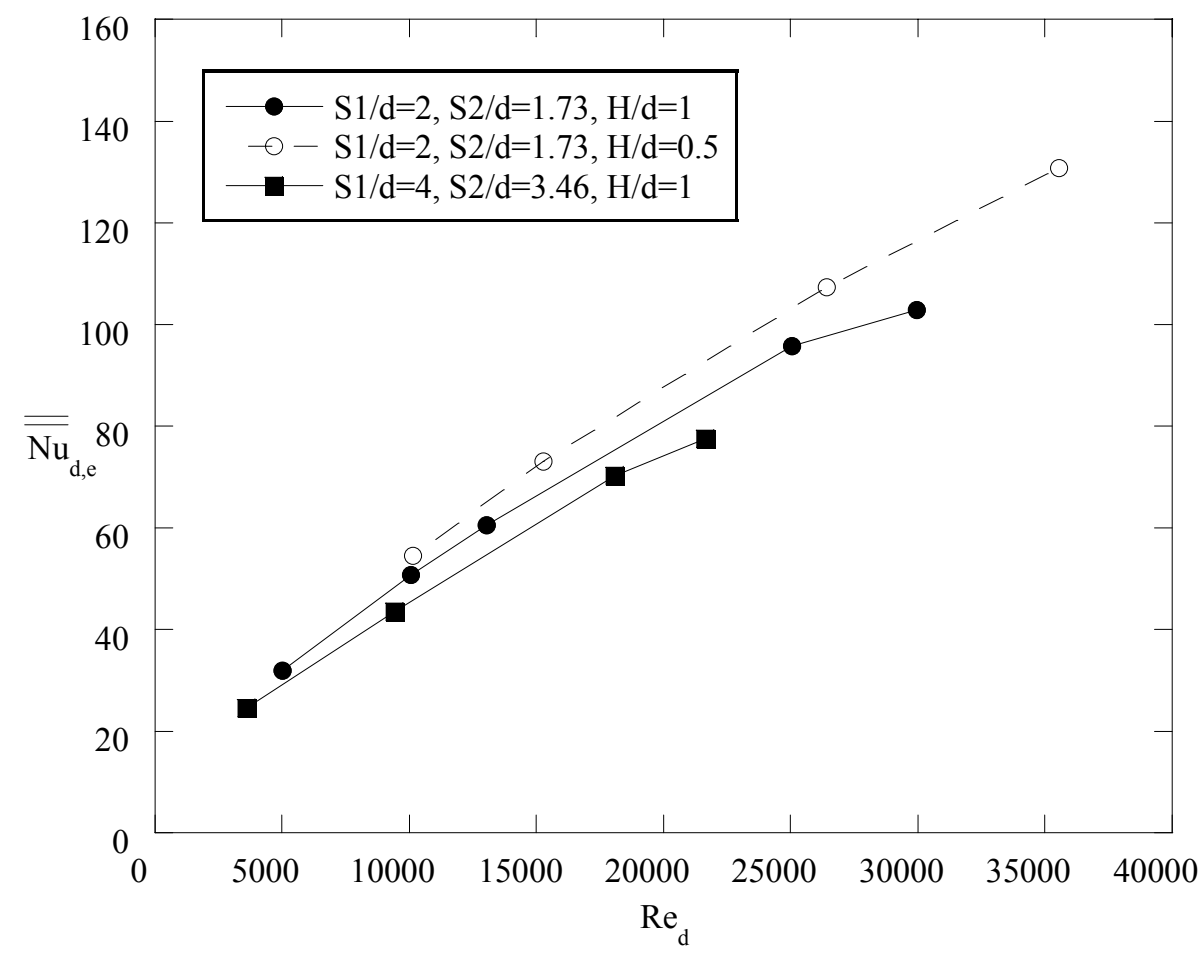

Figure 2.8. Average endwall Nusselt numbers for the $S 1 / d=2, S 2 / d=1.73$ arrays with $H / d=0.5$ and $H / d=1$ along with the $S 1 / d=4, S 2 / d=3.46$ array with $H / d=1$. 


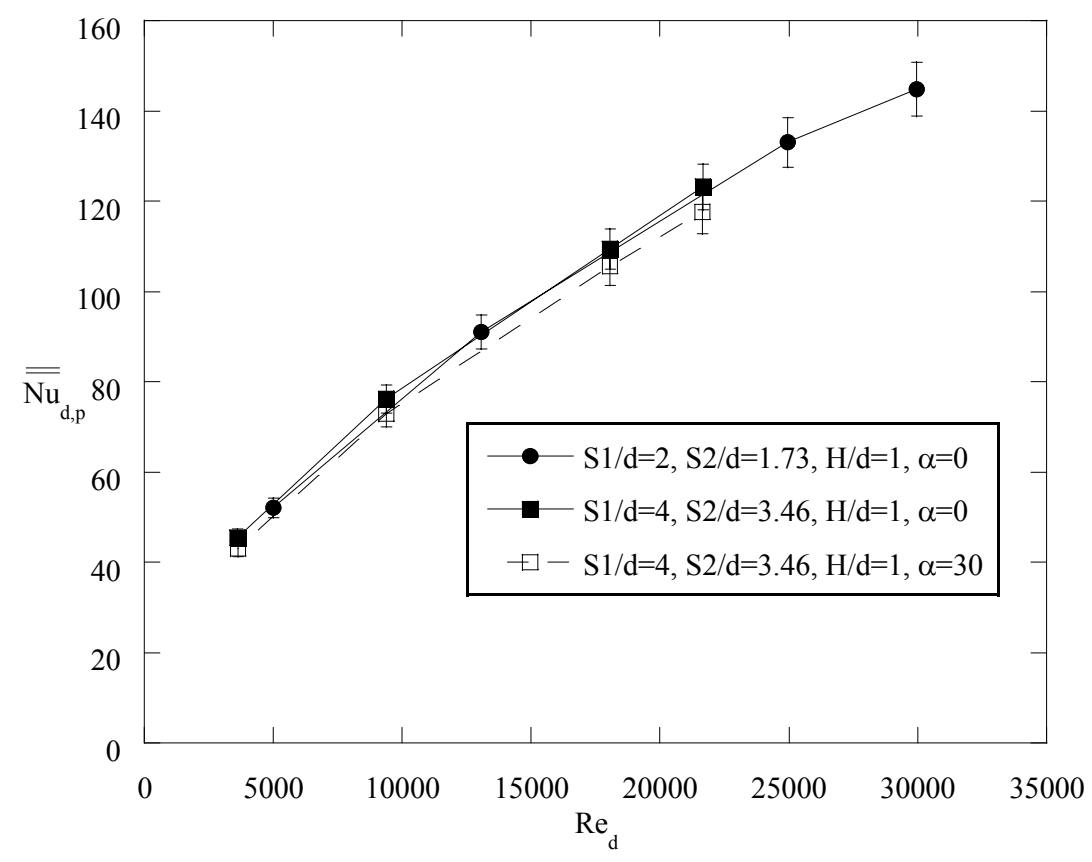

Figure 2.9. Average pin Nusselt numbers for the $S 1 / d=2, S 2 / d=1.73, H / d=1, \alpha=0^{\circ}$, the $S 1 / d=4, S 2 / d=3.46, H / d=1, \alpha=0^{\circ}$, and the $S 1 / d=4, S 2 / d=3.46, H / d=1, \alpha=30^{\circ}$ geometries.

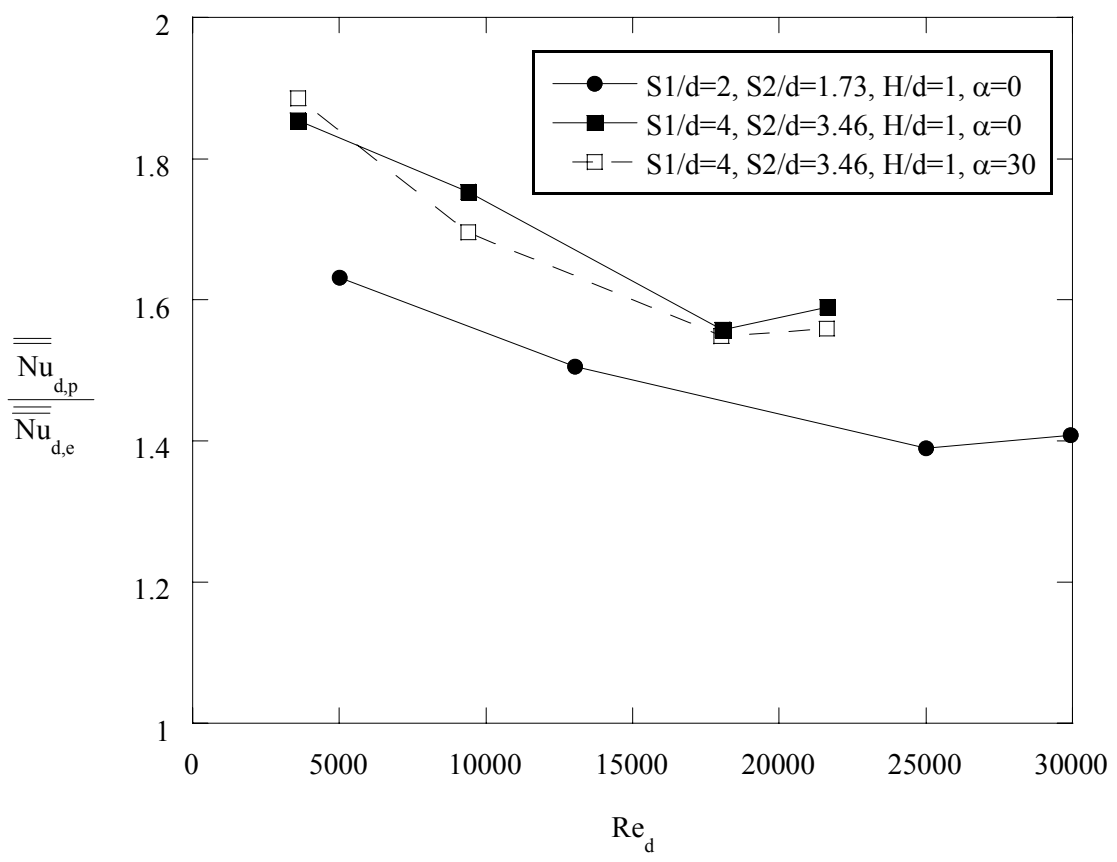

Figure 2.10. Pin-to-endwall Nusselt number ratio for the $S 1 / d=2, S 2 / d=1.73, \alpha=0^{\circ}$, the $S 1 / d=4, S 2 / d=3.46, \alpha=0^{\circ}$, and the $S 1 / d=4, S 2 / d=3.46, \alpha=30^{\circ}$ geometries all having $\mathrm{H} / \mathrm{d}=1$. 


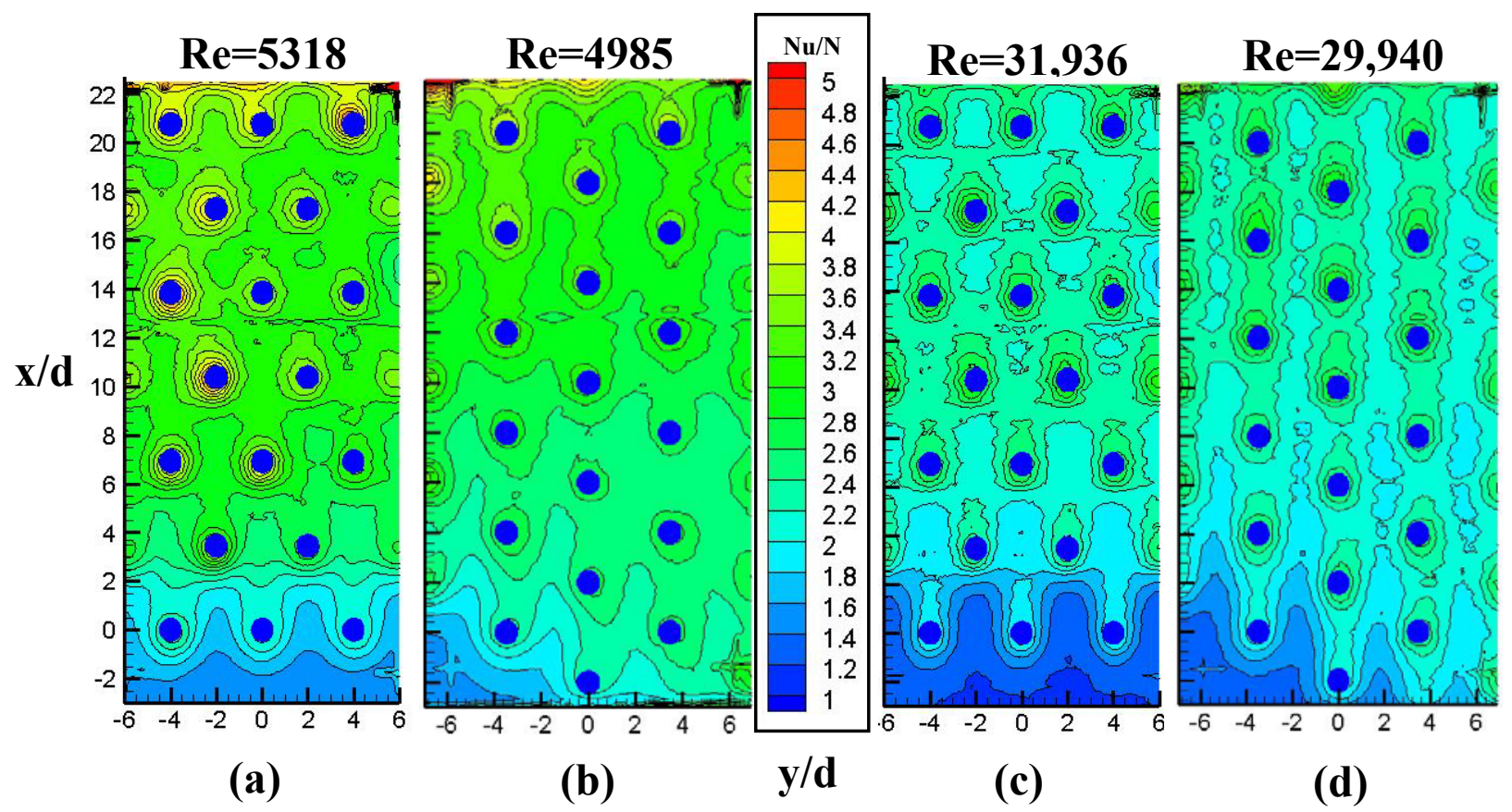

Figure 2.11. Augmentation contour plots for $S 1 / d=4$ arrays at (a) $\alpha=0^{\circ}, R e=5318$ (b) $\alpha=30^{\circ}, \operatorname{Re}=4985$ (c) $\alpha=0^{\circ}, \operatorname{Re}=31,936$, (d) $\alpha=30^{\circ}, \operatorname{Re}=29,940$.

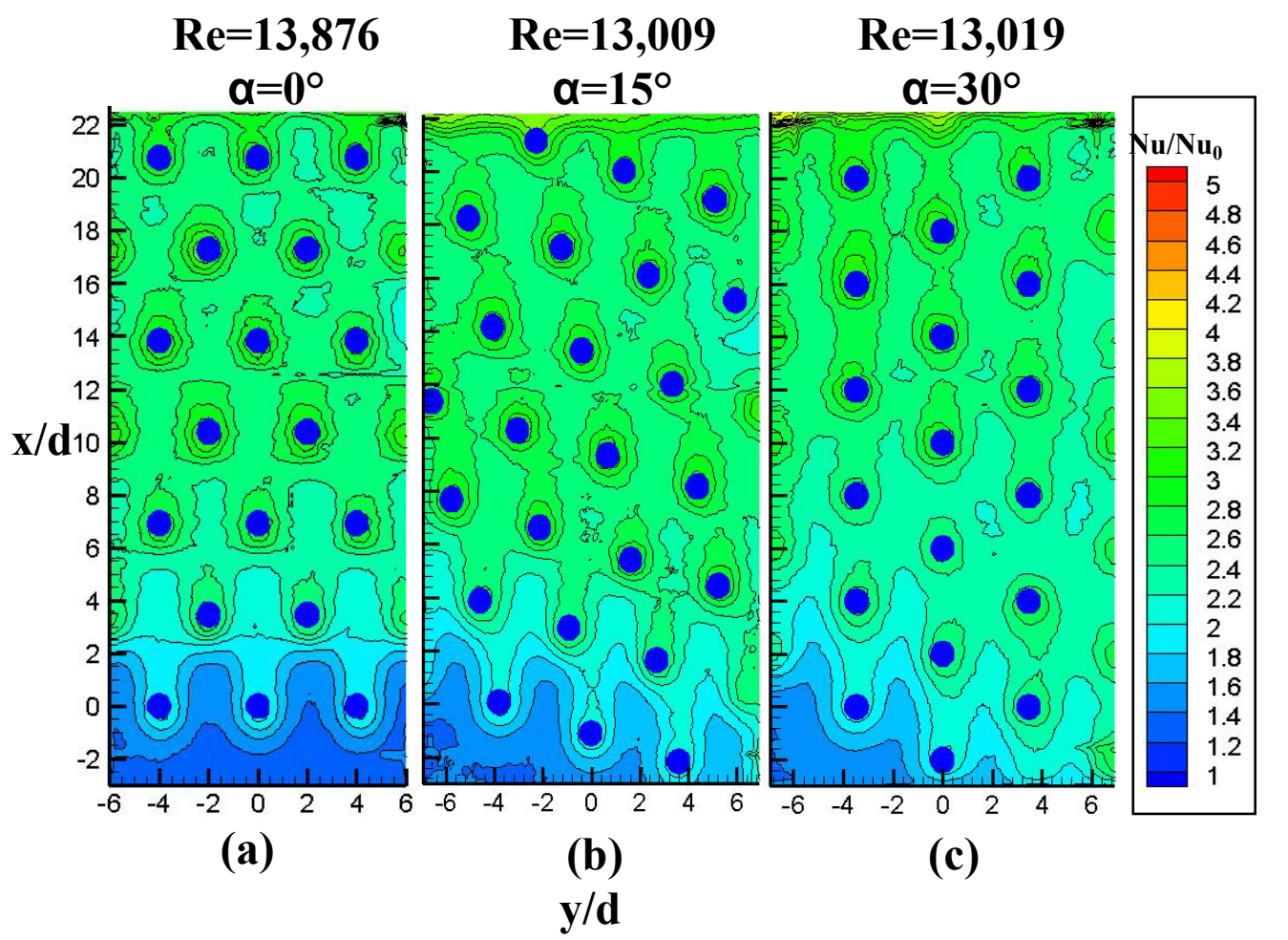

Figure 2.12. Augmentation contour plots for $S 1 / d=4, S 2 / d=3.46$ arrays at (a) $\alpha=0^{\circ}$, $\operatorname{Re}=13,876$ (b) $\alpha=15^{\circ}, \operatorname{Re}=13,009$, (c) $\alpha=30^{\circ}, \operatorname{Re}=13,019$. 


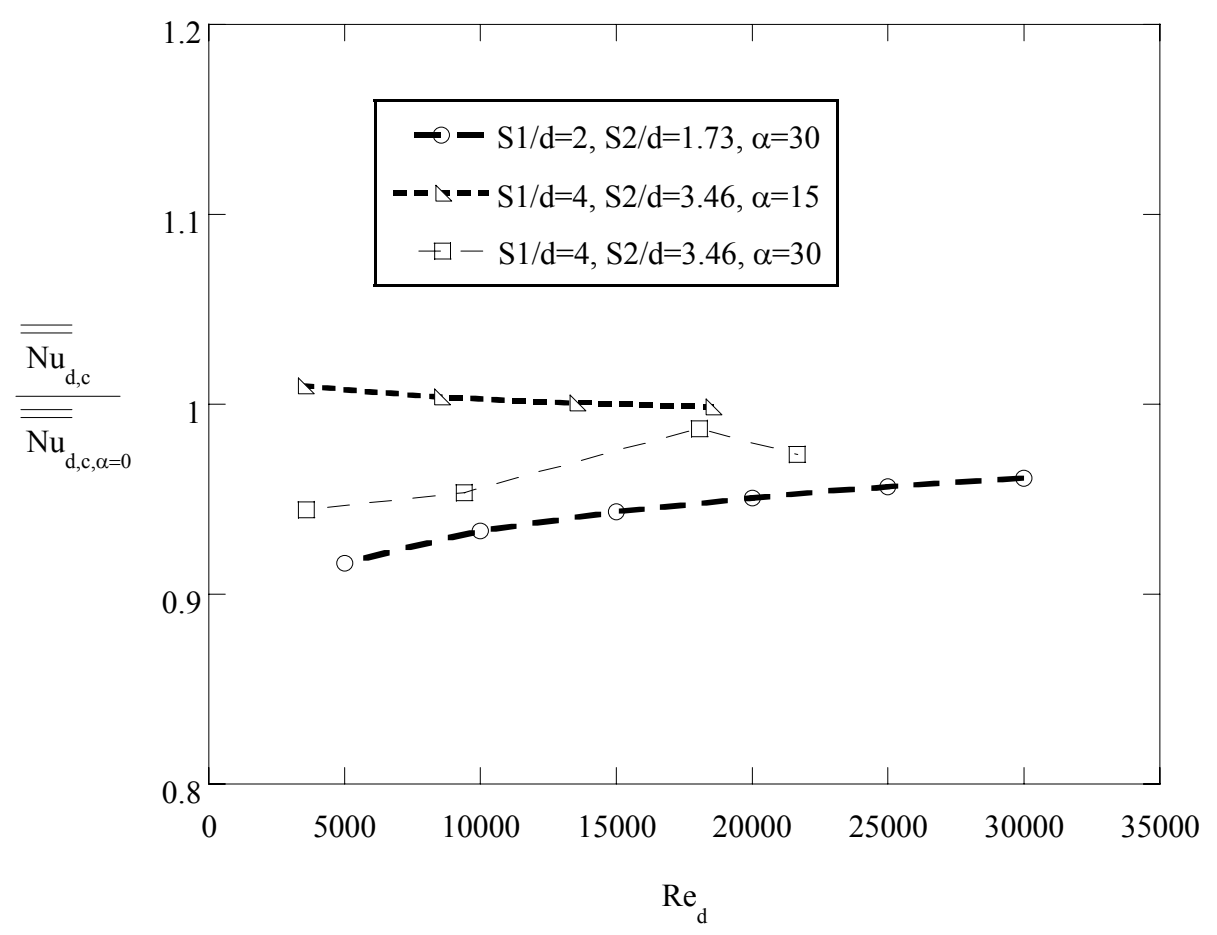

Figure 2.13. Array-average incidence angle effectiveness ratios for the $S 1 / d=2$, $S 2 / d=1.73, \alpha=30^{\circ}$ array as well as the $S 1 / d=4, S 2 / d=3.46, \alpha=15^{\circ}$, and $\alpha=30^{\circ}$ arrays.

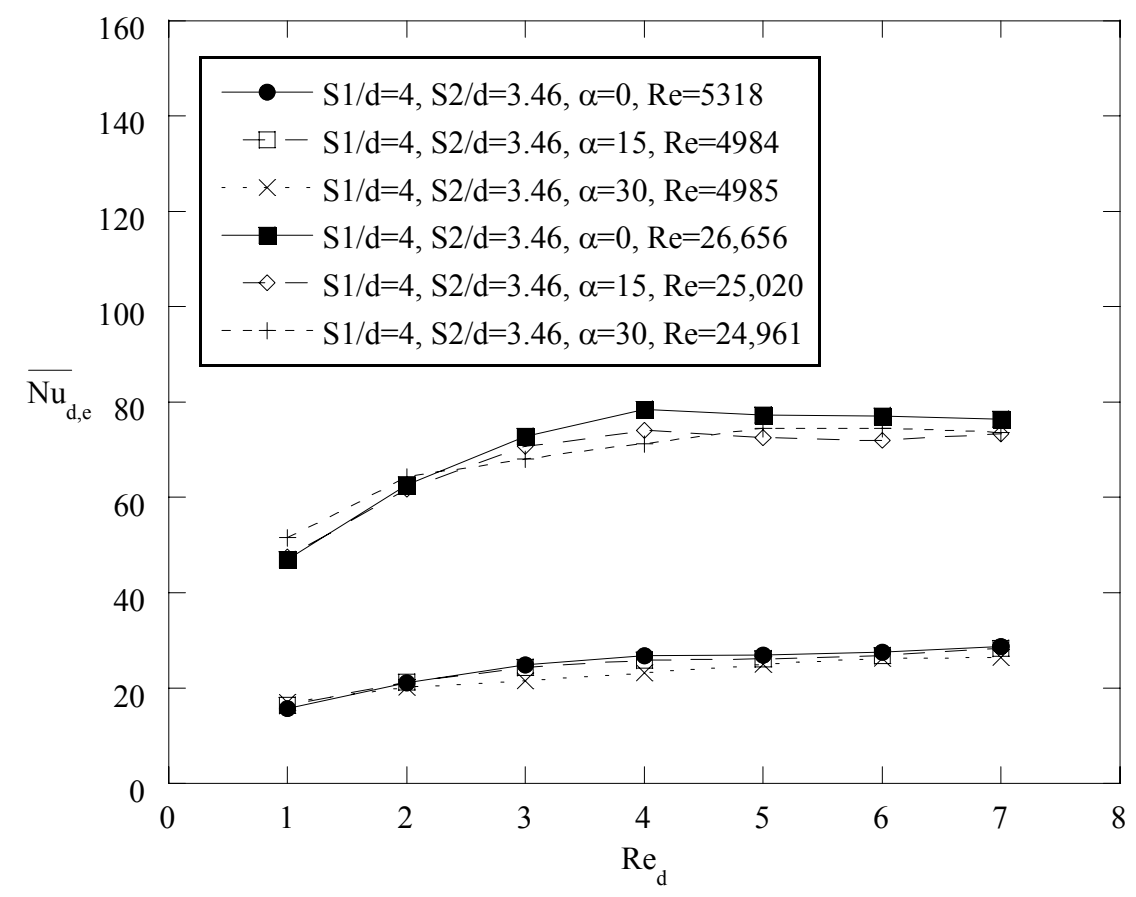

Figure 2.14. Row-resolved endwall Nusselt numbers for $\mathrm{S} 1 / \mathrm{d}=4, \mathrm{~S} 2 / \mathrm{d}=3.46, \mathrm{H} / \mathrm{d}=1$ arrays at $\alpha=0^{\circ}, 15^{\circ}$, and $30^{\circ}$. 


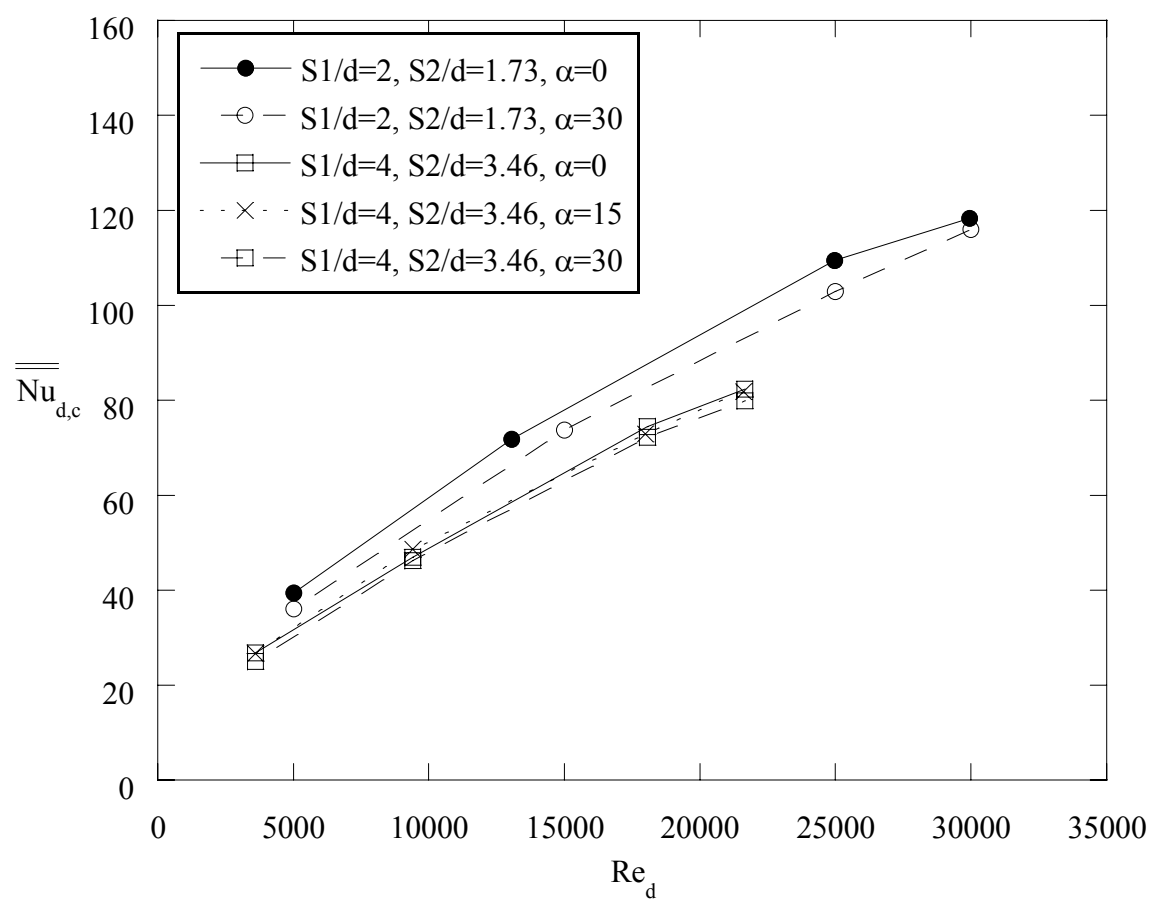

Figure 2.15. Array-average Nusselt numbers for $S 1 / d=2, S 2 / d=1.73, H / d=1, \alpha=0^{\circ}$ and $30^{\circ}$ arrays along with $\mathrm{S} 1 / \mathrm{d}=4, \mathrm{~S} 2 / \mathrm{d}=3.46, \mathrm{H} / \mathrm{d}=1, \alpha=0^{\circ}, 15^{\circ}$ and $30^{\circ}$ arrays.

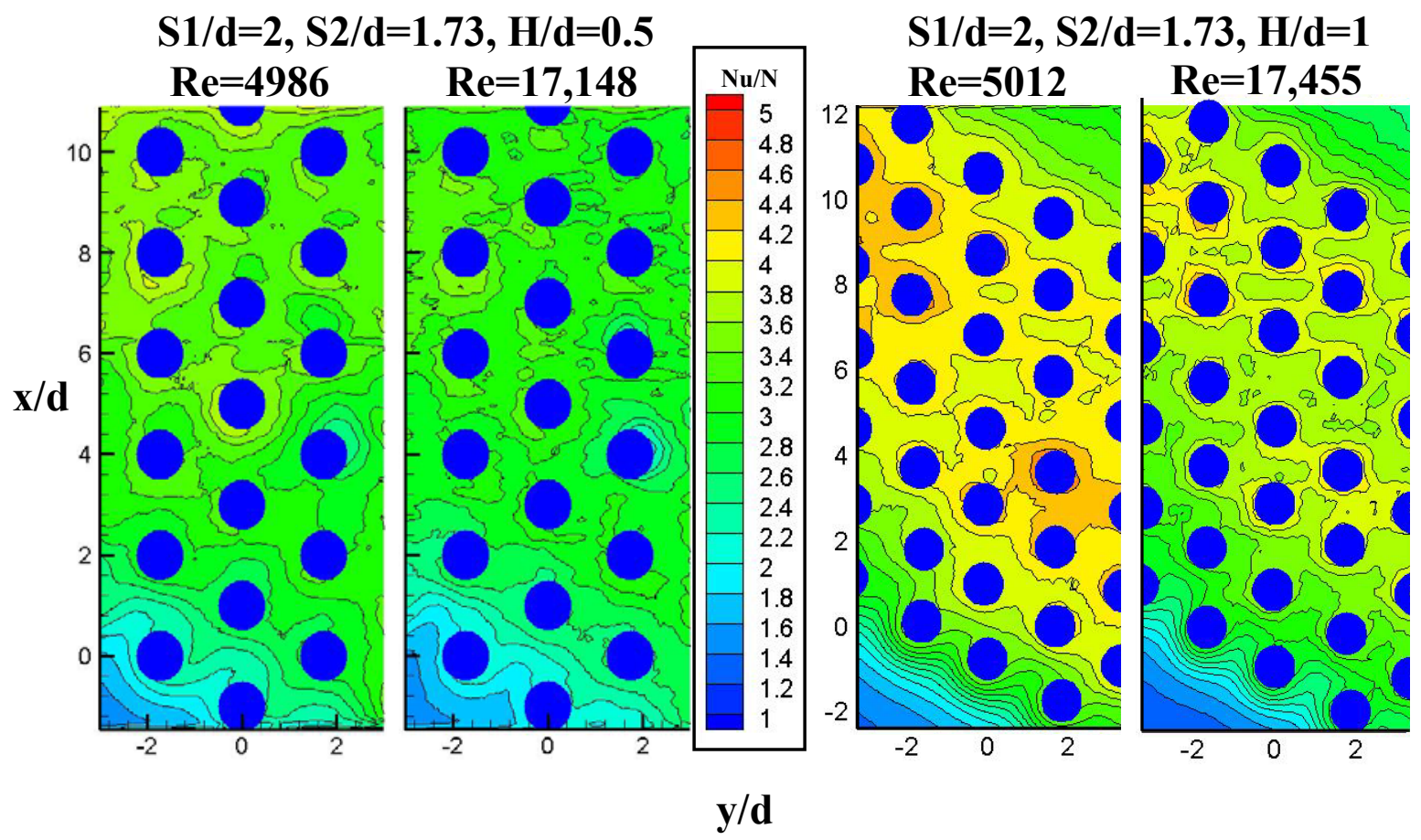

Figure 2.16. Endwall Nusselt number augmentation contour plots for the $S 1 / d=2$, $\mathrm{S} 2 / \mathrm{d}=1.73, \mathrm{H} / \mathrm{d}=0.5$ and $\mathrm{H} / \mathrm{d}=1$ arrays at a flow incidence angle of $\alpha=30^{\circ}$. 


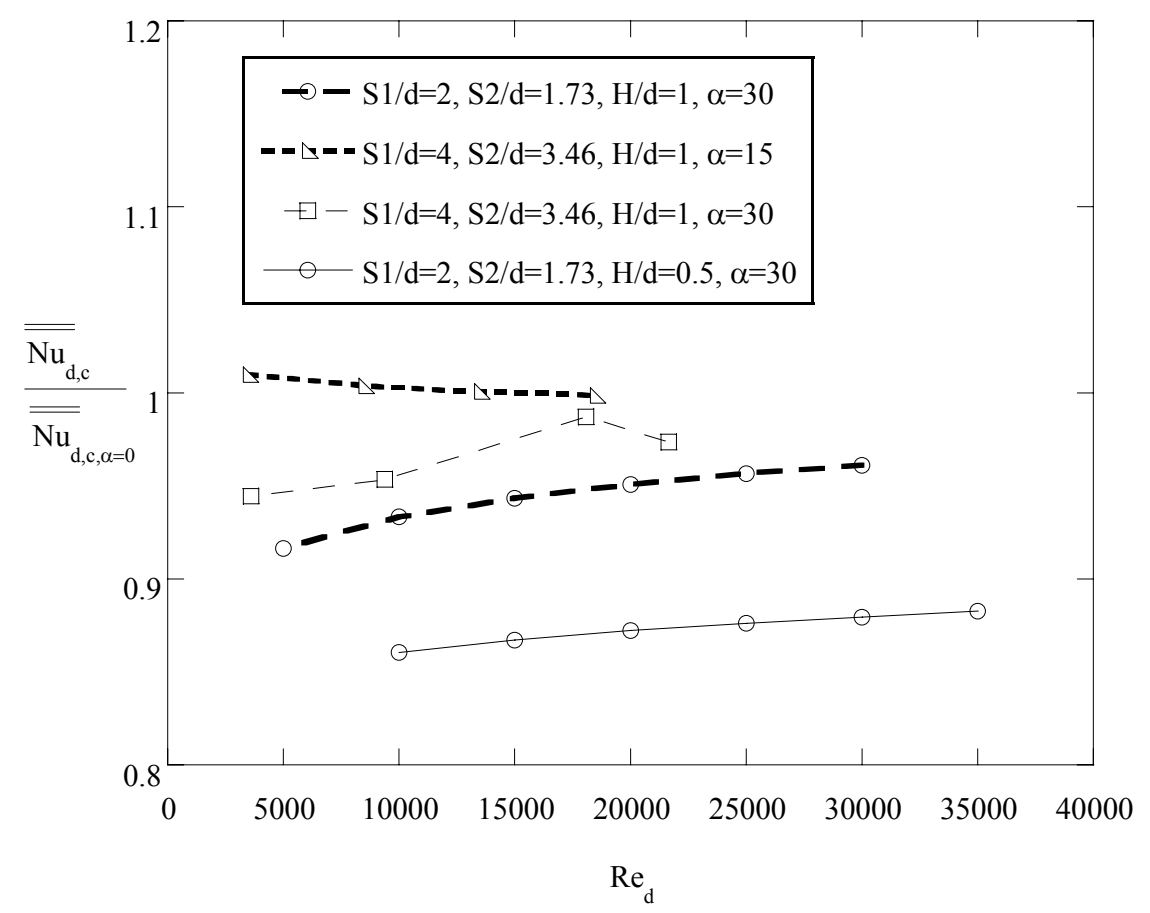

Figure 2.17. Array-average incidence angle effectiveness ratios for all studied cases with flow incidence angles.

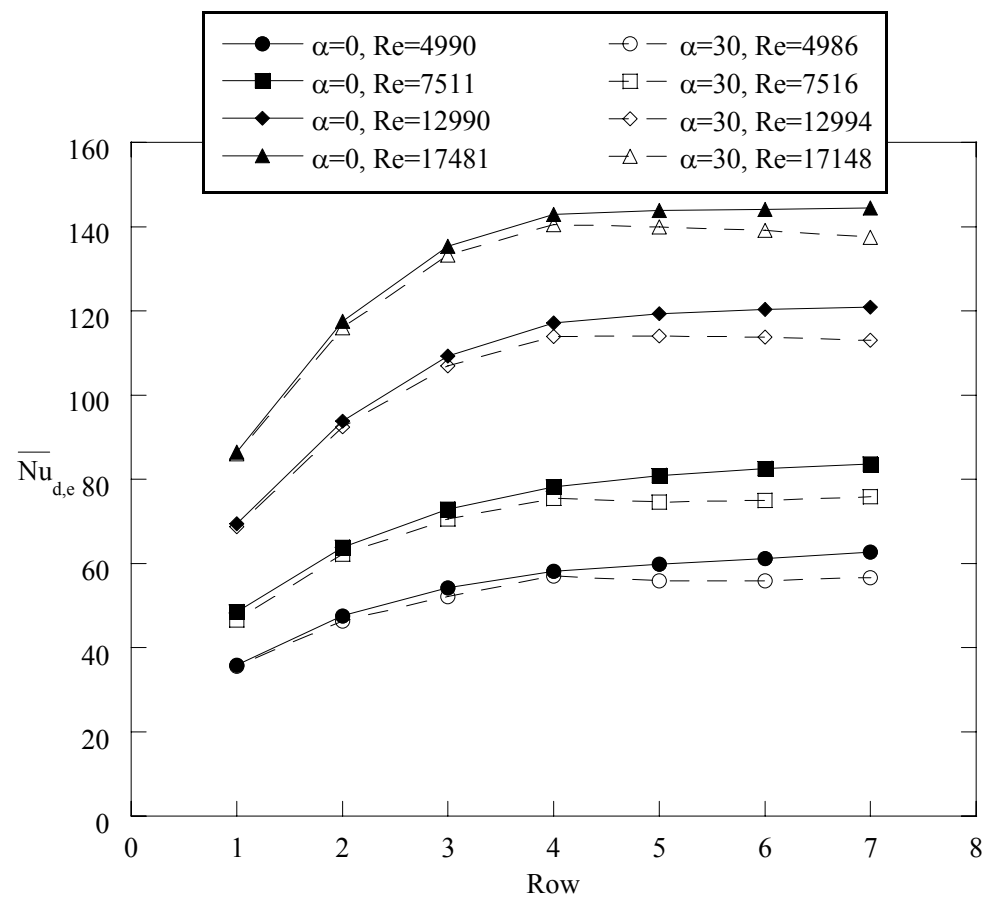

Figure 2.18. Row-resolved Endwall Nusselt numbers through the $S 1 / d=2, S 2 / d=1.73$, $\mathrm{H} / \mathrm{d}=0.5$ array at flow incidence angles of $\alpha=0^{\circ}$ and $\alpha=30^{\circ}$. 


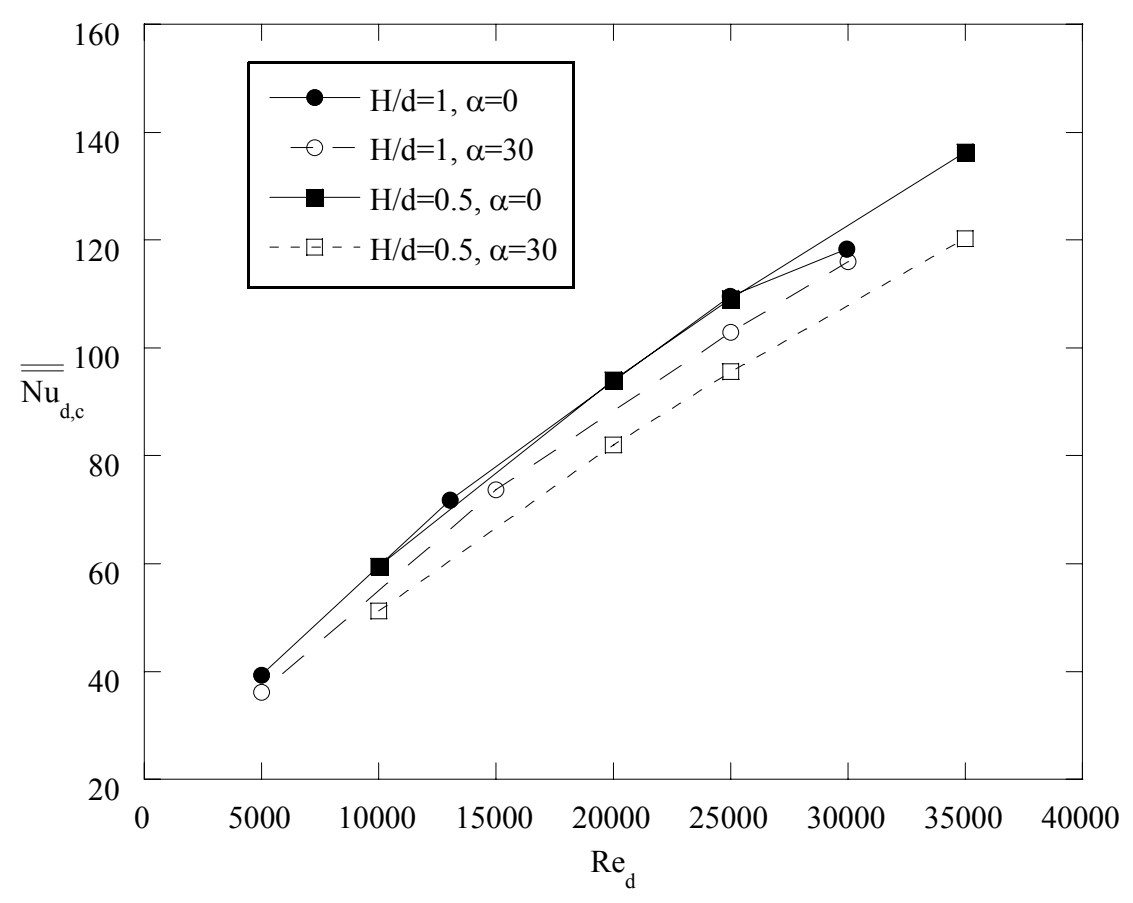

Figure 2.19. Array-average Nusselt number with respect to Reynolds number for the $\mathrm{S} 1 / \mathrm{d}=2, \mathrm{~S} 2 / \mathrm{d}=1.73, \alpha=0^{\circ}$ and $\alpha=30^{\circ}$ arrays at aspect ratios of $\mathrm{H} / \mathrm{d}=0.5$ and $\mathrm{H} / \mathrm{d}=1$. 


\section{Conclusions and Summary}

A test facility was constructed to conduct experiments on scaled up models of pin fin arrays for turbine blade cooling applications. Low aspect ratio arrays of pin fins are commonly placed in the internal cooling channels through the trailing edge of turbine blades. Pin and endwall Nusselt numbers were measured to test the array heat transfer effects of pin spacing, pin aspect ratio, and flow incidence angle. An infrared thermography technique was used to measure spatially resolved heat transfer patterns on the endwalls of the pin fin arrays. Instrumented pin fins were used to make discrete thermocouple measurements to deduce Nusselt numbers around the circumference of pin fins placed in an array of interest.

Pin Nusselt numbers were measured for three separate arrays with different pin spacings and flow incidence angles. The average pin Nusselt numbers for the three arrays tested were all within experimental uncertainty of one another indicating that average pin Nusselt number is more dependent on Reynolds number than pin spacing or flow incidence angle. A correlation to predict average pin Nusselt number based on array Reynolds number was developed from the results obtained.

Endwall Nusselt numbers were measured for nine different seven row arrays to test the independent effects of spanwise spacing, streamwise spacing, aspect ratio, and flow incidence angle. The results indicated that the endwall Nusselt number was affected by both streamwise and spanwise spacing with a higher dependence on streamwise spacing. The Nusselt number development through an array was dependent on the relationship between streamwise and spanwise spacing. Nusselt number reached a higher fully developed value farther downstream in the array when the ratio of streamwise to spanwise spacing was less than one. Arrays with the identical pin spacings were tested at pin aspect ratios of $\mathrm{H} / \mathrm{d}=0.5$ and $\mathrm{H} / \mathrm{d}=1$. The results indicated that endwall Nusselt number augmentation decreased slightly with a decrease in aspect ratio. When plotted against array Reynolds number $\left(\mathrm{Re}_{\mathrm{d}}\right)$, which uses the maximum array velocity as the velocity scale, the endwall Nusselt number was higher at the lower aspect ratio implying that the effect of changing aspect ratio did not scale with the maximum velocity. These conclusions lead to the recommendation that local turbulence measurements should be made to determine the difference in the driving mechanism behind convection between different pin aspect ratios.

Endwall Nusselt numbers were also measured for arrays with different flow incidence angles $(\alpha)$. The results showed that endwall Nusselt number was very similar for identically spaced arrays arranged at different flow incidence angles. The spatially resolved heat transfer patterns for arrays with various flow incidence angles were very different. When triangularly spaced arrays were arranged at a $30^{\circ}$ angle, they took a form similar to an in-line array providing less flow blockage through the channel. The heat transfer patterns on the endwall showed very little augmentation between pin columns indicating decreased pin wake interaction through the in-line $\left(\alpha=30^{\circ}\right)$ array. The $\alpha=30^{\circ}$ arrangement yielded slightly lower endwall Nusselt numbers than the arrays with perpendicular flow. The flow incidence angle effect on array-average Nusselt number was larger for arrays with wider pin spacings. One array was tested at flow incidence angles of $0^{\circ}, 15^{\circ}$, and $30^{\circ}$ to observe the effect of setting an intermediate flow incidence angle; however, the results from all three flow incidence angles were within experimental uncertainty of one another.

The heat transfer effect of pin aspect ratio on arrays with flow incidence angles was also tested. Arrays with the same spanwise and streamwise spacings were tested at flow incidence 
angles of $0^{\circ}$ and $30^{\circ}$ and aspect ratios of $\mathrm{H} / \mathrm{d}=0.5$ and $\mathrm{H} / \mathrm{d}=1$. The results showed that the effect of flow incidence angle was larger at $\mathrm{H} / \mathrm{d}=0.5$ than at $\mathrm{H} / \mathrm{d}=1$. The larger effect of flow incidence angle at the low aspect ratio was a result of decreased wake interaction between pins caused by decreased aspect ratio and in-line flow incidence angle.

Pin-to-endwall Nusselt number ratios were also observed for arrays with different spacings and flow incidence angles. The ratio was dependent on Reynolds number and pin spacing with little-to-no dependence on flow incidence angle. The ratio ranged from 1.4 at the highest Reynolds number and lowest pin spacing tested to 1.85 at the lowest Reynolds number and highest pin spacing tested.

Correlations were developed to predict average endwall, average pin, and array-average Nusselt numbers and are shown in Table 1.4 and Table 2.2. A correlation was also developed to predict array-average Nusselt numbers based on spanwise spacing, streamwise spacing and Reynolds number and was shown by Equation 1.3.

The results from the experiments conducted for this project along with the results from the literature have provided a great understanding of the effects that different array geometries have on pin and endwall heat transfer. Turbine designers will be able to use the quantitative results from these experiments combined with the heat transfer patterns observed in the endwall contour plots to build a better design tool for trailing edge internal cooling of turbine blades. The spatially resolved heat transfer results illustrate the pin wake behavior on the endwall that would not otherwise be observed.

Limited work has been completed to explore the local effects that turbulence has in arrays with different pin spacings, aspect ratios, and angles relative to the coolant flow. Measurement techniques have also been limited by the scale of the experimental models tested. I recommend testing different array geometries for internal cooling at a larger scale to allow for more detailed analysis of local cooling effects on the pin and endwall surfaces. Local turbulence measurements should be made to explore the driving mechanism behind convection for different pin fin array configurations. 


\section{Appendix A: Uncertainty Analysis}

This appendix is devoted to explaining the calculations involved in the uncertainty analysis for the present study. The methods used were those described by Moffat [1988]. Calculation procedures for the duct Reynolds number $(\mathrm{Re})$, the Nusselt number $\left(\mathrm{Nu}_{\mathrm{d}, \mathrm{p}}\right)$, arrayaverage Nusselt number $\left(\mathrm{Nu}_{\mathrm{d}, \mathrm{c}}\right)$, duct Nusselt number $(\mathrm{Nu})$, and duct Nusselt number augmentation $\left(\mathrm{Nu} / \mathrm{Nu}_{0}\right)$ are described below.

\section{Nomenclature}

\begin{tabular}{|c|c|}
\hline A & area \\
\hline $\mathrm{C}_{\mathrm{p}}$ & specific heat \\
\hline d & pin diameter \\
\hline $\mathrm{D}_{\mathrm{h}}$ & unobstructed duct hydraulic diameter \\
\hline $\mathrm{dP}$ & pressure drop across venturi flowmeter \\
\hline $\mathrm{h}$ & heat transfer coefficient which uses bulk fluid temperature as reference \\
\hline $\mathrm{H}$ & channel and pin fin height \\
\hline $\mathrm{k}$ & thermal conductivity \\
\hline $\mathrm{K}$ & venturi flow coefficient \\
\hline $\mathrm{L}$ & length \\
\hline $\mathrm{m}$ & mass flow rate \\
\hline $\mathrm{N}$ & the number of a quantity \\
\hline $\mathrm{Nu}$ & duct Nusselt number based on $\mathrm{D}_{\mathrm{h}}, \mathrm{hD}_{\mathrm{h}} / \mathrm{k}$ \\
\hline $\mathrm{Nu}_{0}$ & $\begin{array}{l}\text { Smooth duct Nusselt number based on correlation by Kays and Crawford } \\
{[1980], \mathrm{Nu} 0=0.022 \operatorname{Re}_{\mathrm{d}}{ }^{0.8} \operatorname{Pr}^{0.5}}\end{array}$ \\
\hline $\mathrm{Nu}_{\mathrm{d}}$ & array Nusselt number based on $\mathrm{d}, \mathrm{hd} / \mathrm{k}$ \\
\hline $\mathrm{Nu}_{\mathrm{d}, \mathrm{e}}$ & endwall Nusselt number \\
\hline $\mathrm{Nu}_{\mathrm{d}, \mathrm{p}}$ & pin Nusselt number \\
\hline $\mathrm{Nu}_{\mathrm{d}, \mathrm{c}}$ & array-average Nusselt number \\
\hline $\mathrm{P}$ & power; perimeter \\
\hline $\operatorname{Pr}$ & Prandtl number \\
\hline q" & heat flux \\
\hline $\mathrm{Q}$ & heat rate \\
\hline $\mathrm{R}$ & electrical resistance \\
\hline $\mathrm{Ra}$ & Rayleigh number \\
\hline $\operatorname{Re}$ & duct Reynolds number based on $\mathrm{U}$ and $\mathrm{Dh}, \mathrm{UD}_{\mathrm{h}} / v$ \\
\hline $\operatorname{Re}_{\mathrm{d}}$ & array Reynolds number based on $U_{\max }$ and $d, U_{\max } \mathrm{d} / \nu$ \\
\hline $\mathrm{S} 1$ & spacing between pin centers in a row \\
\hline $\mathrm{S} 2$ & spacing between rows of pins \\
\hline $\mathrm{T}$ & temperature \\
\hline $\mathrm{u}$ & uncertainty \\
\hline $\mathrm{U}$ & average velocity in unobstructed channel \\
\hline $\mathrm{U}_{\max }$ & maximum average velocity between the pin fins \\
\hline V & voltage \\
\hline
\end{tabular}


W

$\mathrm{X}$

\section{Greek:}

$\alpha$

$\beta$

$v$

$\rho$

\section{$\underline{\text { Subscripts: }}$}

\begin{tabular}{l}
$\overline{\text { variable }}$ \\
\hline$\overline{\text { variable }}$ \\
0 \\
amb \\
b \\
c \\
d \\
f \\
fe \\
fp \\
in \\
ins \\
k \\
Kapton \\
loss \\
MDF \\
meter \\
net \\
p \\
std \\
w \\
wet
\end{tabular}

width of channel and endwall heaters

streamwise distance

flow incidence angle; thermal diffusivity

volume expansion coefficient

dynamic viscosity

density

spanwise averaged value

area averaged value

unobstructed duct baseline condition

ambient conditions

bulk fluid

corrected value

pin diameter

inconel foil heater

endwall fraction

pin fraction

inlet

insulation

Kapton property

DuPont brand of polyimide film

amount subtracted from a total to give a net value

medium density fiberboard

venturi flowmeter

value accounting for losses

pin fin; precision resistor

standard

wall

exposed to the flow

\section{Duct Reynolds Number Uncertainty Calculations}

The duct Reynolds number is characterized by the bulk velocity through the duct and uses the duct hydraulic diameter as the length scale. The duct Reynolds number as defined is shown in Equation A.1

$$
\operatorname{Re}=\frac{2 Q_{\text {std }} \cdot \rho_{\text {std }}}{\mu(W+H)},
$$


where $\mathrm{Q}_{\text {std }}$ is the volume flowrate through the duct, $\rho_{\text {std }}$ is the air density at the volume flowmeter, $\mu$ is the dynamic viscosity of the air, $\mathrm{W}$ is the width of the duct, and $\mathrm{H}$ is the height of the duct. The first step in determining the uncertainty of the duct Reynolds number is calculating the volume flow rate and the uncertainty associated with it. The equation for the volume flowrate through the venturi flowmeter is shown in Equation A.2

$$
\mathrm{Q}_{\text {std }}=\frac{5.9816 \cdot \mathrm{d}^{2} \cdot \mathrm{K} \cdot \mathrm{Y} \cdot \sqrt{\mathrm{dp}} \cdot \sqrt{\frac{2.703 \cdot \mathrm{P}_{\mathrm{L}}}{460+\mathrm{T}_{\mathrm{L}}}}}{\frac{2.703 \cdot 14.7}{460+60}} \cdot \frac{4.71936 \cdot 10^{-4} \frac{\mathrm{m}^{3}}{\mathrm{~s}}}{1 \mathrm{SCFM}},
$$

where $\mathrm{Y}$ is the gas expansion factor, $\mathrm{K}$ is the flow coefficient, dp $\left(\mathrm{in}-\mathrm{H}_{2} \mathrm{O}\right)$ is the pressure difference across the venturi, $\mathrm{P}_{\mathrm{L}}$ (psia) is the absolute pressure at the venturi, and $\mathrm{T}_{\mathrm{L}}\left({ }^{\circ} \mathrm{F}\right)$ is the temperature at the venturi. The propagation of uncertainty for the volume flowrate is shown by Equation A.3

$$
\mathrm{u}_{\mathrm{Q}_{\text {std }}}=\sqrt{\left(\frac{\partial \mathrm{Q}_{\mathrm{std}}}{\partial \mathrm{dp}} \mathrm{u}_{\mathrm{dp}}\right)^{2}+\left(\frac{\partial \mathrm{Q}_{\mathrm{std}}}{\partial \mathrm{T}_{\mathrm{L}}} \mathrm{u}_{\mathrm{T}_{\mathrm{L}}}\right)^{2}+\left(\frac{\partial \mathrm{Q}_{\text {std }}}{\partial \mathrm{P}_{\mathrm{L}}} \mathrm{u}_{\mathrm{P}_{\mathrm{L}}}\right)^{2}+\mathrm{u}_{\text {meter }}^{2}}
$$

where $\mathrm{u}_{\text {meter }}$ is the bias uncertainty associated with the flowmeter. The propagation of uncertainty for the duct Reynolds number is shown by Equation A.4

$$
\mathrm{u}_{\mathrm{Re}}=\sqrt{\left(\frac{\partial \mathrm{Re}}{\partial \mathrm{Q}_{\mathrm{std}}} \mathrm{u}_{\mathrm{Q}_{\mathrm{std}}}\right)^{2}+\left(\frac{\partial \mathrm{Re}}{\partial \mathrm{W}} \mathrm{u}_{\mathrm{W}}\right)^{2}+\left(\frac{\partial \mathrm{Re}}{\partial \mathrm{H}} \mathrm{u}_{\mathrm{H}}\right)^{2}}
$$

Tables A.1 and A.2 show the uncertainty values associated with the duct Reynolds number for $\mathrm{Re}=4995$ and $\mathrm{Re}=29,869$ respectively.

Table A.1. Re=4995 Uncertainty

\begin{tabular}{|l|r|r|r|r|c|}
\hline Variable & \multicolumn{1}{c|}{ Value } & \multicolumn{1}{c|}{ Bias } & Precision & Uncertainty & $\%$ \\
\hline Re & 4995.660 & & & 197.58 & 3.96 \\
\hline $\mathrm{q}\left(\mathrm{m}^{3} / \mathrm{s}\right)$ & 0.024 & & & $9.31 \mathrm{E}-04$ & 3.95 \\
\hline $\mathrm{W}(\mathrm{m})$ & 0.610 & & & $7.94 \mathrm{E}-04$ & 0.13 \\
\hline $\mathrm{H}(\mathrm{m})$ & 0.010 & & & $3.97 \mathrm{E}-04$ & 4.17 \\
\hline $\mathrm{dP}(\mathrm{Pa})$ & 8.027 & 0.62275 & $1.34 \mathrm{E}-04$ & $6.23 \mathrm{E}-01$ & 7.76 \\
\hline $\mathrm{P}_{\mathrm{L}}(\mathrm{kPa})$ & 95.000 & & & $1.10 \mathrm{E}-02$ & 0.01 \\
\hline $\mathrm{T}_{\mathrm{L}}(\mathrm{K})$ & 301.901 & 0.2 & 0.0272 & $2.02 \mathrm{E}-01$ & 0.07 \\
\hline
\end{tabular}


Table A.2. $\operatorname{Re}=29,869$ Uncertainty

\begin{tabular}{|l|r|l|l|r|c|}
\hline Variable & \multicolumn{1}{|c|}{ Value } & Bias & Precision & Uncertainty & $\%$ \\
\hline $\operatorname{Re}$ & 29869.140 & & & 723.09 & 2.42 \\
\hline $\mathrm{q}\left(\mathrm{m}^{\mathrm{s}} / \mathrm{s}\right)$ & 0.137 & & & $3.32 \mathrm{E}-03$ & 2.42 \\
\hline $\mathrm{W}(\mathrm{m})$ & 0.610 & & & $7.94 \mathrm{E}-04$ & 0.13 \\
\hline $\mathrm{H}(\mathrm{m})$ & 0.010 & & & $3.97 \mathrm{E}-04$ & 4.17 \\
\hline $\mathrm{dP}(\mathrm{Pa})$ & 271.207 & 12.46 & $1.34 \mathrm{E}-04$ & $1.25 \mathrm{E}+01$ & 4.59 \\
\hline $\mathrm{P}_{\mathrm{L}}(\mathrm{kPa})$ & 92.273 & & & $1.10 \mathrm{E}-02$ & 0.01 \\
\hline $\mathrm{T}_{\mathrm{L}}(\mathrm{K})$ & 294.361 & 0.2 & 0.0082 & $2.00 \mathrm{E}-01$ & 0.07 \\
\hline
\end{tabular}

\section{Pin Nusselt Number Uncertainty Calculations}

The pin Nusselt number is the dimensionless heat transfer coefficient used to describe the heat transfer characteristics of the pin surfaces in the array. The pin Nusselt number uses the pin diameter as the characteristic length and is shown by Equation A.5

$$
\mathrm{Nu}_{\mathrm{d}, \mathrm{p}}=\frac{\left(\frac{\mathrm{V}_{\mathrm{p}}}{\mathrm{R}_{\mathrm{p}}}\right)^{2} \mathrm{R}_{\mathrm{f}} \cdot \mathrm{d}}{\mathrm{k} \cdot \mathrm{A}_{\mathrm{f}}\left(\mathrm{T}_{\mathrm{p}}-\mathrm{T}_{\mathrm{b}}\right)},
$$

where $V_{p}$ is the measured voltage across the precision resistor, $R_{p}$ is the resistance of the precision resistor, $R_{f}$, is the measured resistance of the inconel foil heater, $d$ is the pin diameter, $k$ is the thermal conductivity of the air, $A_{f}$ is the area of the inconel foil heater, $T_{p}$ is the temperature of the location of interest on the pin surface, and $\mathrm{T}_{\mathrm{b}}$ is the bulk air temperature. The propagation of uncertainty for the pin Nusselt number is shown by Equation A.6

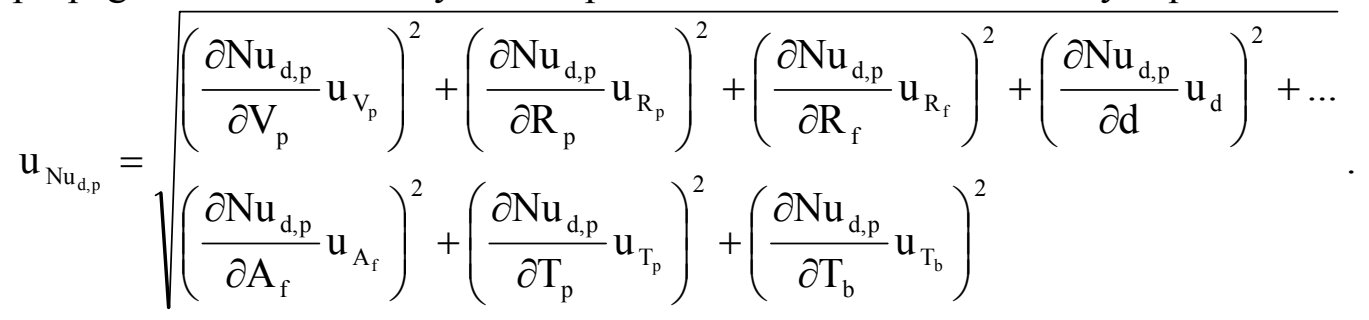

Tables A.3 through A.6 show the uncertainty values associated with the lowest and highest measured pin Nusselt numbers at $\mathrm{Re}=4995$ and $\mathrm{Re}=29,869$. 
Table A.3. $\mathrm{Re}=4995$ High $\mathrm{Nu}_{\mathrm{d}, \mathrm{p}}$ Uncertainty

\begin{tabular}{|l|r|r|r|r|r|}
\hline Variable & \multicolumn{1}{|c|}{ Value } & Bias & Precision & Uncertainty & $\%$ \\
\hline $\mathrm{Nu}_{d}$ & 44.28 & & & 2.313 & 5.22 \\
\hline $\mathrm{V}_{p}(\mathrm{~V})$ & 2.00 & & & 0.007 & 0.35 \\
\hline $\mathrm{R}_{\mathrm{p}}(\mathrm{ohm})$ & 1.00 & & & 0.010 & 1.00 \\
\hline $\mathrm{R}_{\mathrm{f}}(\mathrm{ohm})$ & 0.13 & & & 0.003 & 2.29 \\
\hline $\mathrm{d}(\mathrm{m})$ & $9.53 \mathrm{E}-03$ & & & $6.48 \mathrm{E}-06$ & 0.07 \\
\hline $\mathrm{A}_{\mathrm{f}}\left(\mathrm{m}^{2}\right)$ & $2.53 \mathrm{E}-04$ & & & $8.29 \mathrm{E}-07$ & 0.33 \\
\hline $\mathrm{T}_{\mathrm{p}}(\mathrm{C})$ & 30.40 & 0.2 & 0.0362 & 0.203 & 0.67 \\
\hline $\mathrm{T}_{\mathrm{b}}(\mathrm{C})$ & 17.81 & 0.2 & 0.0044 & 0.200 & 1.12 \\
\hline
\end{tabular}

Table A.4. $\mathrm{Re}=4995$ Low $\mathrm{Nu}_{\mathrm{d} . \mathrm{p}}$ Uncertainty

\begin{tabular}{|l|r|r|r|r|c|}
\hline Variable & Value & Bias & Precision & Uncertainty & $\%$ \\
\hline $\mathrm{Nu}_{d}$ & 42.01 & & & 1.122 & 2.67 \\
\hline $\mathrm{V}_{p}(\mathrm{~V})$ & 2.03 & & & 0.007 & 0.35 \\
\hline $\mathrm{R}_{p}(\mathrm{ohm})$ & 1.00 & & & 0.010 & 1.00 \\
\hline $\mathrm{R}_{\mathrm{f}}(\mathrm{ohm})$ & 0.13 & & & 0.003 & 2.36 \\
\hline $\mathrm{d}(\mathrm{m})$ & $9.53 \mathrm{E}-03$ & & & $6.48 \mathrm{E}-06$ & 0.07 \\
\hline $\mathrm{A}_{\mathrm{f}}\left(\mathrm{m}^{2}\right)$ & $2.53 \mathrm{E}-04$ & & & $8.29 \mathrm{E}-07$ & 0.33 \\
\hline $\mathrm{T}_{\mathrm{p}}(\mathrm{C})$ & 40.77 & 0.2 & 0.0437 & 0.205 & 0.50 \\
\hline $\mathrm{T}_{\mathrm{b}}(\mathrm{C})$ & 17.81 & 0.2 & 0.0044 & 0.200 & 1.12 \\
\hline
\end{tabular}

Table A.5. $\mathrm{Re}=29,869$ High $\mathrm{Nu}_{\mathrm{d}, \mathrm{p}}$ Uncertainty

\begin{tabular}{|l|r|r|r|r|c|}
\hline Variable & Value & Bias & Precision & Uncertainty & $\%$ \\
\hline $\mathrm{Nu}_{d}$ & 120.71 & & & 5.559 & 4.61 \\
\hline $\mathrm{V}_{\mathrm{p}}(\mathrm{V})$ & 3.50 & & & 0.012 & 0.33 \\
\hline $\mathrm{R}_{\mathrm{p}}(\mathrm{ohm})$ & 1.00 & & & 0.010 & 1.00 \\
\hline $\mathrm{R}_{\mathrm{f}}(\mathrm{ohm})$ & 0.13 & & & 0.003 & 2.29 \\
\hline $\mathrm{d}(\mathrm{m})$ & $9.53 \mathrm{E}-03$ & & & $6.48 \mathrm{E}-06$ & 0.07 \\
\hline $\mathrm{A}_{\mathrm{f}}\left(\mathrm{m}^{2}\right)$ & $2.53 \mathrm{E}-04$ & & & $8.29 \mathrm{E}-07$ & 0.33 \\
\hline $\mathrm{T}_{\mathrm{p}}(\mathrm{C})$ & 36.11 & 0.2 & 0.0526 & 0.207 & 0.57 \\
\hline $\mathrm{T}_{\mathrm{b}}(\mathrm{C})$ & 20.92 & 0.2 & 0.0044 & 0.220 & 1.05 \\
\hline
\end{tabular}


Table A.6. $\mathrm{Re}=29,869$ Low $\mathrm{Nu}_{\mathrm{d}, \mathrm{p}}$ Uncertainty

\begin{tabular}{|l|r|r|r|r|c|}
\hline Variable & \multicolumn{1}{|c|}{ Value } & Bias & Precision & Uncertainty & $\%$ \\
\hline $\mathrm{Nu}_{\mathrm{d}}$ & 108.26 & & & 3.304 & 3.05 \\
\hline $\mathrm{V}_{\mathrm{p}}(\mathrm{V})$ & 3.55 & & & 0.012 & 0.33 \\
\hline $\mathrm{R}_{\mathrm{p}}(\mathrm{ohm})$ & 1.00 & & & 0.010 & 1.00 \\
\hline $\mathrm{R}_{\mathrm{f}}(\mathrm{ohm})$ & 0.13 & & & 0.003 & 2.36 \\
\hline $\mathrm{d}(\mathrm{m})$ & $9.53 \mathrm{E}-03$ & & & $6.48 \mathrm{E}-06$ & 0.07 \\
\hline $\mathrm{A}_{\mathrm{f}}\left(\mathrm{m}^{2}\right)$ & $2.53 \mathrm{E}-04$ & & & $8.29 \mathrm{E}-07$ & 0.33 \\
\hline $\mathrm{T}_{\mathrm{p}}(\mathrm{C})$ & 44.50 & 0.2 & 0.058 & 0.208 & 0.47 \\
\hline $\mathrm{T}_{\mathrm{b}}(\mathrm{C})$ & 20.92 & 0.2 & 0.092 & 0.220 & 1.05 \\
\hline
\end{tabular}

\section{Duct Nusselt Number Uncertainty Calculations}

The duct Nusselt number is the dimensionless heat transfer coefficient used to describe the heat transfer characteristics of the endwall of a pin fin array. Rather than using the pin diameter as the characteristic length it uses the duct hydraulic diameter which in this case is twice the height of the duct. The duct Nusselt number definition is shown in by Equation A.7

$$
\mathrm{Nu}=\frac{2 \mathrm{q}_{\mathrm{net}}^{\prime \prime} \cdot \mathrm{W} \cdot \mathrm{H}}{\mathrm{k}(\mathrm{W}+\mathrm{H})\left(\mathrm{T}_{\mathrm{c}}-\mathrm{T}_{\mathrm{b}}\right)},
$$

where $\mathrm{qnet}$ " is the net heat flux entering the flow from the pin fin array, $\mathrm{T}_{\mathrm{c}}$ is the corrected wall temperature, and $\mathrm{T}_{\mathrm{b}}$ is the bulk air temperature. The bulk air temperature is calculated using Equation A.8

$$
\mathrm{T}_{\mathrm{b}}=\mathrm{T}_{\mathrm{in}}+\frac{\overline{\bar{Q}}_{\text {net }}}{\mathrm{mC}_{\mathrm{p}}}\left(\frac{\mathrm{x}}{\mathrm{L}}\right)
$$

where $T_{i}$ is the duct inlet temperature, $\overline{\overline{Q_{\text {net }}}}$ is the total heat which enters the flow, $\dot{m}$ is the mass flowrate of the air, $\mathrm{C}_{\mathrm{p}}$ is the specific heat of the air, $\mathrm{x}$ is the streamwise heated distance up to the point of interest, and $\mathrm{L}$ is the total streamwise length of the heater. After the endwall temperatures are measured by the IR camera, they must be corrected to account for the thickness of the Kapton heater. This correction is shown by Equation A.9

$$
\mathrm{T}_{\mathrm{c}}=\mathrm{T}_{\mathrm{w}}+\frac{\mathrm{q}_{\mathrm{net}}^{\prime \prime} \mathrm{L}_{\mathrm{k}}}{\mathrm{k}_{\mathrm{k}}}
$$

where $T_{w}$ is the measured endwall temperature, $L_{k}$ is the thickness of the Kapton heater, and $k_{k}$ is the thermal conductivity of the Kapton heater. The net heat flux to the flow is calculated using Equation A.10

$$
q_{\text {net }}^{\prime \prime}=\frac{P-q_{\text {loss }}^{\prime \prime}(2 \mathrm{~A})}{2 \mathrm{~A}+0.5 \mathrm{~N} \pi \mathrm{dH}},
$$

where $\mathrm{P}$ is the total power provided to the heaters, qloss" is the calculated heat loss flux through the walls of the duct, $\mathrm{A}$ is the area of the Kapton heater, and $\mathrm{N}$ is the number of pins on the heater. The heat loss flux is calculated using Equation A.11 


$$
q_{\text {loss }}^{\prime \prime}=\frac{\mathrm{T}_{\mathrm{w}}-\mathrm{T}_{\text {loss }}}{\frac{\mathrm{L}_{\mathrm{mdf}}}{\mathrm{k}_{\mathrm{mdf}}}} .
$$

The heat loss flux calculation is fully described in Appendix B. The propagation of uncertainty is used to determine the uncertainty for the values calculated in Equations A.7 through A.11. These uncertainty equations are shown in Equations A.12 through A.16.

$$
\begin{aligned}
& \mathrm{u}_{\mathrm{Nu}}=\sqrt{\left(\frac{\partial \mathrm{Nu}}{\partial \mathrm{q}_{\text {net }}^{\prime \prime}} \mathrm{u}_{\mathrm{q}_{\text {net }}}\right)^{2}+\left(\frac{\partial \mathrm{Nu}}{\partial \mathrm{W}} \mathrm{u}_{\mathrm{w}}\right)^{2}+\left(\frac{\partial \mathrm{Nu}}{\partial \mathrm{H}} \mathrm{u}_{\mathrm{H}}\right)^{2}+\left(\frac{\partial \mathrm{Nu}}{\partial \mathrm{T}_{\text {corr }}} \mathrm{u}_{\mathrm{T}_{\text {corr }}}\right)^{2}+\left(\frac{\partial \mathrm{Nu}}{\partial \mathrm{T}_{\text {bulk }}} \mathrm{u}_{\mathrm{T}_{\text {bulk }}}\right)^{2}} \text {, } \\
& \mathrm{u}_{\mathrm{T}_{\text {bulk }}}=\sqrt{\left(\frac{\partial \mathrm{T}_{\text {bulk }}}{\partial \mathrm{T}_{\text {in }}} \mathrm{u}_{\mathrm{T}_{\text {in }}}\right)^{2}+\left(\frac{\partial \mathrm{T}_{\text {bulk }}}{\partial \overline{\overline{\mathrm{Q}_{\text {net }}}}} \mathrm{u}_{\overline{\mathrm{Q}_{\text {net }}}}\right)^{2}+\left(\frac{\partial \mathrm{T}_{\text {bulk }}}{\partial \mathrm{m}} \mathrm{u}_{\mathrm{m}}\right)^{2}+\left(\frac{\partial \mathrm{T}_{\text {bulk }}}{\partial \mathrm{x}} \mathrm{u}_{\mathrm{x}}\right)^{2}+\left(\frac{\partial \mathrm{T}_{\text {bulk }}}{\partial \mathrm{L}} \mathrm{u}_{\mathrm{L}}\right)^{2}} \\
& \mathrm{u}_{\mathrm{T}_{\text {cor }}}=\sqrt{\left(\frac{\partial \mathrm{T}_{\text {corr }}}{\partial \mathrm{T}_{\mathrm{w}}} \mathbf{u}_{\mathrm{T}_{\mathrm{w}}}\right)^{2}+\left(\frac{\partial \mathrm{T}_{\text {corr }}}{\partial \mathrm{q}_{\text {net }}} \mathbf{u}_{\mathrm{q}_{\text {net }}}\right)^{2}}, \\
& u_{\mathrm{q}_{\text {net }}}=\sqrt{\left(\frac{\partial \mathrm{q}_{\text {net }}^{\prime \prime}}{\partial \mathrm{P}_{\text {total }}} \mathrm{u}_{\mathrm{P}_{\text {total }}}\right)^{2}+\left(\frac{\partial \mathrm{q}_{\text {net }}^{\prime \prime}}{\partial \mathrm{q}_{\text {loss }}^{\prime \prime}} \mathrm{u}_{\mathrm{q}_{\text {loss }}}\right)^{2}+\left(\frac{\partial \mathrm{q}_{\text {net }}^{\prime \prime}}{\partial \mathrm{A}_{\text {heater }}} \mathrm{u}_{\mathrm{A}_{\text {heater }}}\right)^{2}+\left(\frac{\partial \mathrm{q}_{\text {net }}^{\prime \prime}}{\partial \mathrm{d}} \mathrm{u}_{\mathrm{d}}\right)^{2}}, \\
& \mathrm{u}_{\mathrm{q}_{\text {loss }}}=\sqrt{\left(\frac{\partial \mathrm{q}_{\text {loss }}^{\prime \prime}}{\partial \mathrm{T}_{\mathrm{w}}} \mathbf{u}_{\mathrm{T}_{\mathrm{w}}}\right)^{2}+\left(\frac{\partial \mathrm{q}_{\text {loss }}^{\prime \prime}}{\partial \mathrm{T}_{\text {amb }}} \mathbf{u}_{\mathrm{T}_{\text {amb }}}\right)^{2}} .
\end{aligned}
$$

Tables A.7 through A.10 show the uncertainty values associated with the lowest and highest measured duct Nusselt numbers at $\mathrm{Re}=4995$ and $\mathrm{Re}=29,869$.

Table A.7. $\mathrm{Re}=4995$ High Nu Uncertainty

\begin{tabular}{|l|r|r|r|r|c|}
\hline \multicolumn{1}{|c|}{ Variable } & \multicolumn{1}{c|}{ Value } & \multicolumn{1}{c|}{ Bias } & Precision & Uncertainty & $\%$ \\
\hline $\mathrm{Nu}$ & 58.964 & & & 5.280 & 8.96 \\
\hline $\mathrm{q}_{\text {net }}\left(\mathrm{W} / \mathrm{m}^{2}\right)$ & 1187.948 & & & 86.456 & 7.28 \\
\hline $\mathrm{W}(\mathrm{m})$ & 0.610 & & & $7.620 \mathrm{E}-04$ & 0.13 \\
\hline $\mathrm{H}(\mathrm{m})$ & 0.010 & & & $3.969 \mathrm{E}-04$ & 4.17 \\
\hline $\mathrm{T}_{\mathrm{c}}(\mathrm{C})$ & 32.146 & & & 0.403 & 1.25 \\
\hline $\mathrm{T}_{\mathrm{b}}(\mathrm{C})$ & 17.728 & & & 0.517 & 2.92 \\
\hline $\mathrm{T}_{\mathrm{w}}(\mathrm{C})$ & 32.900 & 0.2 & 0.345 & 0.399 & 1.21 \\
\hline $\mathrm{T}_{\text {in }}(\mathrm{C})$ & 12.502 & 0.2 & 0.007 & 0.200 & 1.60 \\
\hline $\mathrm{T}_{\text {loss }}(\mathrm{C})$ & 33.481 & 0.2 & 0.008 & 0.2 & 0.60 \\
\hline
\end{tabular}


Table A.8. $\mathrm{Re}=4995$ Low Nu Uncertainty

\begin{tabular}{|l|r|r|r|r|c|}
\hline \multicolumn{1}{|c|}{ Variable } & \multicolumn{1}{c|}{ Value } & Bias & Precision & Uncertainty & $\%$ \\
\hline $\mathrm{Nu}$ & 28.101 & & & 2.287 & 8.14 \\
\hline $\mathrm{q}_{\text {net }}\left(\mathrm{W} / \mathrm{m}^{2}\right)$ & 1146.146 & & & 86.456 & 7.54 \\
\hline $\mathrm{W}(\mathrm{m})$ & 0.610 & & & $7.620 \mathrm{E}-04$ & 0.13 \\
\hline $\mathrm{H}(\mathrm{m})$ & 0.010 & & & $3.969 \mathrm{E}-04$ & 4.17 \\
\hline $\mathrm{T}_{\mathrm{c}}(\mathrm{C})$ & 43.642 & & & 0.403 & 0.92 \\
\hline $\mathrm{T}_{\mathrm{b}}(\mathrm{C})$ & 14.453 & & & 0.272 & 1.88 \\
\hline $\mathrm{T}_{\mathrm{w}}(\mathrm{C})$ & 44.370 & 0.2 & 0.345 & 0.399 & 0.90 \\
\hline $\mathrm{T}_{\text {in }}(\mathrm{C})$ & 12.502 & 0.2 & 0.007 & 0.200 & 1.60 \\
\hline $\mathrm{T}_{\text {loss }}(\mathrm{C})$ & 37.946 & 0.2 & 0.006 & 0.2 & 0.53 \\
\hline
\end{tabular}

Table A.9. $\mathrm{Re}=29,869$ High Nu Uncertainty

\begin{tabular}{|l|r|r|r|r|r|}
\hline \multicolumn{1}{|c|}{ Variable } & Value & Bias & Precision & Uncertainty & $\%$ \\
\hline $\mathrm{Nu}$ & 191.440 & & & 25.680 & 13.41 \\
\hline $\mathrm{q}_{\text {net }}\left(\mathrm{W} / \mathrm{m}^{2}\right)$ & 2123.766 & & & 146.025 & 6.88 \\
\hline $\mathrm{W}(\mathrm{m})$ & 0.610 & & & $7.620 \mathrm{E}-04$ & 0.13 \\
\hline $\mathrm{H}(\mathrm{m})$ & 0.010 & & & $3.969 \mathrm{E}-04$ & 4.17 \\
\hline $\mathrm{T}_{\mathrm{c}}(\mathrm{C})$ & 22.551 & & & 0.850 & 3.77 \\
\hline $\mathrm{T}_{\mathrm{b}}(\mathrm{C})$ & 14.710 & & & 0.229 & 1.56 \\
\hline $\mathrm{T}_{\mathrm{w}}(\mathrm{C})$ & 23.900 & 0.2 & 0.821 & 0.845 & 3.54 \\
\hline $\mathrm{T}_{\text {in }}(\mathrm{C})$ & 13.097 & 0.2 & 0.012 & 0.200 & 1.53 \\
\hline $\mathrm{T}_{\text {loss }}(\mathrm{C})$ & 23.187 & 0.2 & 0.008 & 0.2 & 0.86 \\
\hline
\end{tabular}

Table A.10. $\mathrm{Re}=29,869$ Low Nu Uncertainty

\begin{tabular}{|l|r|r|r|r|c|}
\hline \multicolumn{1}{|c|}{ Variable } & Value & Bias & Precision & Uncertainty & $\%$ \\
\hline $\mathrm{Nu}$ & 83.234 & & & 7.396 & 8.89 \\
\hline $\mathrm{q}_{\text {net }}\left(\mathrm{W} / \mathrm{m}^{2}\right)$ & 2100.279 & & & 146.025 & 6.95 \\
\hline $\mathrm{W}(\mathrm{m})$ & 0.610 & & & $7.620 \mathrm{E}-04$ & 0.13 \\
\hline $\mathrm{H}(\mathrm{m})$ & 0.010 & & & $3.969 \mathrm{E}-04$ & 4.17 \\
\hline $\mathrm{T}_{\mathrm{c}}(\mathrm{C})$ & 31.536 & & & 0.850 & 2.70 \\
\hline $\mathrm{T}_{\mathrm{b}}(\mathrm{C})$ & 13.699 & & & 0.205 & 1.50 \\
\hline $\mathrm{T}_{\mathrm{w}}(\mathrm{C})$ & 32.870 & 0.2 & 0.821 & 0.845 & 2.57 \\
\hline $\mathrm{T}_{\text {in }}(\mathrm{C})$ & 13.097 & 0.2 & 0.012 & 0.200 & 1.53 \\
\hline $\mathrm{T}_{\text {loss }}(\mathrm{C})$ & 28.221 & 0.2 & 0.005 & 0.2 & 0.71 \\
\hline
\end{tabular}

\section{Combined Pin Surface and Endwall (Array-average) Nusselt Number Uncertainty}

The array-average Nusselt number is calculated by taking an area-average of the Nusselt number associated with endwall and Nusselt number associated with the pin. The Nusselt number associated with the endwall in this case is defined using the pin diameter as the characteristic length so that it can be averaged with the pin Nusselt number. The array-average Nusselt number is shown by Equation A.17 


$$
\mathrm{Nu}_{\mathrm{d}, \mathrm{c}}=\mathrm{Nu}_{\mathrm{d}, \mathrm{e}} \mathrm{A}_{\mathrm{fe}}+\mathrm{Nu}_{\mathrm{d}, \mathrm{p}} \mathrm{A}_{\mathrm{fp}},
$$

where $\mathrm{Nu}_{\mathrm{d}, \mathrm{e}}$ is the endwall Nusselt number, $\mathrm{A}_{\mathrm{fe}}$ is the fraction of area associated with the endwall, $\mathrm{Nu}_{\mathrm{d}, \mathrm{p}}$ is the pin surface Nusselt number, and $\mathrm{A}_{\mathrm{fp}}$ is the fraction of area associated with the pin surface. The endwall Nusselt number uncertainty $\left(\mathrm{u}_{\mathrm{Nu}_{\mathrm{d}, \mathrm{e}}}\right)$ for the cases analyzed is half the uncertainty of the duct Nusselt number $\left(\mathrm{u}_{\mathrm{Nu}}\right)$ because the ratio of length scales relating pin Nusselt number to duct Nusselt number is one half. The propagation of uncertainty for the combined Nusselt number is shown by Equation A.18

$$
\mathrm{u}_{\mathrm{Nu}_{\mathrm{d}, \mathrm{e}}}=\sqrt{\left(\frac{\partial \mathrm{Nu}_{\mathrm{d}, \mathrm{c}}}{\partial \mathrm{Nu}_{\mathrm{d}, \mathrm{e}}} \mathrm{u}_{\mathrm{Nu}_{\mathrm{d}, \mathrm{e}}}\right)^{2}+\left(\frac{\partial \mathrm{Nu}_{\mathrm{d}, \mathrm{c}}}{\partial \mathrm{Nu}_{\mathrm{d}, \mathrm{p}}} \mathrm{u}_{\mathrm{Nu}_{\mathrm{d}, \mathrm{p}}}\right)^{2}} .
$$

Tables A.11 through A.14 show the uncertainty values associated with the lowest and highest array-average Nusselt numbers at $\mathrm{Re}=4995$ and $\mathrm{Re}=29,869$.

Table A.11. $\mathrm{Re}=4995$ High $\mathrm{Nu}_{\mathrm{d}, \mathrm{c}}$ Uncertainty

\begin{tabular}{|l|c|c|r|r|c|}
\hline Variable & Value & Bias & Precision & Uncertainty & $\%$ \\
\hline $\mathrm{Nu}_{\mathrm{d}, \mathrm{c}}$ & 34.95 & & & 1.87 & 5.35 \\
\hline $\mathrm{Nu}_{\mathrm{d}, \mathrm{e}}$ & 29.48 & & & 2.64 & 8.96 \\
\hline $\mathrm{Nu}_{\mathrm{d}, \mathrm{p}}$ & 44.28 & & & 2.31 & 5.22 \\
\hline
\end{tabular}

Table A.12. $\mathrm{Re}=4995$ Low $\mathrm{Nu}_{\mathrm{d}, \mathrm{c}}$ Uncertainty

\begin{tabular}{|l|c|c|c|r|c|}
\hline Variable & Value & Bias & Precision & Uncertainty & $\%$ \\
\hline $\mathrm{Nu}_{\mathrm{d}, \mathrm{c}}$ & 24.38 & & & 0.832 & 3.41 \\
\hline $\mathrm{Nu}_{\mathrm{d}, \mathrm{e}}$ & 14.05 & & & 1.144 & 8.14 \\
\hline $\mathrm{Nu}_{\mathrm{d}, \mathrm{p}}$ & 42.01 & & & 1.122 & 2.67 \\
\hline
\end{tabular}

Table A.13. $\mathrm{Re}=29,869$ High $\mathrm{Nu}_{\mathrm{d}, \mathrm{c}}$ Uncertainty

\begin{tabular}{|l|r|r|r|r|r|}
\hline Variable & Value & Bias & Precision & Uncertainty & $\%$ \\
\hline $\mathrm{Nu}_{\mathrm{d}, \mathrm{c}}$ & 104.96 & & & 8.351 & 7.96 \\
\hline $\mathrm{Nu}_{\mathrm{d}, \mathrm{e}}$ & 95.72 & & & 12.840 & 13.41 \\
\hline $\mathrm{Nu}_{\mathrm{d}, \mathrm{p}}$ & 120.71 & & & 5.559 & 4.61 \\
\hline
\end{tabular}

Table A.14. $\mathrm{Re}=29,869$ Low $\mathrm{Nu}_{\mathrm{d}, \mathrm{c}}$ Uncertainty

\begin{tabular}{|l|r|l|l|r|c|}
\hline Variable & Value & Bias & Precision & Uncertainty & $\%$ \\
\hline $\mathrm{Nu}_{\mathrm{d}, \mathrm{c}}$ & 66.25 & & & 2.632 & 3.97 \\
\hline $\mathrm{Nu}_{\mathrm{d}, \mathrm{e}}$ & 41.62 & & & 3.698 & 8.89 \\
\hline $\mathrm{Nu}_{\mathrm{d}, \mathrm{p}}$ & 108.26 & & & 3.304 & 3.05 \\
\hline
\end{tabular}




\section{Nusselt Number Augmentation Uncertainty}

The Nusselt number augmentation is calculated by taking the ratio of the duct Nusselt number to the smooth duct Nusselt number $\left(\mathrm{Nu}_{0}\right)$ correlation by Kays and Crawford [1980]. The augmentation Nusselt number was calculated using Equation A.19

$$
\frac{\mathrm{Nu}}{\mathrm{Nu}_{0}}=\frac{\mathrm{Nu}}{0.022 \mathrm{Re}^{0.8} \operatorname{Pr}^{0.5}},
$$

where Pr is the Prandtl number of the fluid which in this case is air. The propagation of uncertainty for the Nusselt number augmentation is shown by Equation A.20

$$
\mathrm{u}_{\frac{\mathrm{Nu}}{\mathrm{Nu}_{0}}}=\sqrt{\left(\frac{\partial \frac{\mathrm{Nu}}{\mathrm{Nu}}}{\partial \mathrm{Nu}} \mathbf{u}_{\mathrm{Nu}}\right)^{2}+\left(\frac{\partial \frac{\mathrm{Nu}}{\mathrm{Nu}}}{\partial \mathrm{Re}} \mathbf{u}_{\mathrm{Re}}\right)^{2}} .
$$

Tables A.15 through A.18 show the uncertainty values associated with the lowest and highest measured combined augmentation Nusselt numbers at $R e=4995$ and $R e=29,869$.

Table A.15. $\mathrm{Re}=4995$ High $\mathrm{Nu} / \mathrm{Nu}_{0}$ Uncertainty

\begin{tabular}{|l|r|l|l|r|c|}
\hline Variable & Value & Bias & Precision & Uncertainty & $\%$ \\
\hline $\mathrm{Nu} / \mathrm{Nu}_{0}$ & 3.50 & & & 0.333 & 9.50 \\
\hline $\mathrm{Nu}$ & 58.96 & & & 5.280 & 8.96 \\
\hline $\mathrm{Re}$ & 4995.66 & & & 197.579 & 3.96 \\
\hline
\end{tabular}

Table A.16. $\mathrm{Re}=4995$ Low Nu/Nu$u_{0}$ Uncertainty

\begin{tabular}{|l|r|l|l|r|c|}
\hline Variable & Value & Bias & Precision & Uncertainty & $\%$ \\
\hline $\mathrm{Nu} / \mathrm{Nu}_{0}$ & 1.67 & & & 0.146 & 8.73 \\
\hline $\mathrm{Nu}$ & 28.10 & & & 2.287 & 8.14 \\
\hline $\mathrm{Re}$ & 4995.66 & & & 197.579 & 3.96 \\
\hline
\end{tabular}

Table A.17. $\mathrm{Re}=29,869$ High $\mathrm{Nu} / \mathrm{Nu}_{0}$ Uncertainty

\begin{tabular}{|l|r|l|l|r|c|}
\hline Variable & \multicolumn{1}{|c|}{ Value } & Bias & Precision & Uncertainty & $\%$ \\
\hline $\mathrm{Nu} / \mathrm{Nu}_{0}$ & 2.72 & & & 0.369 & 13.55 \\
\hline $\mathrm{Nu}$ & 191.44 & & & 25.680 & 13.41 \\
\hline $\mathrm{Re}$ & 29869.14 & & & 723.090 & 2.42 \\
\hline
\end{tabular}

Table A.18. $\mathrm{Re}=29,869$ Low $\mathrm{Nu} / \mathrm{Nu}_{0}$ Uncertainty

\begin{tabular}{|l|r|r|r|r|r|}
\hline Variable & \multicolumn{1}{|c|}{ Value } & Bias & Precision & Uncertainty & $\%$ \\
\hline $\mathrm{Nu} / \mathrm{Nu}_{0}$ & 1.18 & & & 0.108 & 9.09 \\
\hline $\mathrm{Nu}$ & 83.23 & & & 7.396 & 8.89 \\
\hline $\mathrm{Re}$ & 29869.14 & & & 723.090 & 2.42 \\
\hline
\end{tabular}




\section{Appendix B: Duct Heat Loss Calculations}

\section{Nomenclature}

g acceleration due to gravity

$\mathrm{h}$ heat transfer coefficient which uses bulk fluid temperature as reference

$\mathrm{k}$ thermal conductivity

L length

q" heat flux

$\mathrm{R}$ thermal resistance

$\mathrm{Ra}$ Rayleigh number

$\mathrm{T}$ temperature

\section{Greek:}

$\alpha \quad$ thermal diffusivity

$\beta \quad$ volume expansion coefficient

$v$ dynamic viscosity

\section{Subscripts:}

air air

amb ambient conditions

ins insulation

IRW infrared widow

loss amount subtracted from a total to give a net value

MDF medium density fiberboard

W wall

In order to accurately estimate the heat loss from the test section to the surroundings, an analysis of the heat flux paths had to be conducted. Figure B.1 shows a schematic of the area-ofinterest of the test section. During a typical test, most of the heat produced by the heaters goes into the flow; however, some of it is lost through the walls of the test section. This heat loss was taken into account to ensure an accurate calculation of heat transfer coefficient from the endwalls of the pin fin array. 

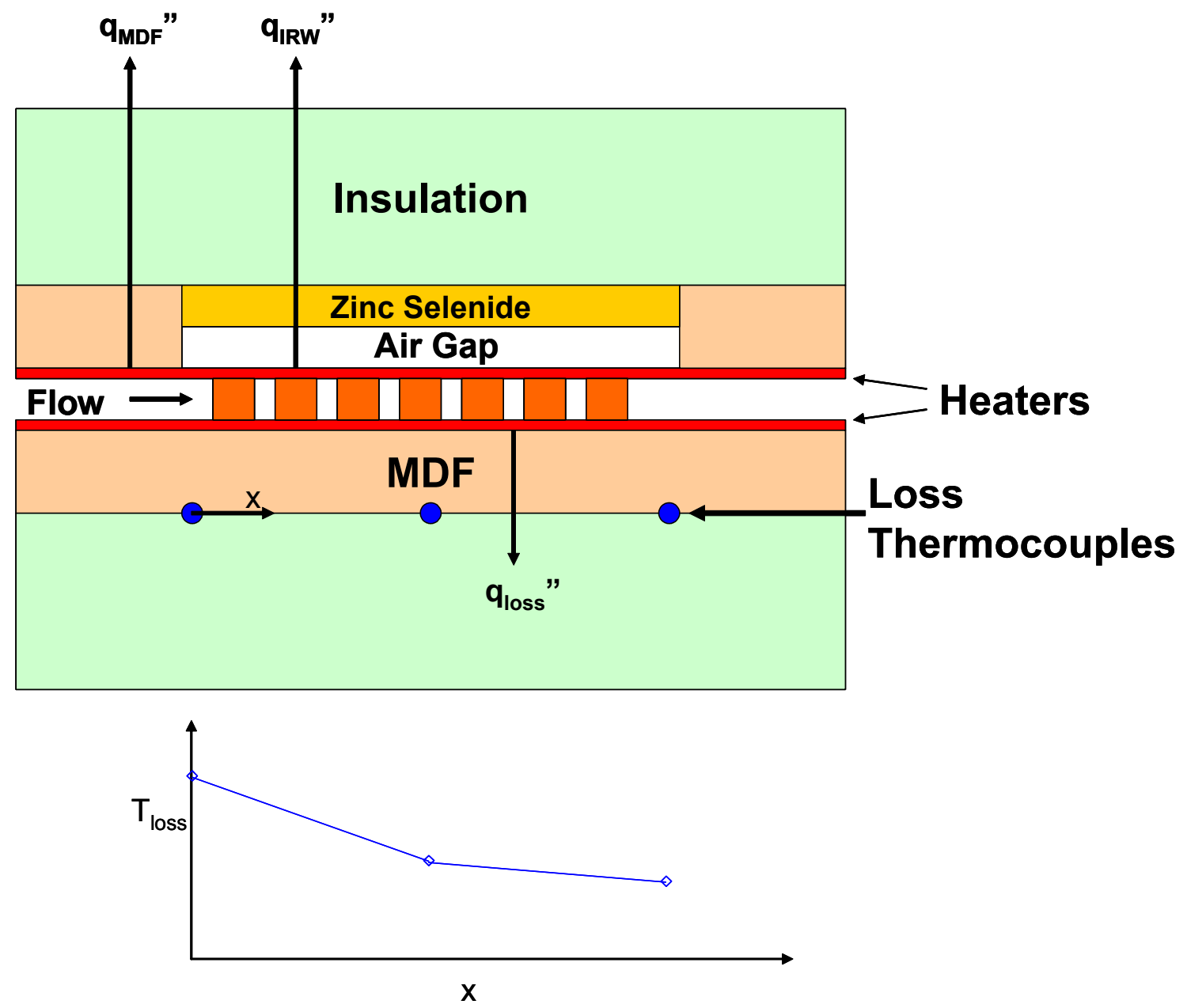

Figure B.1. Detailed schematic of the heat transfer paths from the test section to the surroundings and a typical temperature distribution along the streamwise length of the duct.

First a comparison between the two heat loss paths from the top endwall is conducted. Heat is lost from the top heater either through the medium density fiberboard (MDF) and the insulation ( $\mathrm{q}_{\mathrm{MDF}}$ ") or through an air gap, a zinc selenide window, and the insulation ( $\mathrm{q}_{\mathrm{IRW}}$ "). The thermal resistance through the MDF path is shown below by Equation B.1

$$
\mathrm{R}_{\mathrm{MDF}}^{\prime \prime}=\frac{\mathrm{L}_{\mathrm{MDF}}}{\mathrm{k}_{\mathrm{MDF}}}+\frac{\mathrm{L}_{\text {ins }}}{\mathrm{k}_{\text {ins }}}+\frac{1}{\mathrm{~h}_{\mathrm{amb}}},
$$

where $\mathrm{L}$ is the thickness of either the MDF or the insulation (ins), $\mathrm{k}$ is the thermal conductivity of either the MDF or the insulation, and $h_{a m b}$ is the heat transfer coefficient of the ambient air. The thermal resistance through the IRW path is shown in Equation B.2

$$
\mathrm{R}_{\text {IRW }}^{\prime \prime}=\frac{\mathrm{L}_{\text {air }}}{\mathrm{k}_{\text {air }}}+\frac{\mathrm{L}_{\text {IRW }}}{\mathrm{k}_{\text {IRW }}}+\frac{\mathrm{L}_{\text {ins }}}{\mathrm{k}_{\text {ins }}}+\frac{1}{\mathrm{~h}_{\text {amb }}},
$$


where $\mathrm{L}$ is the thickness of either the air, the infrared window (IRW) or the insulation (ins) and $\mathrm{k}$ is the thermal conductivity of either the air, the IRW or the insulation. Assuming $\mathrm{h}_{\mathrm{amb}}=5$ $\mathrm{W} / \mathrm{m}^{2} \mathrm{~K}$, these resistances are calculated to be $\mathrm{R}_{\mathrm{IRW}}^{\prime \prime}=1.815 \mathrm{~m}^{2}-\mathrm{K} / \mathrm{W}$ and $\mathrm{R}_{\mathrm{MDF}}^{\prime \prime}=1.727 \mathrm{~m}^{2}-$ $\mathrm{K} / \mathrm{W}$, which have a difference of only about $5 \%$. Because they are so similar, it is safe to assume the heat loss through the IRW is the same as the heat loss through the MDF. Table B.1 lists the parameters used to make the resistance calculations.

Table B.1. Heat Loss Parameters

\begin{tabular}{|l|l|l|l|l|}
\hline & MDF & Insulation & Air Gap & IR Window \\
\hline $\mathbf{L}(\mathbf{c m})$ & 1.91 & 5.08 & 0.635 & 1.27 \\
\hline $\mathbf{k}(\mathbf{W} / \mathbf{m}-\mathbf{k})$ & 0.124 & 0.037 & 0.026 & 18.0 \\
\hline
\end{tabular}

The bottom of the channel is also insulated by MDF and insulation, so it is also safe to assume the heat loss from the bottom heater is the same as the heat loss from the top. This heat loss is calculated using three loss thermocouples placed in between the MDF and the insulation underneath the bottom wall of the test section. One thermocouple is placed at the same streamwise distance as the upstream end of the viewing window, one is at the same distance as the downstream end of the window, and one is in the middle. These thermocouples are used to create an approximate loss temperature map along the viewing window. Temperatures can be interpolated for every pixel location in the infrared images using these three loss temperature measurements assuming spanwise temperature uniformity. The thermal resistance of the loss path is calculated using Equation B.3

$$
\mathrm{R}_{\text {loss }}^{\prime \prime}=\frac{\mathrm{L}_{\mathrm{MDF}}}{\mathrm{k}_{\mathrm{MDF}}}
$$

This resistance value is calculated to be $R_{\text {loss }}^{\prime \prime}=1.373 \mathrm{~m}^{2}-\mathrm{K} / \mathrm{W}$. The loss is then calculated using Equation B.4

$$
\mathrm{q}_{\text {loss }}^{\prime \prime}=\frac{\left(\mathrm{T}_{\mathrm{w}}-\mathrm{T}_{\text {loss }}\right)}{\mathrm{R}_{\text {loss }}^{\prime \prime}}
$$

where $T_{\mathrm{w}}$ is the wall temperature measured by the infrared camera at the location of interest and $\mathrm{T}_{\text {loss }}$ is the loss temperature interpolated at the location of interest.

The air gap in between the zinc selenide window and the heater provided high resistance to heat transfer. The resistance through the air gap was calculated assuming that only one dimensional heat conduction was present through the air. To make sure this was an accurate assumption, the estimated Rayleigh number was calculated for this region. The Rayleigh number is defined by Equation B.5

$$
\mathrm{Ra}_{\mathrm{t}}=\frac{\mathrm{g} \cdot \beta\left(\mathrm{T}_{\mathrm{w}}-\mathrm{T}_{\mathrm{air}}\right) \mathrm{t}^{3}}{\alpha \cdot v}
$$

where $g$ is the acceleration due to gravity, $\beta$ is the volume expansion coefficient, $T_{w}$ is the heater wall temperature, $T_{\text {air }}$ is the air temperature within the air gap, $t$ is the thickness of the air gap, $\alpha$ is the thermal diffusivity, and $v$ is the momentum diffusivity. In order to assume free convection does not occur in the air gap, the requirement is that $\mathrm{Ra}_{\mathrm{t}}<1708$. Assuming a conservative temperature difference of $30^{\circ} \mathrm{C}$ the $\mathrm{Ra}_{\mathrm{t}}$ was calculated to be less than 700 . This means there is negligible free convection in the air gap and validates the assumption that only one-dimensional conduction exists. 


\section{Appendix C: Endwall Augmentation Contour Plots}

The following appendix shows the augmentation contour plots for every geometry tested in this study. The contour plots shown are for every Reynolds number tested at every spanwise spacing, streamwise spacing, array angle, and aspect ratio.

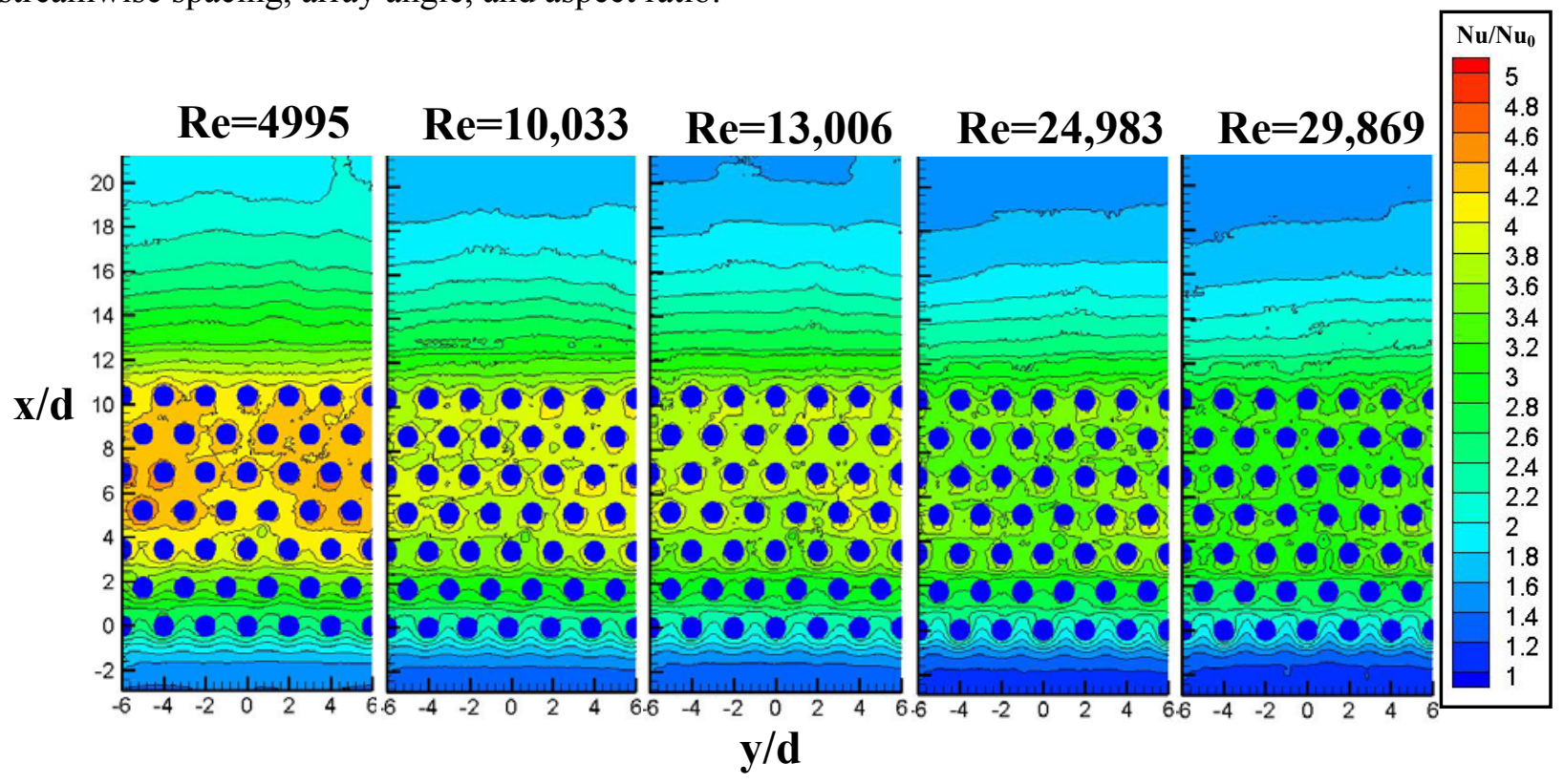

Figure C.1. Augmentation contour plots for the $S 1 / d=2, S 2 / d=1.73, H / d=1, \alpha=0^{\circ}$ geometry.

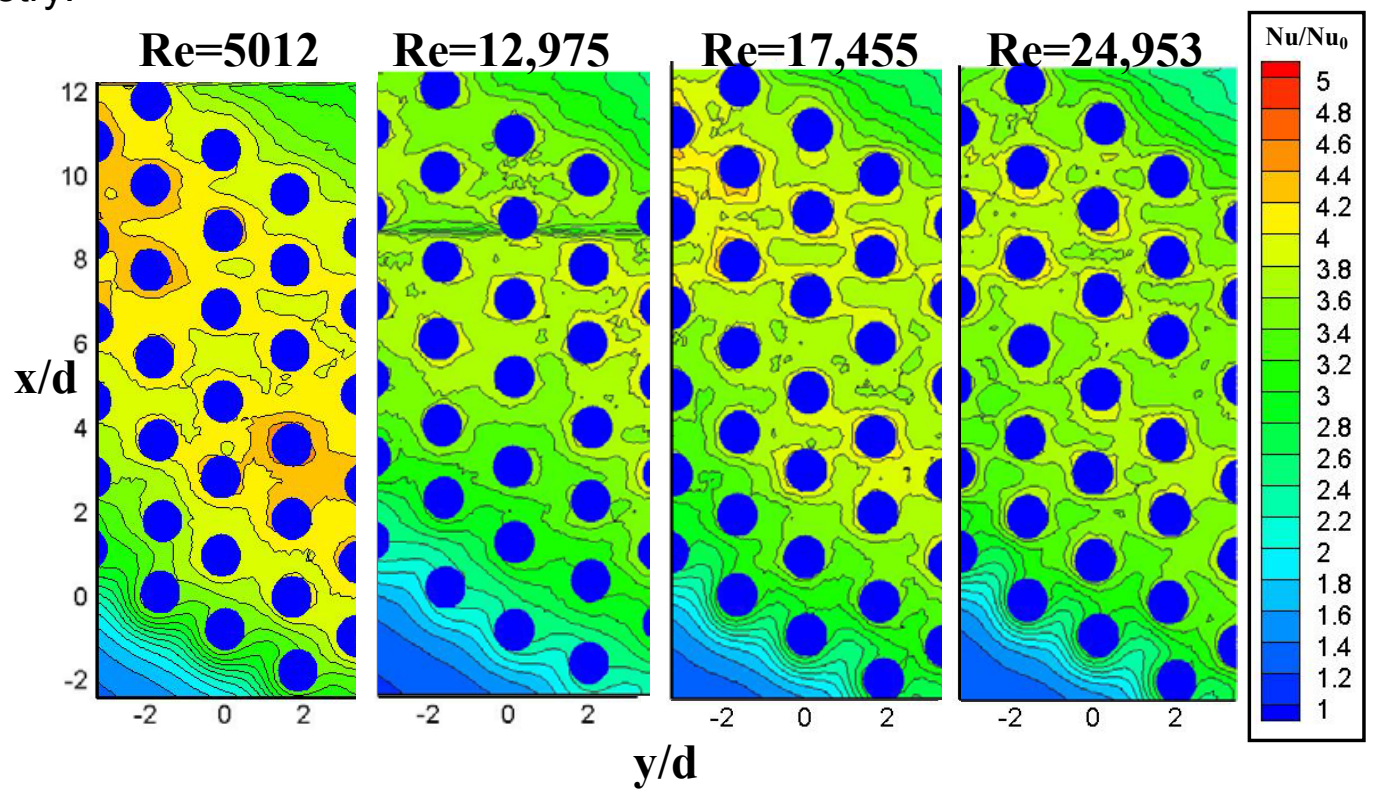

Figure C.2. Augmentation contour plots for the $S 1 / d=2, S 2 / d=1.73, H / d=1, \alpha=30^{\circ}$ geometry. 


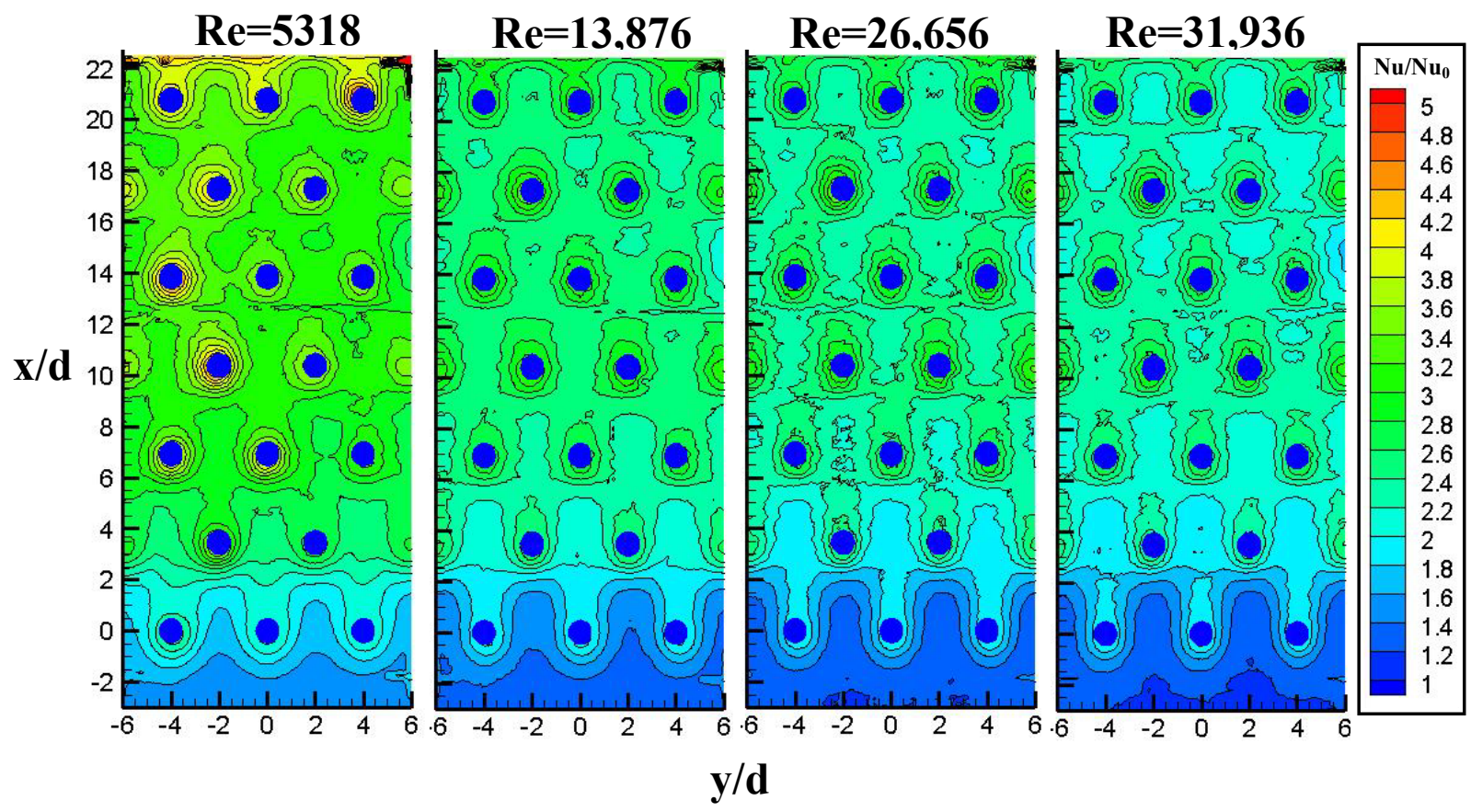

Figure C.3. Augmentation contour plots for the $S 1 / d=4, S 2 / d=3.46, H / d=1, \alpha=0^{\circ}$ geometry.

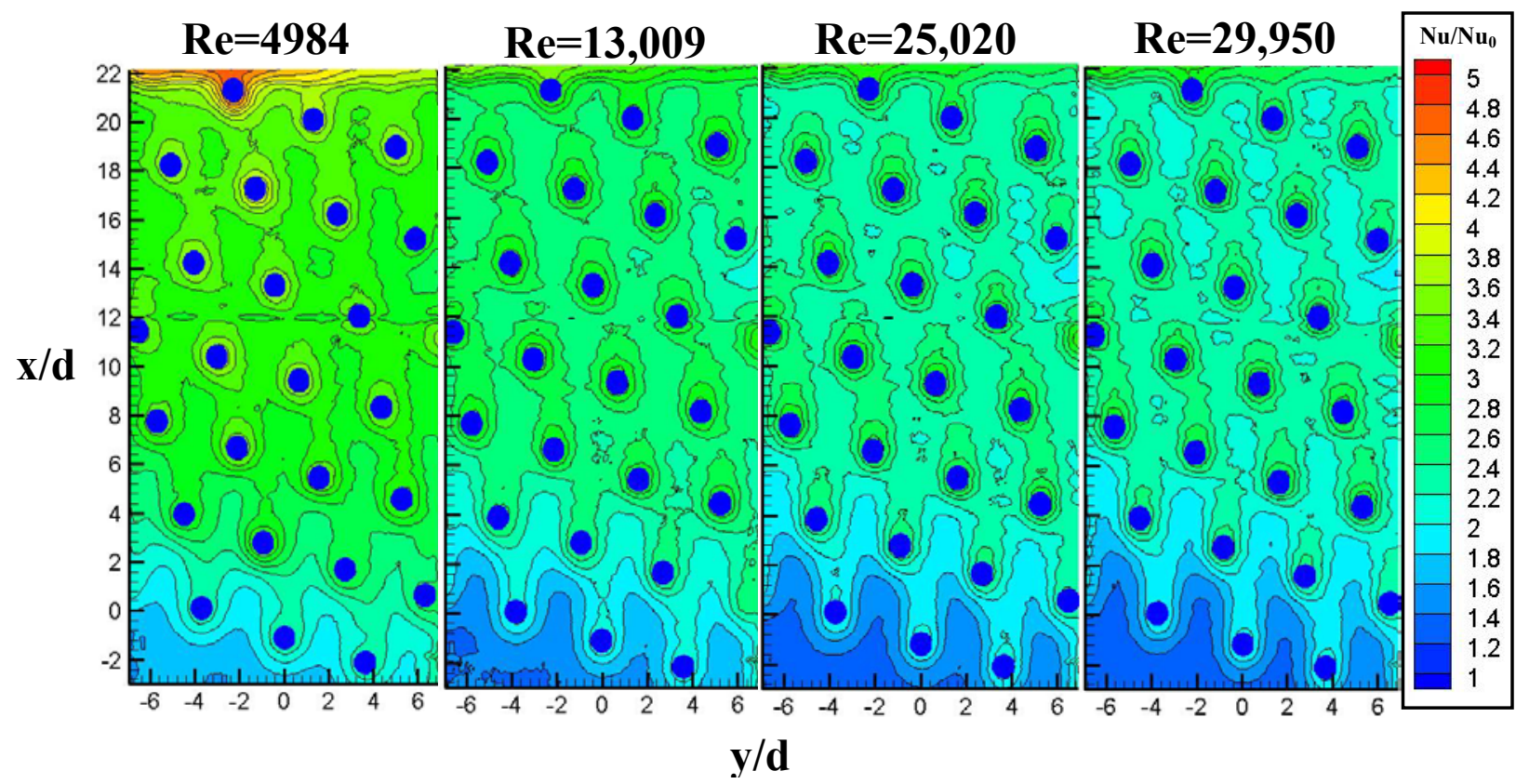

Figure C.4. Augmentation contour plots for the $S 1 / d=4, S 2 / d=3.46, H / d=1, \alpha=15^{\circ}$ geometry. 


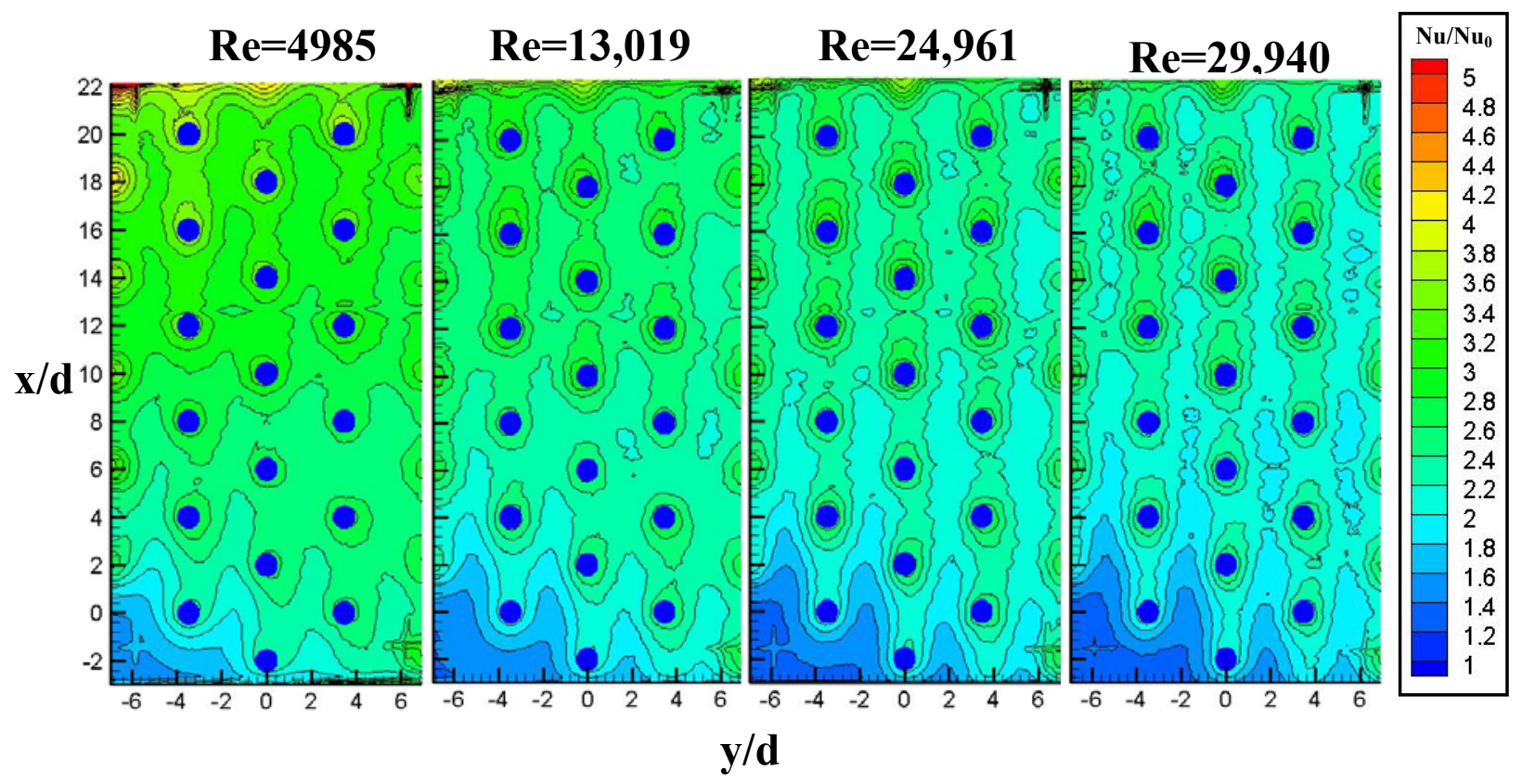

Figure C.5. Augmentation contour plots for the $S 1 / d=4, S 2 / d=3.46, H / d=1, \alpha=30^{\circ}$ geometry.

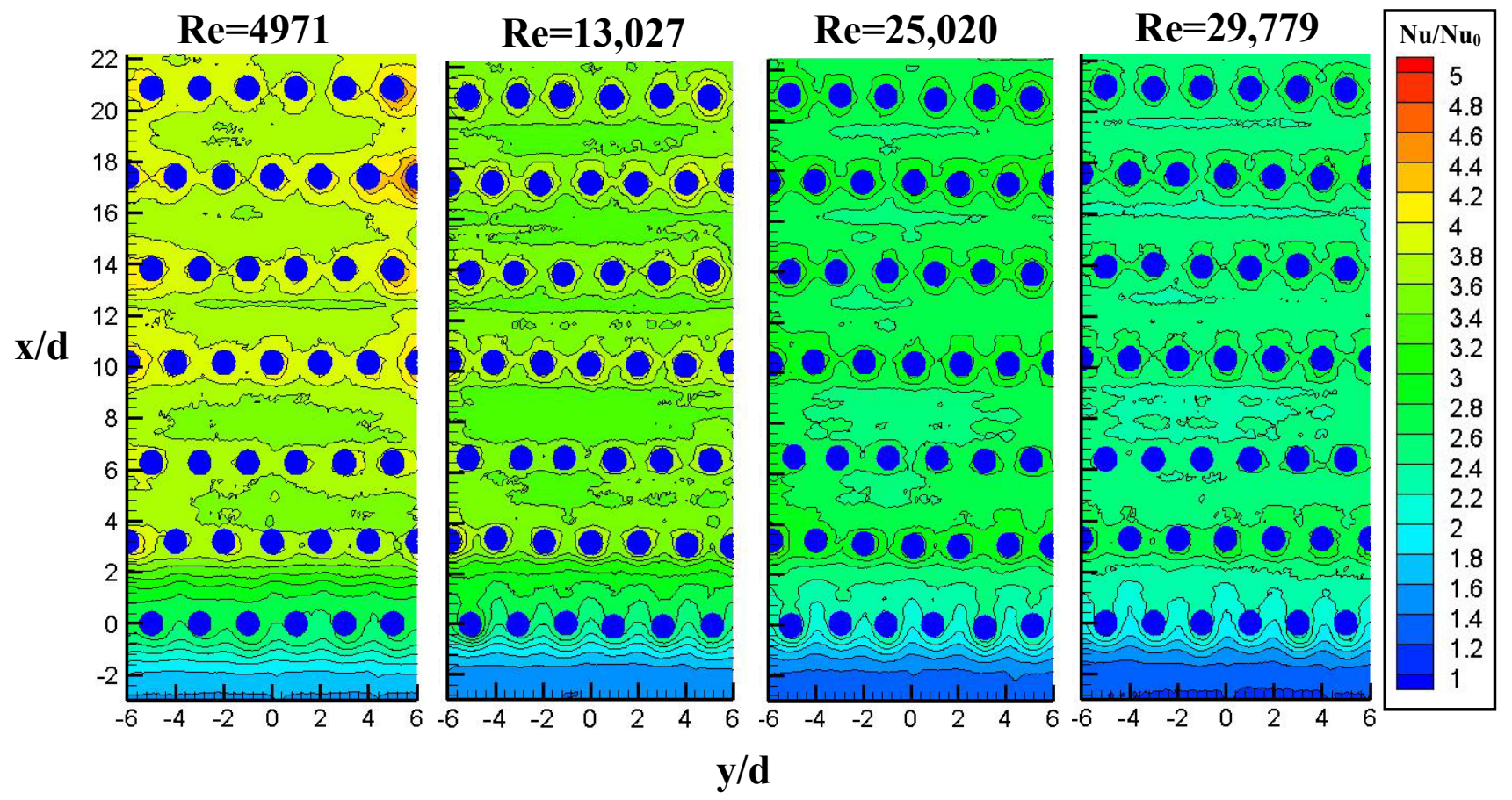

Figure C.6. Augmentation contour plots for the $S 1 / d=2, S 2 / d=3.46, H / d=1, \alpha=0^{\circ}$ geometry. 

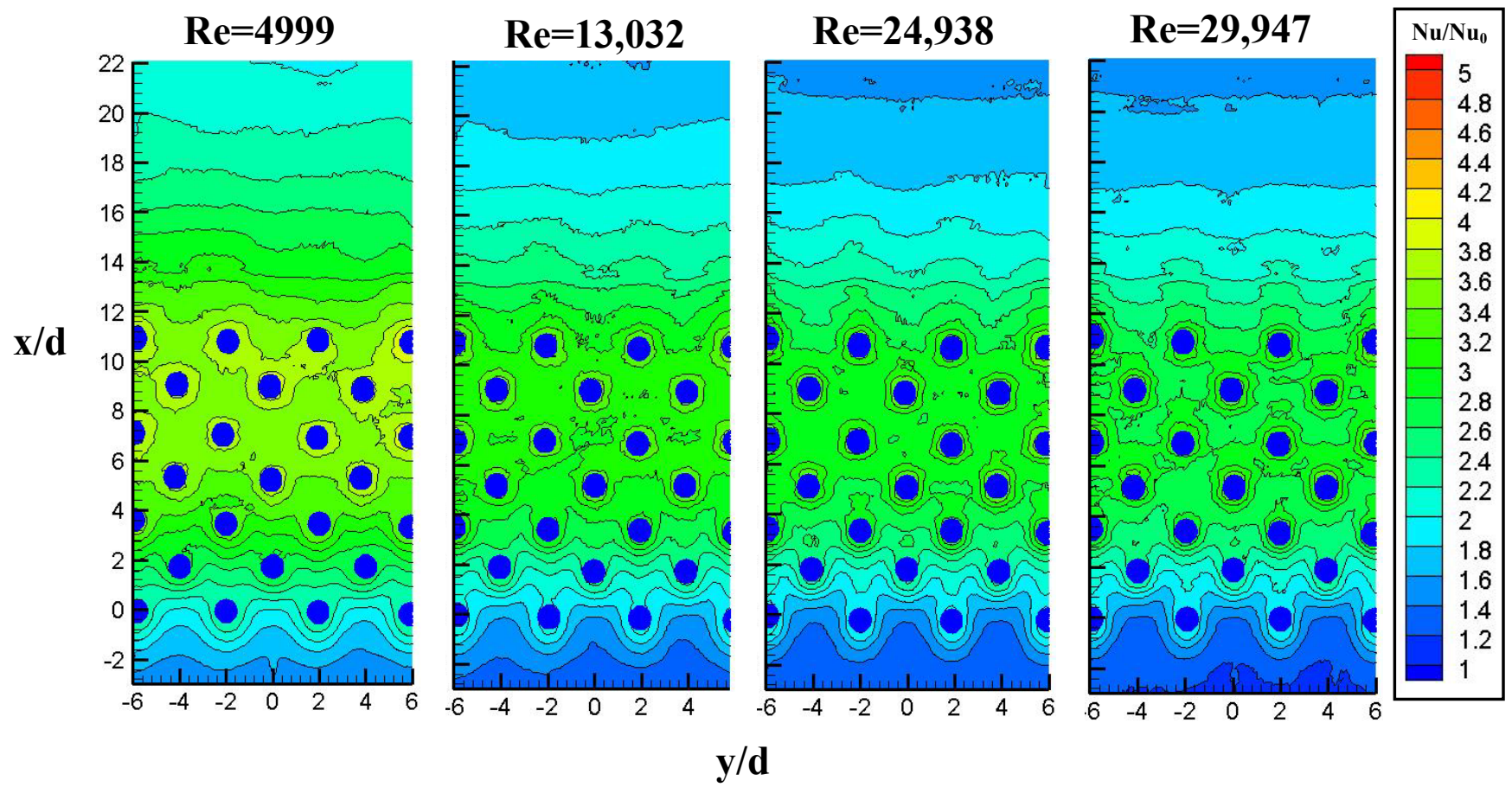

Figure C.7. Augmentation contour plots for the $S 1 / d=4, S 2 / d=1.73, H / d=1, \alpha=0^{\circ}$ geometry.
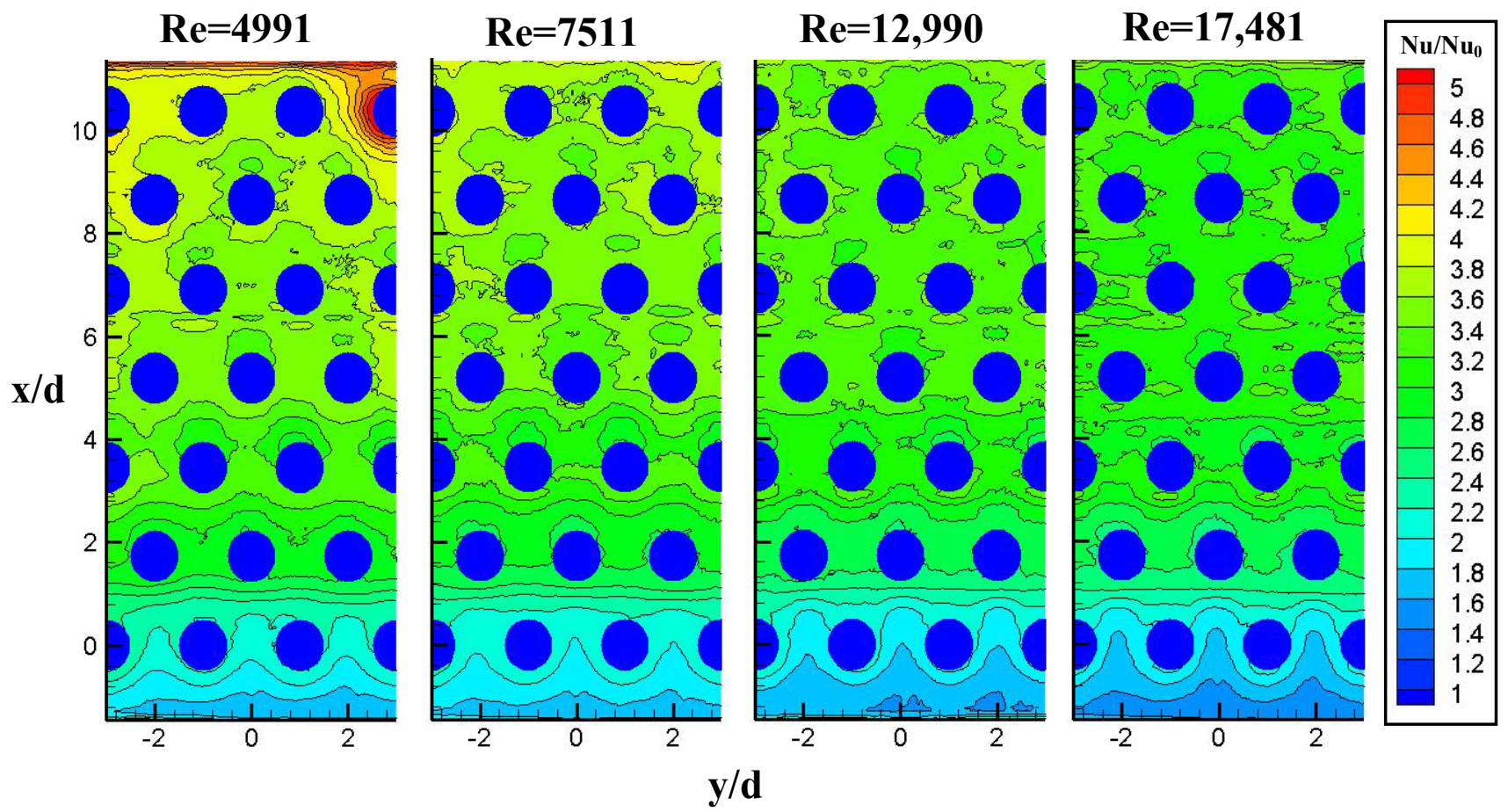

Figure C.8. Augmentation contour plots for the $S 1 / d=2, S 2 / d=1.73, H / d=0.5, \alpha=0^{\circ}$ geometry. 

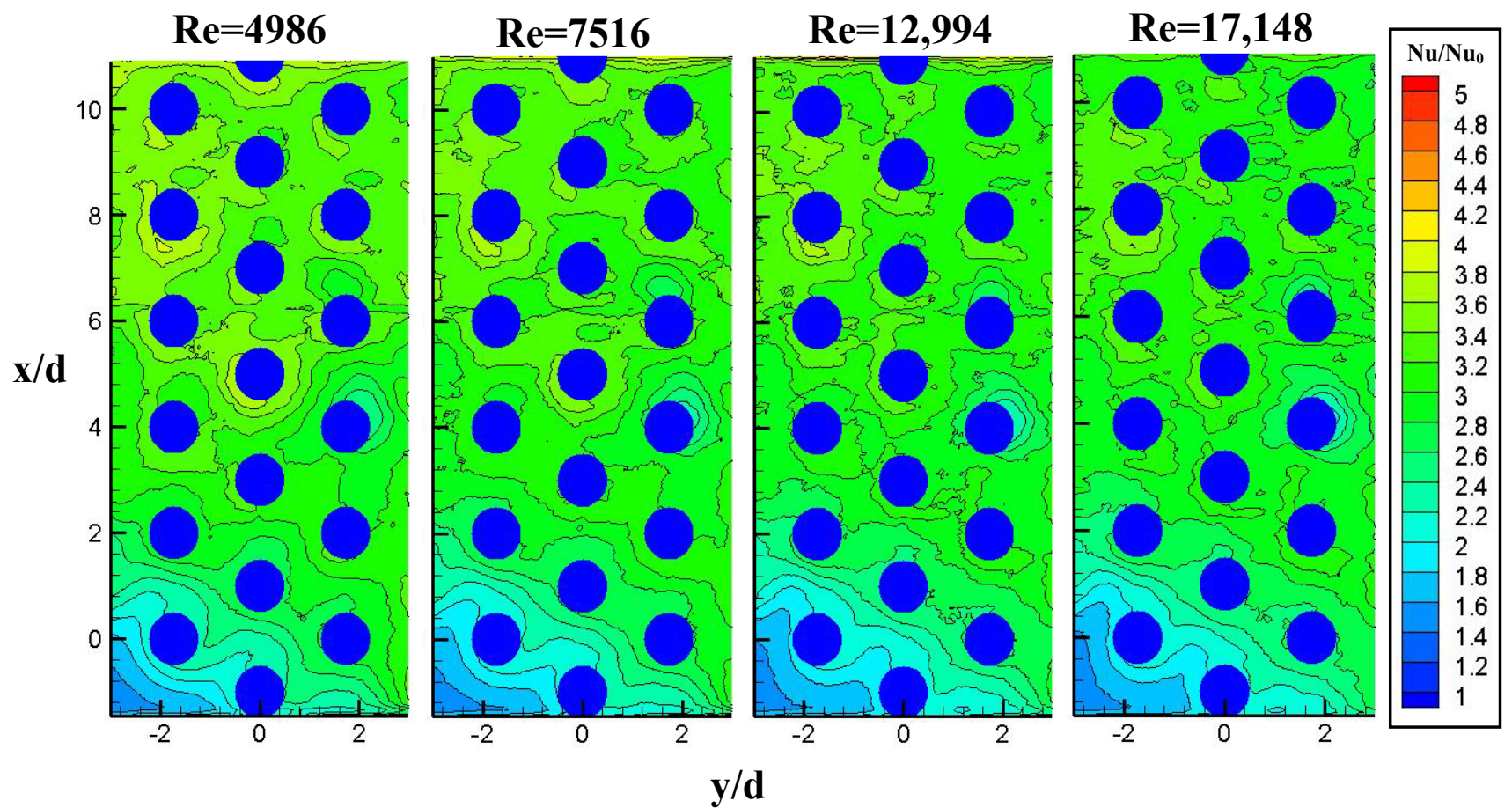

Figure C.9. Augmentation contour plots for the $S 1 / d=2, S 2 / d=1.73, H / d=0.5, \alpha=30^{\circ}$ geometry. 